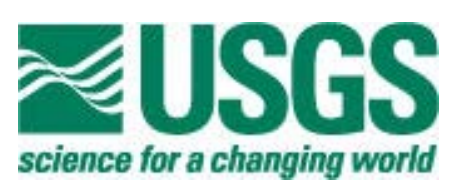

\title{
Audiomagnetotelluric Data to Characterize the Revett-Type Copper-Silver Deposits at Rock Creek in the Cabinet Mountains Wilderness, Montana
}

By Jay A. Sampson and Brian D. Rodriguez

Open-File Report 2011-1174

U.S. Department of the Interior

U.S. Geological Survey 


\section{U.S. Department of the Interior \\ KEN SALAZAR, Secretary}

\section{U.S. Geological Survey \\ Marcia K. McNutt, Director}

U.S. Geological Survey, Reston, Virginia: 2011

For product and ordering information:

World Wide Web: http://www.usgs.gov/pubprod

Telephone: 1-888-ASK-USGS

For more information on the USGS-the Federal source for science about the Earth, its natural and living resources, natural hazards, and the environment:

World Wide Web: http://www.usgs.gov

Telephone: 1-888-ASK-USGS

Suggested citation:

Sampson, J.A., and Rodriguez, B.D., 2011, Audiomagnetotelluric data to characterize the Revett-type copper-silver deposits at Rock Creek in the Cabinet Mountains Wilderness, Montana: United States Geological Survey Open-File Report 2011-1174, 73 p.

Any use of trade, product, or firm names is for descriptive purposes only and does not imply endorsement by the U.S. Government. This report has not been reviewed for stratigraphic nomenclature.

Although this report is in the public domain, permission must be secured from the individual copyright owners to reproduce any copyrighted material contained within this report. 


\section{Contents}

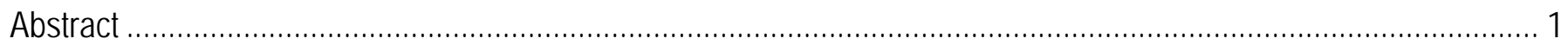

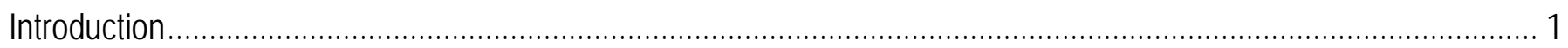

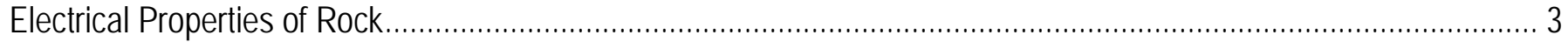

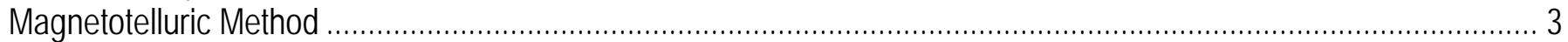

Audiomagnetotelluric Survey Across the Revett-Type Copper-Silver Deposits at Rock Creek................................... 4

Audiomagnetotelluric Data Collected in the Rock Creek Survey .................................................................. 5

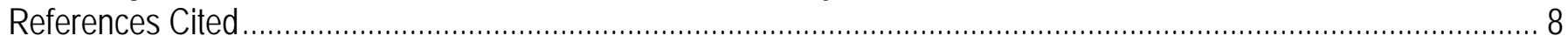

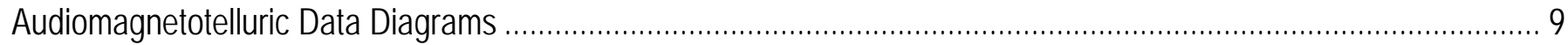

\section{Appendix}

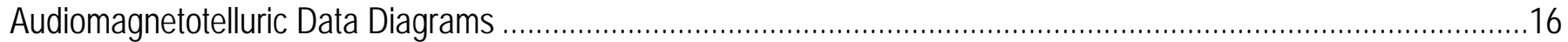

\section{Figure}

1. Audiomagnetotelluric profile across the Revett-type copper-silver deposits at Rock Creek in the Cabinet Mountains Wilderness, Montana

\section{Table}

1. Audiomagnetotelluric station coordinates.

\section{Abbreviations Used in This Report}

$\begin{array}{ll}\Omega-m & \text { ohm-meter } \\ \text { AMT } & \text { udiomagnetotellurics } \\ \text { FFT } & \text { fast Fourier transform } \\ \text { km } & \text { kilometer } \\ \mathrm{m} & \text { meter } \\ \text { MT } & \text { magnetotelluric } \\ \text { S/m } & \text { Siemens/meter } \\ \text { TE } & \text { transverse electric } \\ \text { TM } & \text { transverse magnetic } \\ \text { UTM } & \text { Universal Transverse Mercator }\end{array}$

Vertical coordinate information is referenced to the 1866 Clarke Spheroid. Horizontal coordinate information is referenced to the North American Datum of 1927 (NAD 27). Altitude, as used in this report, refers to distance above the vertical datum. 


\title{
Audiomagnetotelluric Data to Characterize the Revett-Type Copper-Silver Deposits at Rock Creek in the Cabinet Mountains Wilderness, Montana
}

\author{
By Jay A. Sampson and Brian D. Rodriguez
}

\begin{abstract}
The Revett-type deposits at Rock Creek are part of the concealed stratabound coppersilver deposits located in the Cabinet Mountains Wilderness of Montana. The U.S. Geological Survey is conducting a series of multidisciplinary studies as part of the Assessment Techniques for Concealed Mineral Resources project.

Geologic, geochemical, geophysical, and mineral resources data are being evaluated with existing and new mineral deposit models to predict the possibility and probability of undiscovered deposits in covered terranes. To help characterize the size, resistivity, and depth of the mineral deposit concealed beneath thick overburden, a regional southwest-northeast audiomagnetotelluric sounding profile was acquired. Further studies will attempt to determine if induced polarization parameters can be extracted from the magnetotelluric data to determine the size of the mineralized area. The purpose of this report is to release the audiomagnetotelluric sounding data collected along that southwest-northeast profile. No interpretation of the data is included.
\end{abstract}

\section{Introduction}

The Western United States holds great potential for concealed mineral deposits. The U.S. Geological Survey is conducting a series of multidisciplinary studies as part of the Assessment Techniques for Concealed Mineral Resources project.

Geologic, geochemical, geophysical, and mineral resources data are being evaluated with existing and new mineral deposit models to predict the possibility and probability of undiscovered deposits in covered terranes. This study uses the magnetotelluric (MT) method to determine if a polarizable mineral deposit (indicative of metallic content) can be detected when buried beneath thick overburden. Conventional geophysical exploration methods employing induced polarization surveys produce signals of limited penetration depth and require large, cumbersome transmitters. The MT method measures and records the Earth's natural timevarying electromagnetic signals as they pass through the subsurface. A relatively new technique, known as natural field induced polarization (Gasperikova and Morrison, 2001), extracts induced polarization parameters from MT data. To do so, however, the size and electrical resistivity of the target must be known in order to distinguish the electromagnetic response of the mineral deposit from the response of the surrounding host medium. 
The Revett-type deposits at Rock Creek are part of the concealed stratabound coppersilver deposits located in the Cabinet Mountains Wilderness of Montana. To help characterize the size, resistivity, and depth of the mineral deposit concealed beneath thick overburden, a regional southwest-northeast audiomagnetotelluric (AMT) sounding profile was acquired the last week of August, 2009 (fig. 1). Further studies will attempt to determine if induced polarization parameters extracted from the AMT data can also be used to determine the size of the mineralized area. The purpose of this report is to release the AMT sounding data collected along that southwest-northeast profile. No interpretation of the data is included.

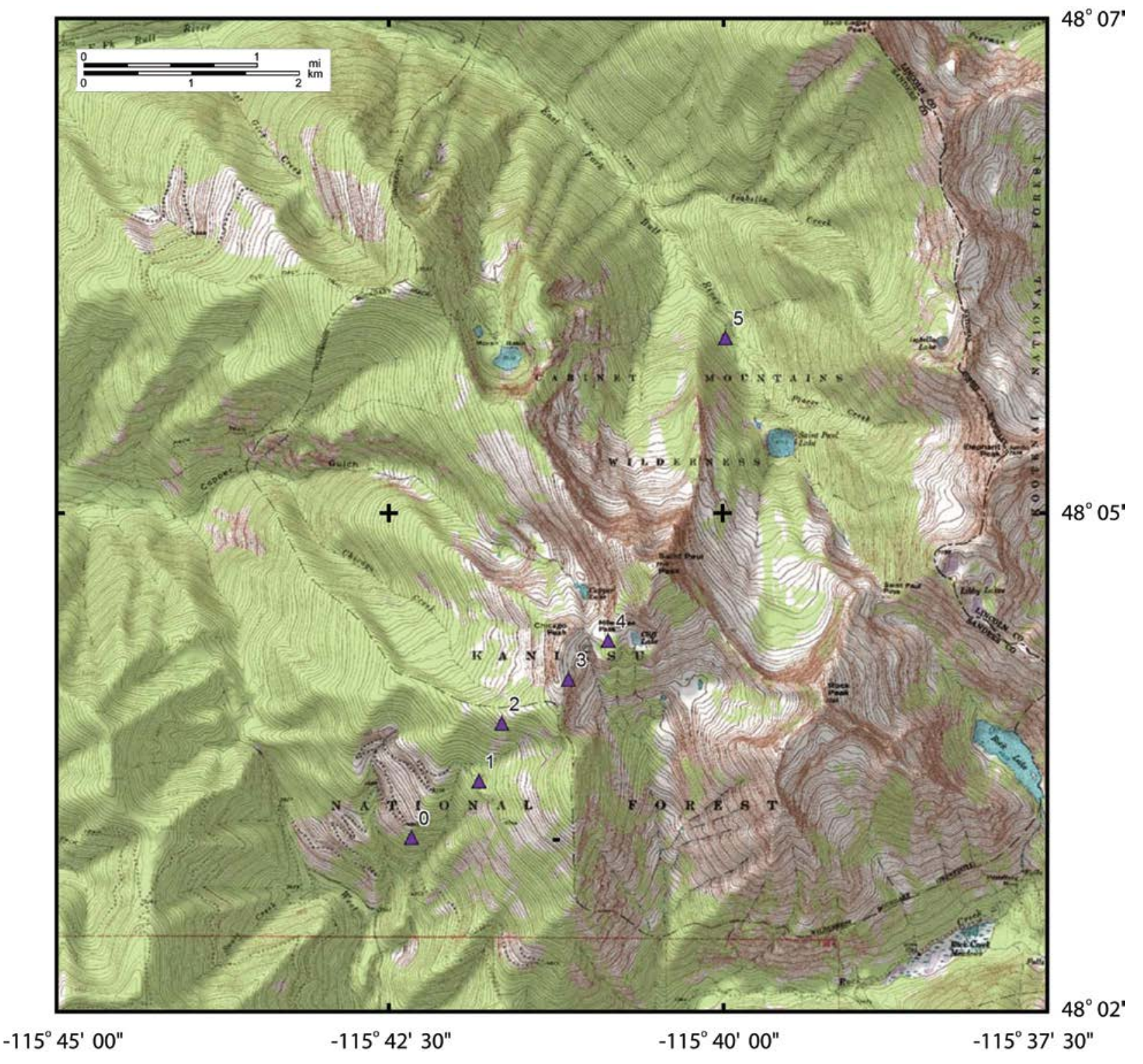

Figure 1. Audiomagnetotelluric profile across the Revett-type copper-silver deposits at Rock Creek in the Cabinet Mountains Wilderness, Montana. Audiomagnetotelluric stations acquired in late August 2009 are numbered purple triangles. Base map from Elephant Peak, Montana, 1:24,000 topographic quadrangle. 


\section{Electrical Properties of Rock}

Electromagnetic geophysical methods detect variations in the electrical properties of rock units - in particular, electrical resistivity, in units of ohm-meters $[\Omega-\mathrm{m}]$, or its inverse, electrical conductivity in units of Siemens/meter $(\mathrm{S} / \mathrm{m})$. Electrical resistivity can be correlated with geologic units on the surface and at depth by using lithologic logs to provide a three-dimensional picture of subsurface geology. In the upper crust, the resistivities of geologic units largely depend upon their fluid content, pore-volume porosity, interconnected fracture porosity, and the presence of conductive minerals (such as clay, graphite, and metallic minerals). Fluids in the pore spaces and fracture openings, especially saline fluids, can increase electrical conductance in an otherwise electrically resistive rock matrix (Keller and Frischknecht, 1966; Hearst and Nelson, 1985; Keller, 1987; Palacky, 1987; Hallenburg, 1998; Hearst and others, 2000). Although no one-to-one relation exists between lithology and resistivity, some general correlations can be made by using typical values, even though different values can be found at other localities (Palacky, 1987) that may fall outside of the ranges presented below. Fine-grained sedimentssuch as clay-rich alluvium, marine shales, and other mudstones - are normally conductive and have resistivities of a few ohm-meters to tens of ohm-meters (Keller, 1987; Palacky, 1987). Metamorphic rocks (not containing graphite) and unaltered, unfractured igneous rocks are normally moderately to highly resistive (a few hundred to thousands of ohm-meters). It is common for altered volcanic rocks to contain replacement minerals that have resistivities only one tenth as high as those of the surrounding rocks (Nelson and Anderson, 1992). Porous carbonate rocks having low fluid content and few impurities can have similarly high resistivities (Keller, 1987; Palacky, 1987). Fault zones may be moderately conductive (tens of ohm-meters) when composed of rocks fractured enough to have hosted fluid transport and consequent mineralogical alteration (Eberhart-Phillips and others, 1995). At greater depths, higher subsurface temperatures increase the mobility of ions in the fluids and reduce rock resistivity (Hallenburg, 1998). Tables of electrical resistivity for a variety of rocks, minerals, and geological environments may be found in Keller (1989) and Palacky (1987).

\section{Magnetotelluric Method}

The MT method is a passive ground-based electromagnetic geophysical technique that investigates the distribution of electrical resistivity below the surface at depths of tens of meters to tens of kilometers (Vozoff, 1991). It does so by measuring time variations in the Earth's natural electric and magnetic fields. Worldwide lightning activity at frequencies of about 1 Hertz to 10,000 Hertz and geomagnetic micropulsations at frequencies of 0.001 Hertz to 1 Hertz provide the main source of signals used by the MT method. The natural electromagnetic waves propagate vertically in the Earth because the very large resistivity contrast between the air and the Earth causes a vertical refraction of the electromagnetic wave at the Earth's surface (Vozoff, 1972).

The horizontal electric and magnetic fields are recorded in two orthogonal directions and the vertical magnetic field is also recorded. The resulting time-series signals are used to derive tensor apparent resistivities and phases after first converting them to complex cross spectra by using fast Fourier transform (FFT) techniques and least-squares, cross-spectral analysis (Bendat and Piersol, 1971) to solve for a tensor transfer function. If one assumes that the Earth consists of a two-input, two-output linear system in which the orthogonal magnetic fields are input and the 
orthogonal electric fields are output, then a transfer function can be calculated that relates the observed electric fields to the magnetic fields. Before the tensor is converted to apparent resistivity and phase, it is normally rotated parallel to geologic strike. Subsurface geologic strike can be estimated by determining the horizontal direction (Hxy or Hyx) in which the vertical magnetic field "tips" (the tipper strike direction).

For a two-dimensional Earth, the MT fields can be decoupled into transverse electric and transverse magnetic modes (commonly referred to as the TE and TM modes). Two-dimensional resistivity modeling is generally computed to fit both modes. When the geology satisfies a two-dimensional assumption, the MT data for the transverse electric mode are assumed to represent the electric field oriented along geologic strike, and the data for the transverse magnetic mode are assumed to represent the electric field oriented across strike. The MT method is well suited for studying complicated geological environments because the electric and magnetic field transfer functions are sensitive to vertical and horizontal variations in resistivity. High-resolution shallow-subsurface characterization is possible for closely spaced MT stations, but the resolution decreases for deeper measurements and for widely spaced stations. The method is capable of establishing whether the electromagnetic fields are responding to subsurface rock bodies of effectively one, two, or three dimensions. An introduction to the MT method and references for a more advanced understanding are contained in Kaufman and Keller (1981), Dobrin and Savit (1988), and Vozoff (1991).

\section{Audiomagnetotelluric Survey Across the Revett-Type Copper-Silver Deposits at Rock Creek}

Six AMT soundings were collected in August 2009 along a 5-km-long profile in northwestern Montana (fig. 1). The profile starts about 9 kilometers (km) northeast of Noxon, Montana, in the Kaniksu National Forest of the Cabinet Mountains, then continues northeasterly, passing just south of Chicago Peak and Saint Paul Peak, and ends about $1 \mathrm{~km}$ northwest of Saint Paul Lake. The profile location dissects patented claims of Revett-type copper-silver deposits at Rock Creek in the Cabinet Mountains Wilderness, Montana.

To avoid vehicle and electrical noise, station locations were chosen in remote areas and next to roads that had no power lines in the vicinity. Data at stations 0,1 , and 2 (Table 1) were collected with an Electromagnetic Instruments, Inc., MT-1 system (Electromagnetic Instruments, Inc., 1996). Horizontal electric fields were recorded using titanium electrodes placed in an Lshaped, three-electrode array with dipole lengths of 15 (station 2), 20 (station 0), and 30 (station 1) meters. The orthogonal horizontal magnetic fields were measured in the direction of the electric-field array and were sensed using high magnetic permeability mu-metal-cored induction coils. Frequencies were sampled from about 4 Hertz to 23,000 Hertz at each station.

Data at stations 1, 3, 4, and 5 (Table 1) were collected within the Cabinet Mountains Wilderness with a portable Electromagnetic Instruments, Inc., MT24HF system (Electromagnetic Instruments, Inc., 2003), since there were no roads for access with the MT-1 system. Horizontal electric fields were recorded using stainless steel electrodes placed in a cross-shaped, fourelectrode array with dipole lengths of 24 meters (m). The orthogonal horizontal magnetic fields were measured in the direction of the electric-field array and were sensed using high magnetic permeability mu-metal-cored induction coils. Frequencies were sampled from about 10 Hertz to 54,000 Hertz at each station. Station 1 has dual recordings from both the MT-1 system and the 
MT24HF system for calibrating the MT24HF data correction (see "Audiomagnetotelluric Data Collected in the Rock Creek Survey” section below).

Table 1. Audiomagnetotelluric station coordinates.

[Unannotated station numbers are MT-1 system stations. Annotated (asterisk) station numbers are MT24HF system stations. Coordinates are referenced to the 1866 Clarke spheroid and North American 1927 Western United States datum. Longitude and latitude format is degrees:minutes:seconds. Universal Transverse Mercator (UTM) zone 11N units and station elevations are in meters. The accuracy of the north and east component is $\pm 5 \mathrm{~m}$ and is $\pm 10 \mathrm{~m}$ for the elevation. $\mathrm{X}$ direction (X Dir) is in degrees clockwise from true north]

\begin{tabular}{ccccccc}
\hline Station & X Dir & Latitude & Longitude & North $(m)$ & East $(m)$ & Elevation $(m)$ \\
\hline \multicolumn{7}{c}{} \\
\hline 0 & 246 & $48: 03: 25$ & $-115: 42: 21$ & $5,323,223$ & 596,446 & 1,490 \\
1 & 010 & $48: 03: 42$ & $-115: 41: 51$ & $5,323,740$ & 597,064 & 1,720 \\
$1^{*}$ & 010 & $48: 03: 42$ & $-115: 41: 51$ & $5,323,740$ & 597,064 & 1,720 \\
2 & 160 & $48: 03: 59$ & $-115: 41: 40$ & $5,324,300$ & 597,267 & 1,920 \\
$3^{*}$ & 000 & $48: 04: 13$ & $-115: 41: 10$ & $5,324,723$ & 597,884 & 2,040 \\
$4^{*}$ & 000 & $48: 04: 24$ & $-115: 40: 52$ & $5,325,087$ & 598,246 & 2,050 \\
$5^{*}$ & 000 & $48: 05: 56$ & $-115: 39: 59$ & $5,327,922$ & 599,290 & 1,250 \\
\hline
\end{tabular}

\section{Audiomagnetotelluric Data Collected in the Rock Creek Survey}

The recorded time-series data were converted to the frequency domain and processed to determine the impedance tensor, which is used to derive apparent resistivities and phases at each site. Rotation of the impedance tensor allows for decoupling into the transverse electric and transverse magnetic modes. The data provided here have not been rotated from the original acquisition orientation (X direction) listed in table 1. During the analysis and interpretation process, each station should be rotated to a fixed angle determined by the given nominal profile orientation. Cross-power files were sorted to select optimal signal-to-noise time-series data sets (see Appendix). Cultural features such as fences, pipelines, communication lines, moving vehicles and trains, and other manmade sources of electromagnetic noise, can contaminate the responses of the MT system. Care was taken to avoid these sources of noise when we acquired these data.

The figures in the Appendix represent the field-processed AMT data for each station, after the time-series data were converted to the frequency domain and the tensor-transfer function was developed.

Data for each station is presented in eight diagrams:

1. Apparent resistivity ( $\mathrm{x}$ and o symbols are $\mathrm{xy}$ and $\mathrm{yx}$ components)

2. $\quad$ Impedance phase ( $\mathrm{x}$ and o symbols are $\mathrm{xy}$ and $\mathrm{yx}$ components)

3. Impedance skew

4. Multiple coherency ( $\mathrm{x}$ and o symbols are xy and yx components)

5. Impedance polar diagrams

6. Tipper magnitude

7. Tipper strike

8. HzHx (x symbol) and HzHy (o symbol) coherency 
Units of measure for the apparent resistivity, phase, and tipper strike are given on the diagrams. The coherency diagrams, the skew, the tipper magnitude, and the polar diagrams have unitless vertical axes. The data for all diagrams are shown over a range of frequencies. Error bars (],[) on the diagrams of apparent resistivity, impedance phase, skew, tipper magnitude, and tipper strike (tipper direction) diagrams represent probable errors within one standard deviation of the sample variance (Gamble and others, 1979).

Apparent resistivity is calculated from the ratio of the electric field strength magnitude over the magnetic field strength magnitude for a given frequency. The impedance phase is proportional to the slope of the apparent-resistivity curve on a log-log diagram, relative to a baseline at -45 degrees (Vozoff, 1991). A measure of the dimensionality for MT data is provided by the impedance skew of the impedance tensor (Vozoff, 1972). If the effective, measured resistivity response to the geology beneath an MT station is truly one- or two-dimensional, then the skew will be zero. Both instrument and environmental sources of noise contribute to nonzero skew values but are typically small (about 0.1 ) for relatively low-noise-level recordings. Higher skews (more than 0.2 ) indicate either the resistivity response to three-dimensional geology or higher levels of noise. Skews with large error bars are due to higher levels of noise.

In the study area, noise from a number of small power lines and small moving vehicles was negligible beyond $0.25 \mathrm{~km}$ from the noise source. Power-line signal amplitudes were measured at each site and were typically less than 20 percent of the maximum recordable signals. Local lightning, wind, and rainstorms also can degrade data quality, but these noise sources were avoided by not recording during active thunderstorms. Burying the magnetic induction coils and keeping the electric dipole wires flat on the ground helped to minimize wind noise.

The figures in the Appendix represent the field-processed AMT data at each station, and they include some data scatter and poor signal-to-noise ratios. The only effort aimed at removing noisy data points was to visually inspect and select the best signal-to-noise field data to combine into the final data diagrams.

Predicted values of the electric field can be computed from the measured values of the magnetic field (Vozoff, 1991). The coherence of the predicted electric field with the measured electric field is a measure of the signal-to-noise ratio provided in the multiple coherency diagrams. Values are normalized between 0 and 1 , where values at 0.5 signify signal levels equal to noise levels. For this data set, coherencies were generally above 0.8 , except in the higher frequencies (greater than about 1,000 Hertz).

The impedance polar diagrams provide a measure of the MT data dimensionality (Reddy and others, 1977). For one-dimensional resistivity structures, the principal impedance (off-diagonal elements) polar diagram (dashed line) is a circle. For two-dimensional or threedimensional resistivity structures, the principal impedance polar diagram (dashed line) elongates. Over resistors, the principal impedance polar diagram elongates perpendicular to strike direction, while over conductors the principal impedance polar diagram elongates parallel to strike direction. For two-dimensional resistivity structures, the additional impedance (on-diagonal elements) polar diagram (solid line) attains the shape of a symmetric clover leaf. For threedimensional resistivity structures, the additional impedance polar diagram (solid line) elongates in one direction, and its amplitude is comparable to that of the principal impedance polar diagram (dashed line), although high noise levels can produce the same effect on the polar diagram. A three-dimensional analysis of polar diagrams at each frequency should also take into account the corresponding coherence and skew values along with their associated error levels. 
The polar diagrams computed for our data show the electromagnetic response for all stations was three-dimensional over all frequencies measured at acceptable noise levels, except for station 2 that showed a mix of two- and three-dimensional electromagnetic response at the lower frequencies.

The tipper can be calculated from the vertical component of the magnetic field. The tipper magnitude is a measure of the tipping of the magnetic field out of the horizontal plane (Vozoff, 1991). The magnitude is zero for the one-dimensional case, typically increases to values between 0.1 and 0.5 , and rarely is as great as 1 as it responds to vertical and subvertical structures. The "tipper strike" (tipper direction) typically is used to help resolve the 90-degree ambiguity in the impedance rotation angle. The tipper magnitudes of these stations were all above 0.1 indicating vertical and subvertical structure at depth.

The HzHx and HzHy coherency is a measure of the signal-to-noise ratio of the vertical magnetic field with respect to each of the orthogonal, horizontal magnetic field directions. Values are normalized between 0 and 1 , where values of 0.5 signify signal levels equal to noise levels. These three components of magnetic-field coherence provide a check on the quality of the measured values in the tipper magnitude and tipper strike diagrams.

Data collected with the MT24HF system requires a data correction to match the data recorded with the MT-1 system, which is a proven system for collecting reliable AMT data. We collected AMT data with both the MT-1 system and the MT24HF system on the same day at station 1 to determine the data correction required to match the MT24HF system apparent resistivities with the MT-1 system apparent resistivities. Data diagrams for station 1 collected with the MT-1 system appear in the Appendix labeled "Station 1". Data diagrams for uncorrected station 1 collected with the MT24HF system appear labeled “Station 1?”. Data diagrams for the corrected station 1 collected with the MT24HF system are labeled "Station 1*”. Through trial and error using the MTR95 data processing program provided by Electromagnetic Instruments, Inc., we found that applying a "Fix Spectra" factor of 6 to both the $\mathrm{x}$ and $\mathrm{y}$ channels of the electric field parameter resulted in the best overall match to the apparent resistivities collected with the MT-1 system. A factor of 5 resulted in better matching apparent resistivities for the upper apparent resistivity curve, while a factor of 7 resulted in better matching apparent resistivities for the lower curve. We applied a "Fix Spectra" factor of 6 to both $\mathrm{x}$ and y channels of the electric field parameters to all of the data collected with the MT24HF system (see Appendix stations labeled $1^{*}, 3^{*}, 4^{*}$, and 5*).

Outstanding differences that remain between the data collected with the MT-1 system and the corrected MT24HF system include an order of magnitude reduction of tipper magnitude between the two systems at the same frequencies. Another difference included tipper strikes (tipper direction) with the MT24HF system that consistently fluctuate (with small oscillations) at either +90 degrees (measured clockwise from North) or +270 degrees (-90 degrees). We found that applying a "Fix Spectra" factor of 10 to the MT24HF system vertical magnetic field channel $(\mathrm{Hz})$ corrected the tipper magnitudes to better match the MT-1 tipper magnitudes, but without any effect on the tipper strike data. We elected to not make any corrections to the vertical magnetic field channel $(\mathrm{Hz})$, since applying a factor of 10 correction did not resolve the tipper strike mismatch between the MT-1 and MT24HF systems. Outstanding differences in impedance skew and coherencies are likely caused by differences in data quality rather than system calibration issues. 


\section{References Cited}

Bendat, J.S., and Piersol, A.G., 1971, Random data-Analysis and measurement procedures: New York, Wiley Interscience, 407 p.

Dobrin, M.D., and Savit, C.H., 1988, Introduction to geophysical prospecting (4th ed.): New York, McGraw-Hill, 867 p.

Eberhart-Phillips, Donna, Stanley, W.D., Rodriguez, B.D., and Lutter, W.J., 1995, Surface seismic and electrical methods to detect fluids related to faulting: Journal of Geophysical Research, v. 100, no. B7, p. 12919-12936.

Electromagnetic Instruments, Inc., 1996, MT-1 magnetotelluric system operation manual, version 3.2: Richmond, Calif., Electromagnetic Instruments, Inc., 220 p.

Electromagnetic Instruments, Inc., 2003, MT24/HF system operation and maintenance manual, revision AA: Richmond, Calif., Electromagnetic Instruments, Inc., 60 p.

Gamble, T.D., Goubau, W.M., and Clarke, J., 1979, Error analysis for remote reference magnetotellurics: Geophysics, v. 44, no. 5, p. 959-968.

Gasperikova, Erika, and Morrison, H. F., 2001, Mapping of induced polarization using natural fields: Geophysics, v. 66, no.1, p.137-147.

Hallenburg, J.K., 1998, Non-hydrocarbon methods of geophysical formation evaluation: Boca Raton, Fla., Lewis Publishers, 265 p.

Hearst, J.R., and Nelson, P.H., 1985, Well logging for physical properties: New York, McGrawHill, 571 p.

Hearst, J.R., Nelson, P.H., and Paillet, F.L., 2000, Well logging for physical properties (2d ed.): New York, John Wiley, 483 p.

Kaufman, A.A., and Keller, G.V., 1981, The magnetotelluric sounding method, in Methods in geochemistry and geophysics, 15: Amsterdam, Elsevier Scientific Publishing Company, 595 p.

Keller, G.V., 1987, Rock and mineral properties, in Nabighian, M.N., ed., Electromagnetic methods in applied geophysics theory: Tulsa, Okla., Society of Exploration Geophysicists, v. 1, p. 13-51.

Keller, G.V., 1989, Electrical properties, in Carmichael, R.S., ed., Practical handbook of physical properties of rocks and minerals: Boca Raton, Fla., CRC Press, p. 359-427.

Keller, G.V., and Frischknecht, F.C. 1966, Electrical methods in geophysical prospecting: Oxford, Pergamon Press Inc., 519 p.

Nelson, P.H., and Anderson, L.A., 1992, Physical properties of ash flow tuff from Yucca Mountain, Nevada: Journal of Geophysical Research, v. 97, no. B5, p. 823-841.

Palacky, G.J., 1987, Resistivity characteristics of geologic targets, in Nabighian, M.N., ed., Electromagnetic methods in applied geophysics: Tulsa, Okla., Society of Exploration Geophysicists, v. 1, p. 53-129.

Reddy, I.K., Rankin, David, and Phillips, R.J., 1977, Three-dimensional modelling in magnetotelluric and magnetic variational sounding: Geophysical Journal of the Royal Astronomical Society, v. 51, p. 313-325.

Vozoff, Keeva, 1972, The magnetotelluric method in the exploration of sedimentary basins: Geophysics, v. 37, p. 980-141.

Vozoff, Keeva, 1991, The magnetotelluric method, in Nabighian, M.N., Electromagnetic methods in applied geophysics: Tulsa, Okla., Society of Exploration Geophysicists, v. 2, pt. B, p. 641-711. 


\section{Appendix}

\section{Audiomagnetotelluric Data Diagrams}

Units of measure for the apparent resistivity, phase, and tipper strike are given on the diagrams. The coherency diagrams, the skew, the tipper magnitude, and the polar diagrams have unitless vertical axes. The data for all diagrams are shown over a range of frequencies. Data for each station is presented in eight diagrams:

1. Apparent resistivity for the unrotated xy (x symbol) and yx (o symbol) modes

2. Impedance phase for the unrotated xy (x symbol) and yx (o symbol) modes

3. Impedance skew for the impedance tensor

4. Multiple coherency for the xy (x symbol) and minimum (o symbol) modes of the electric field

5. Impedance polar diagrams (at 12 selected frequencies)

6. Tipper magnitude for the vertical magnetic field

7. Tipper strike for the vertical magnetic field

8. HzHx (x symbol) and HzHy (o symbol) coherency

Refer to the "Audiomagnetotelluric Data Collected in the Rock Creek Survey” section in this report for an explanation of these diagrams. 


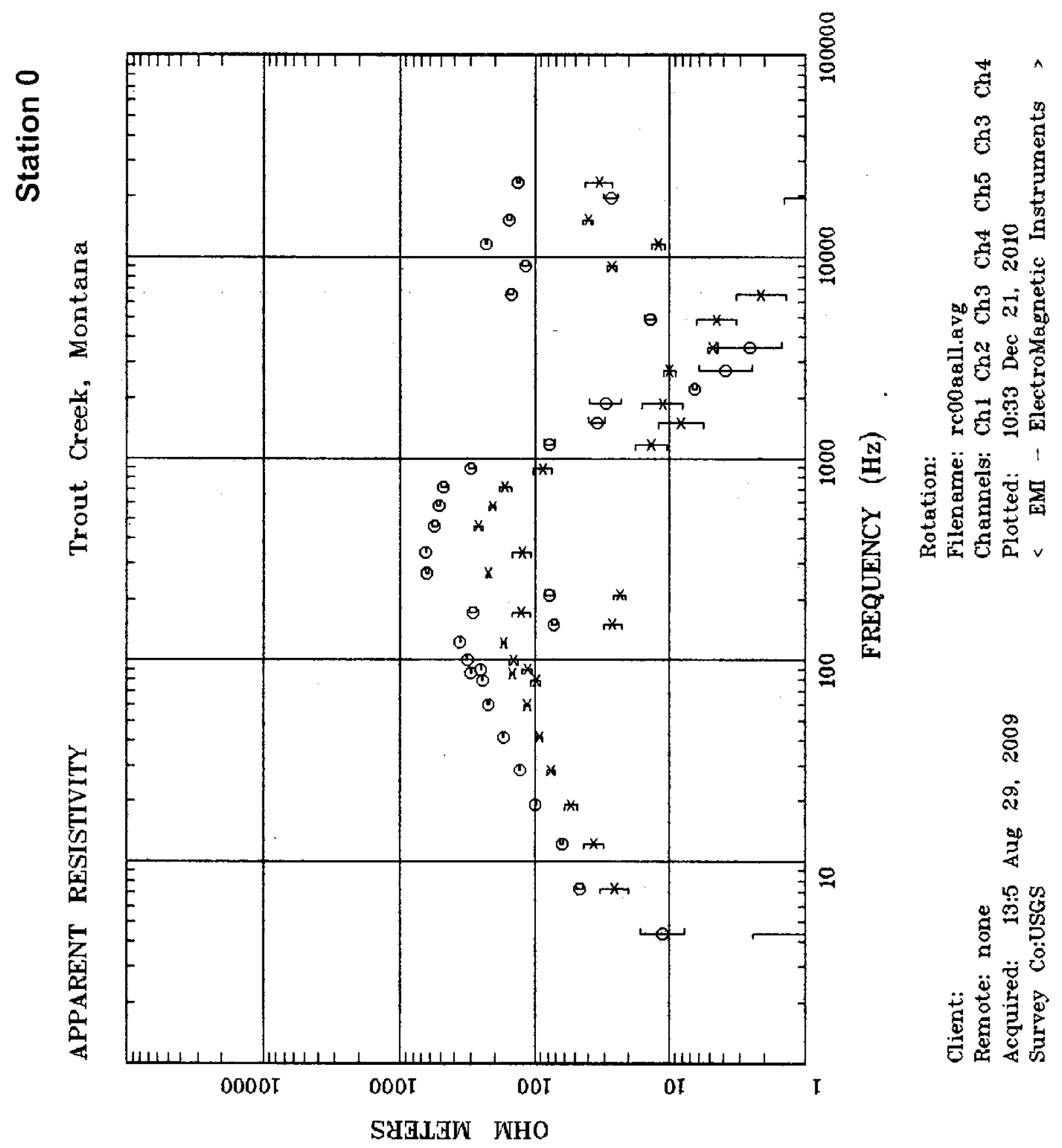




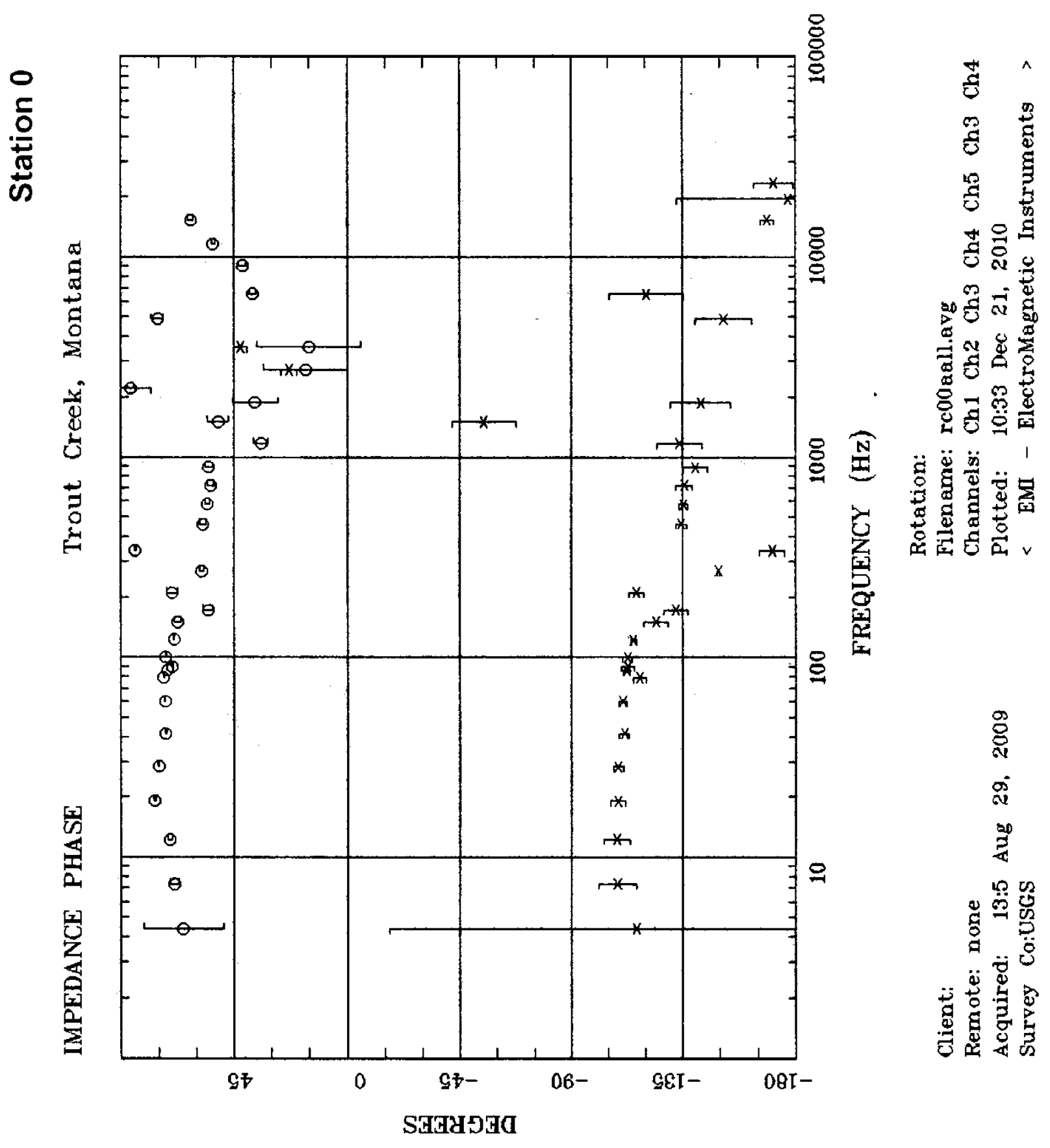




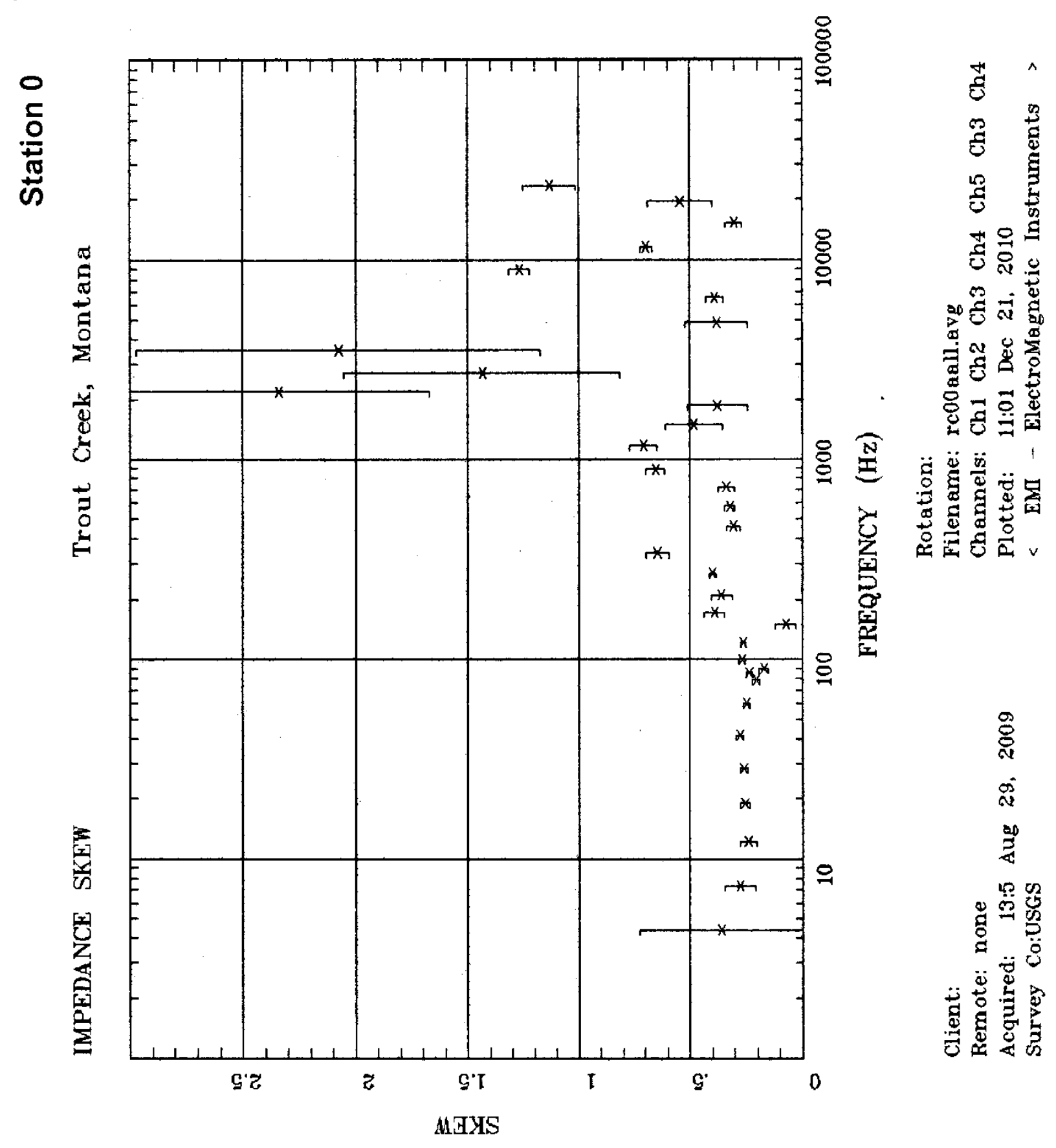




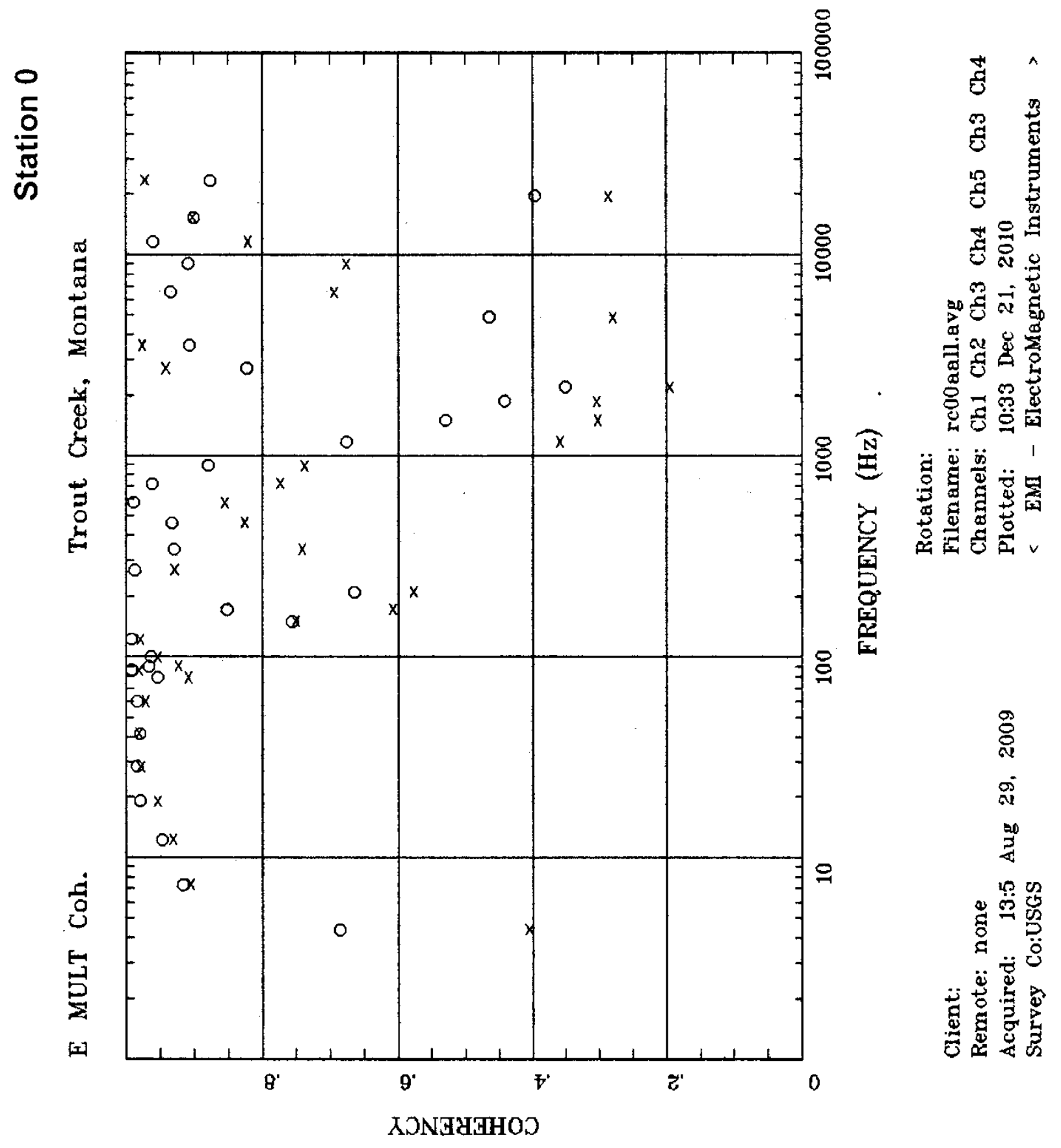




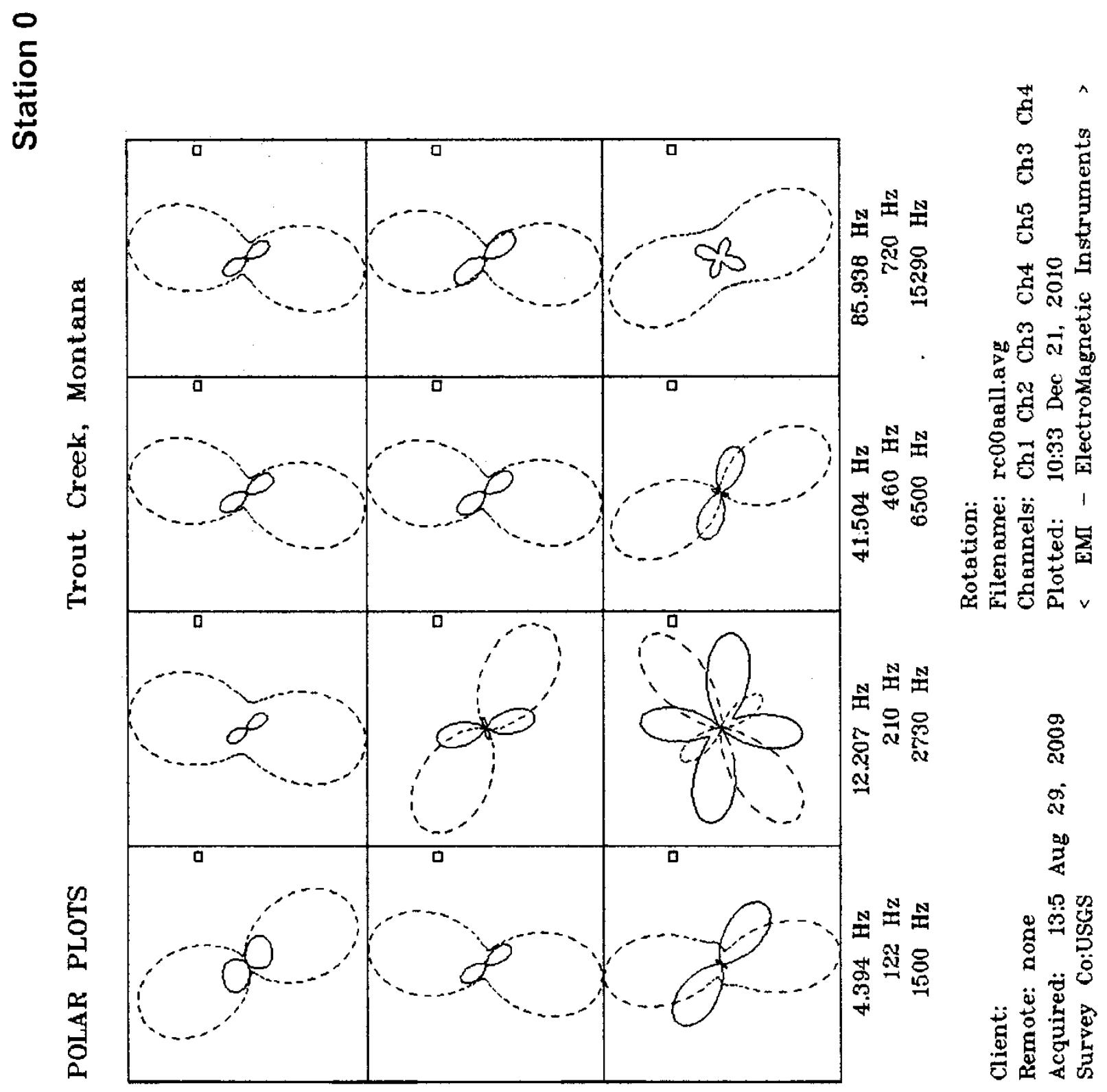




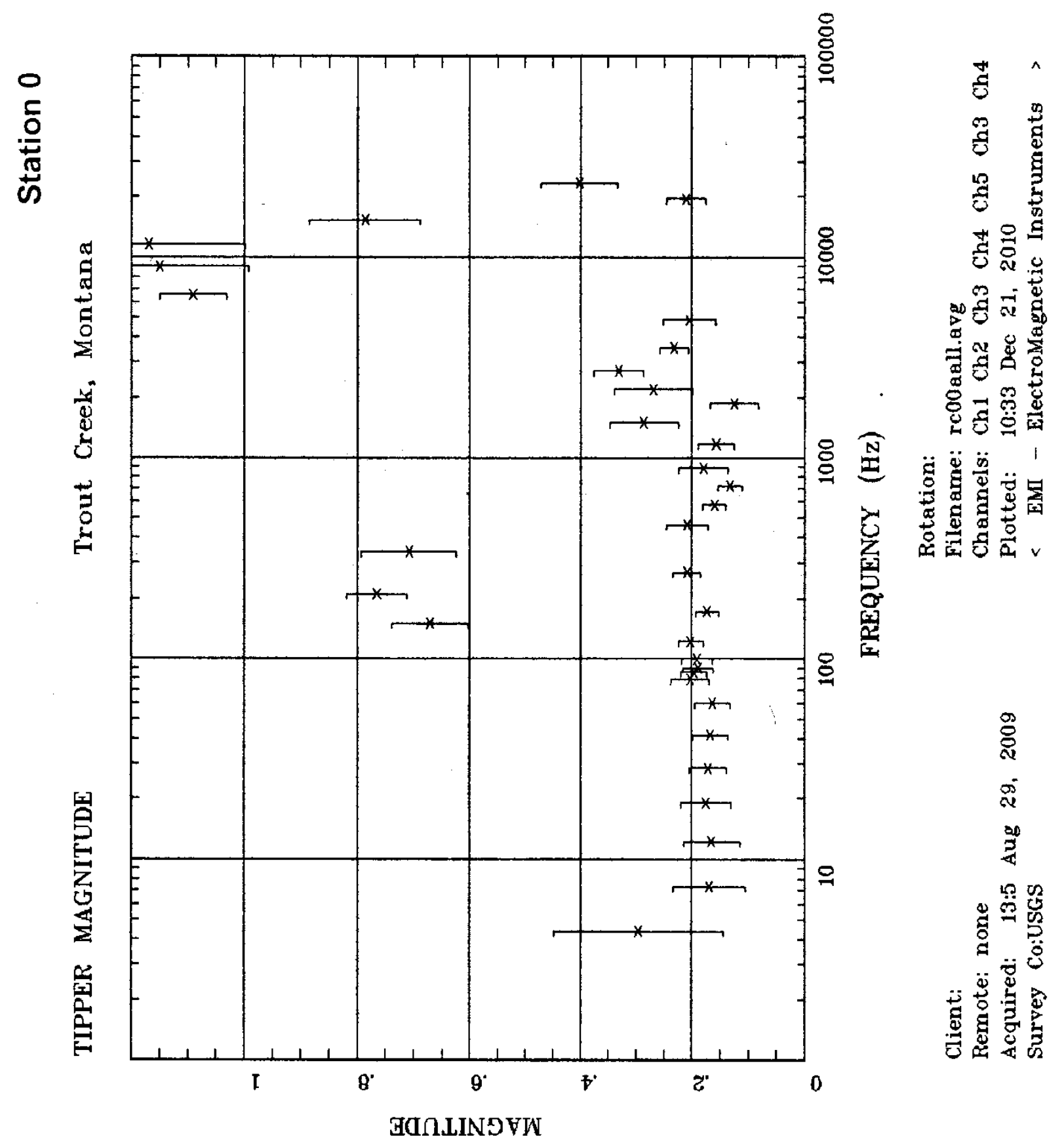




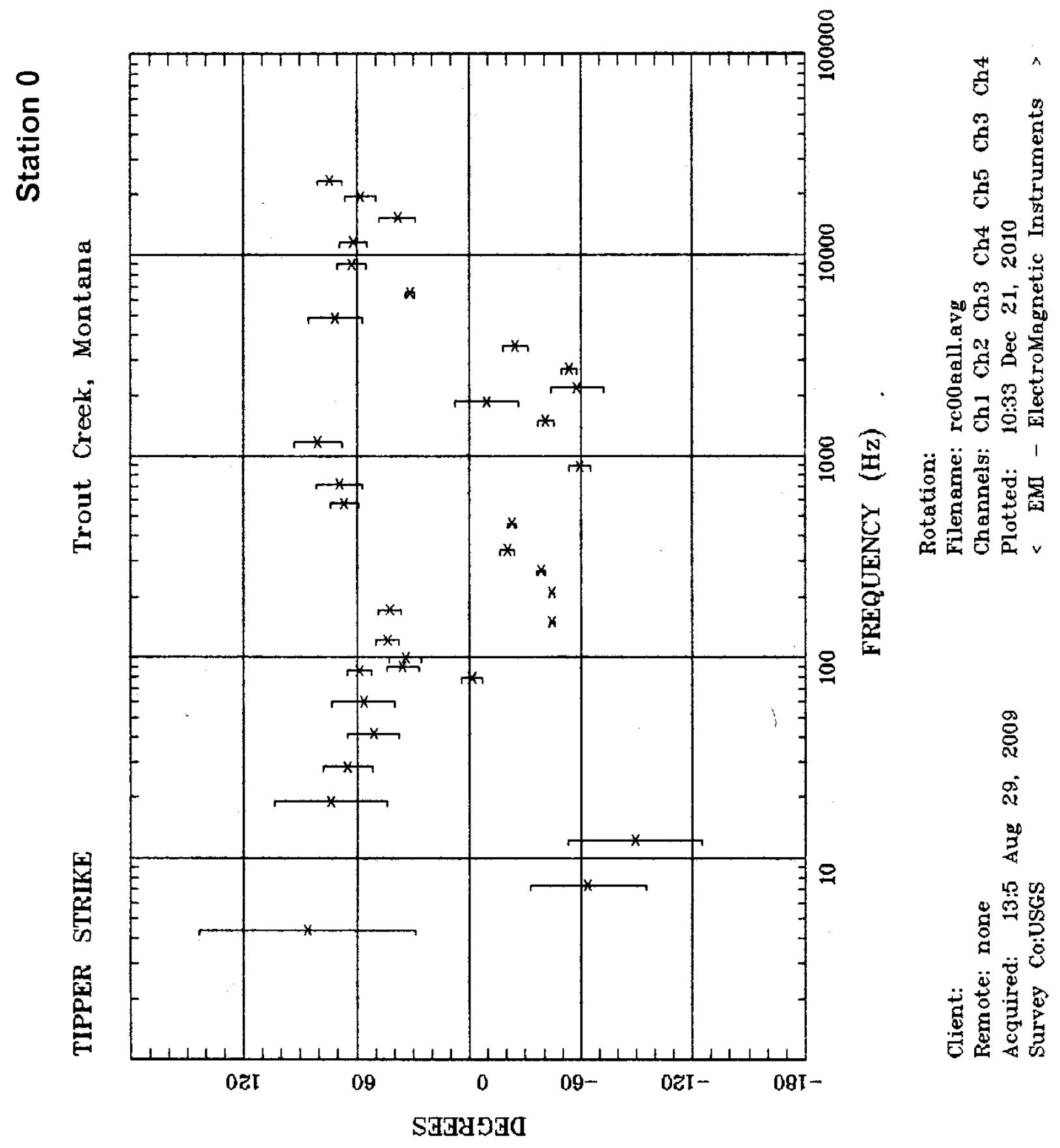




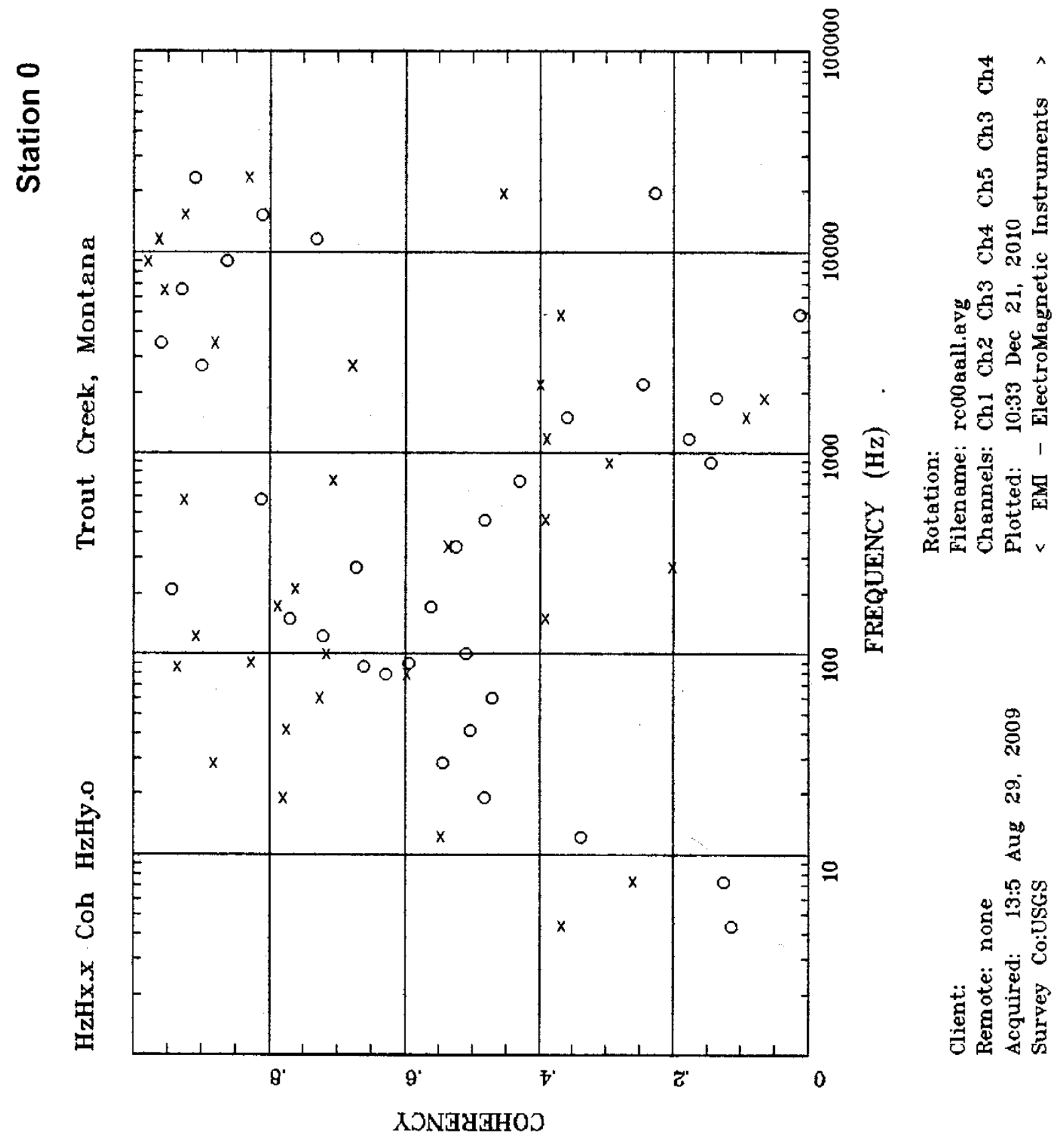




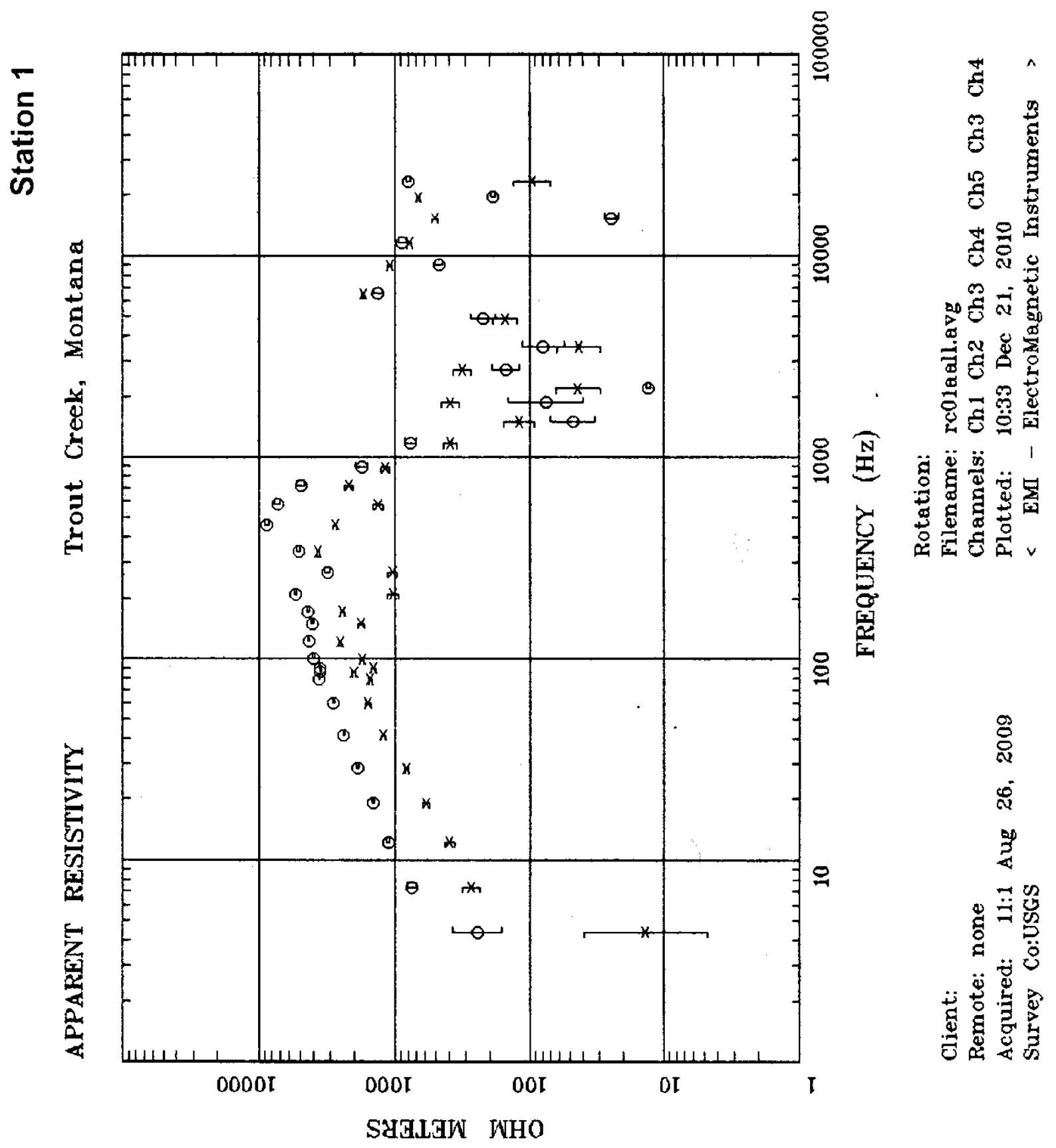




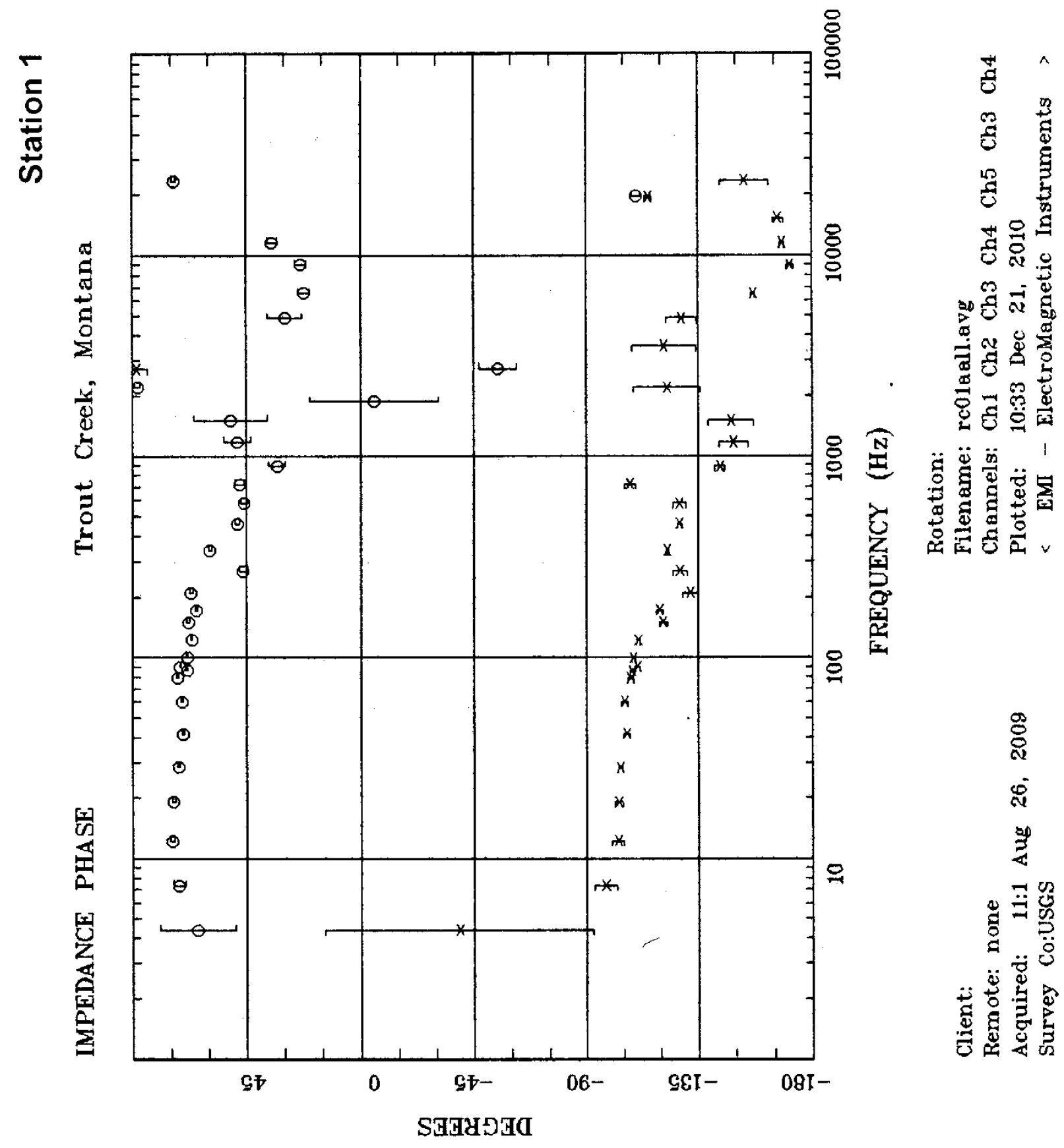




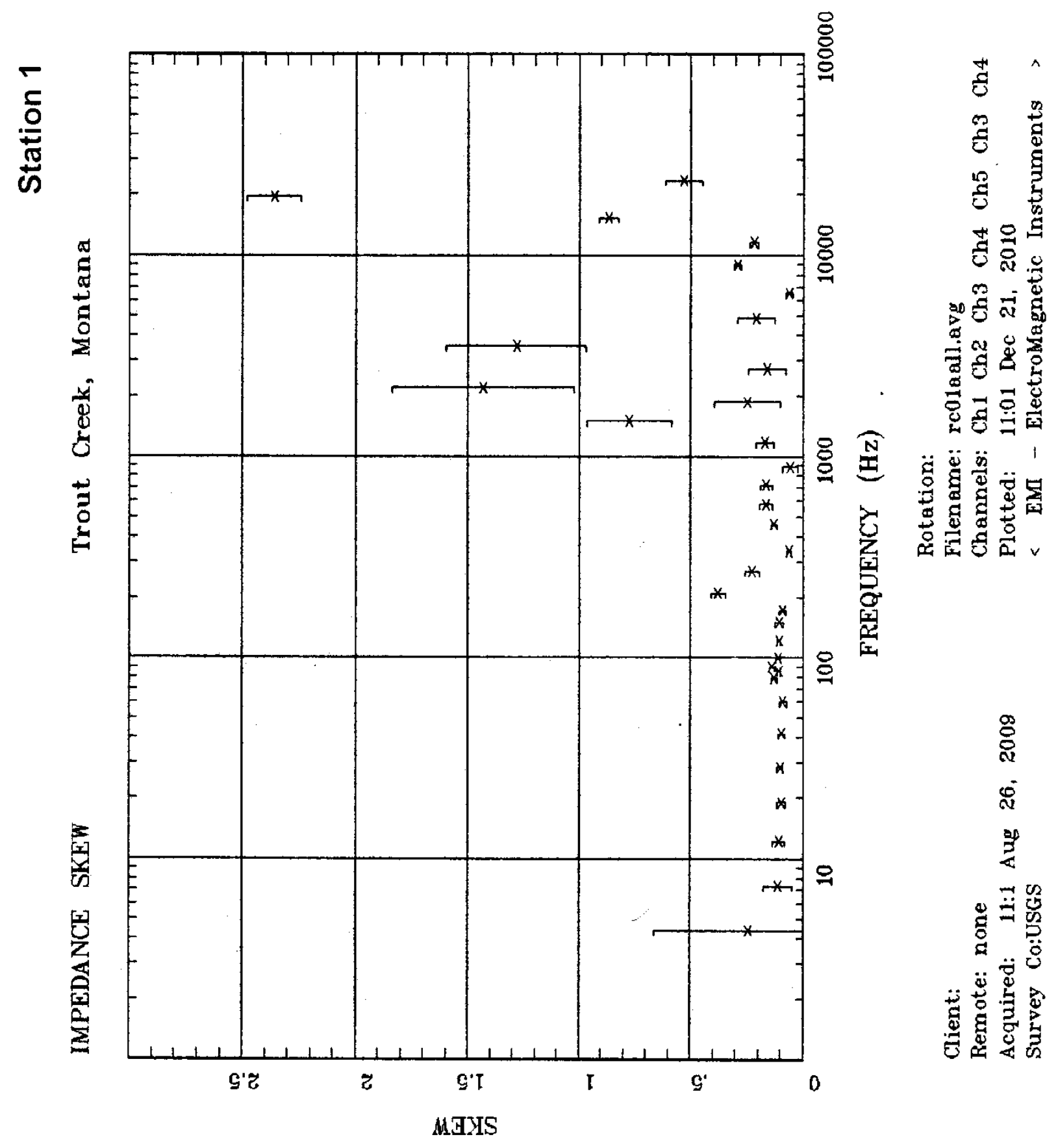




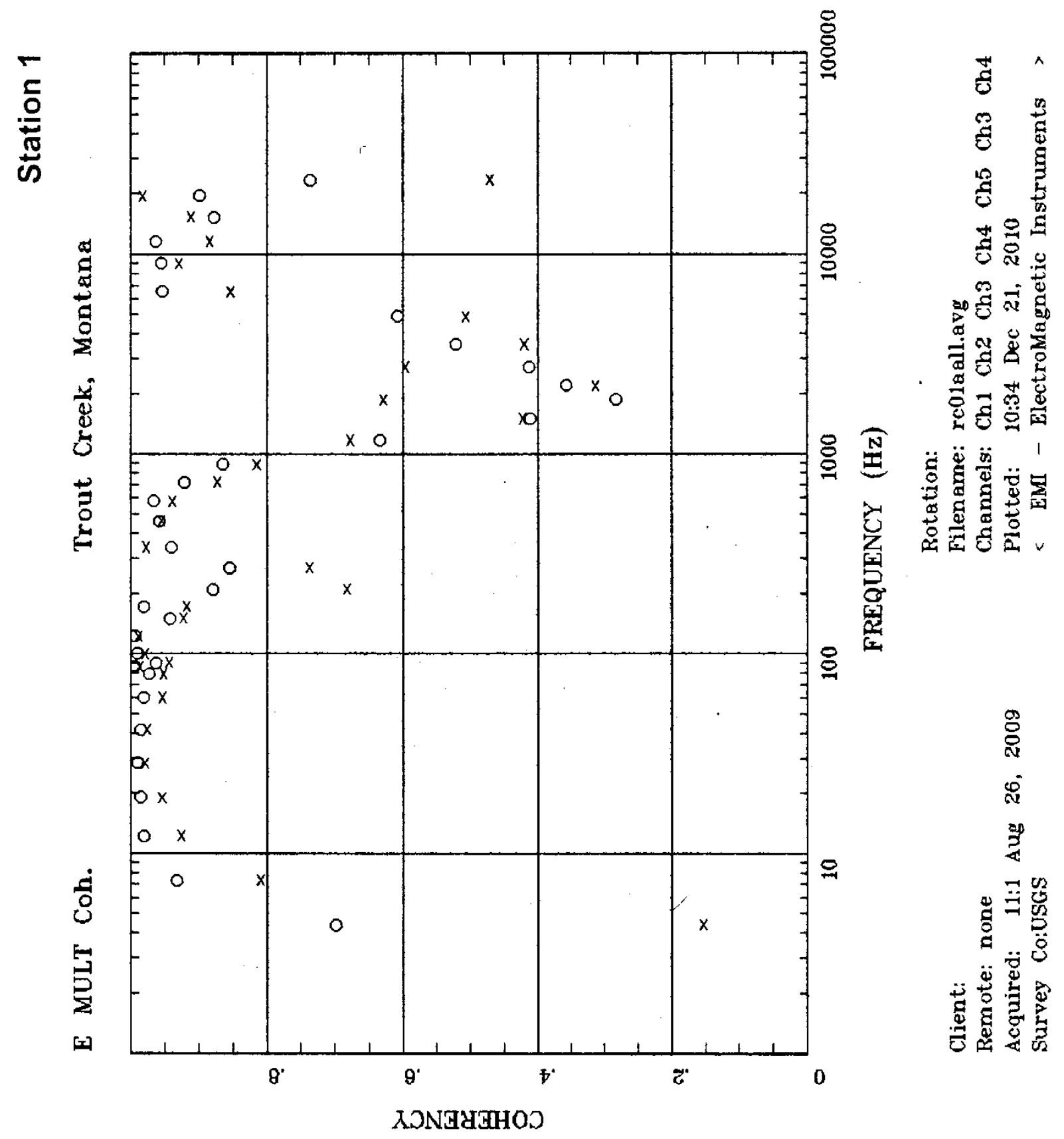


مَ

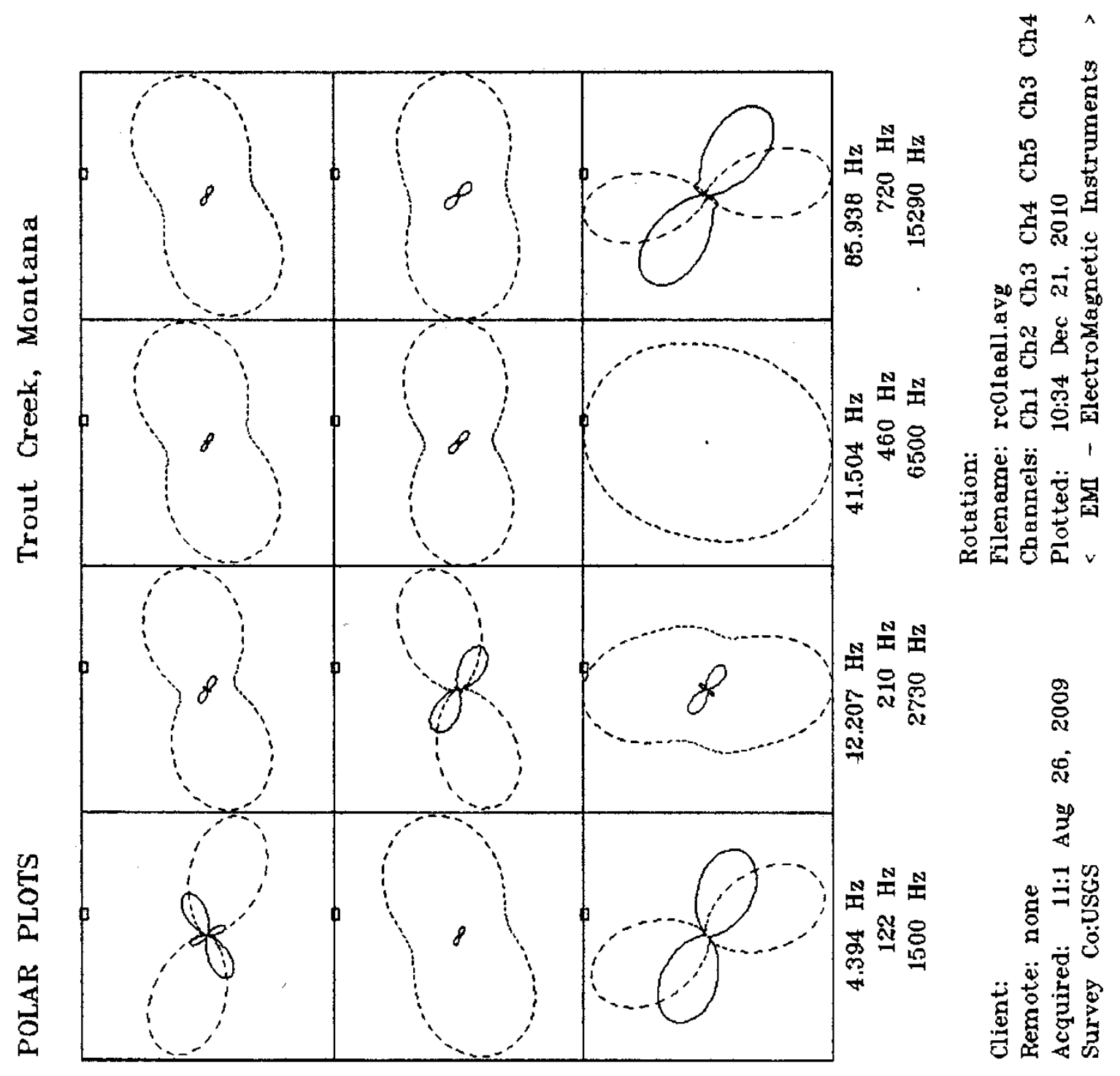




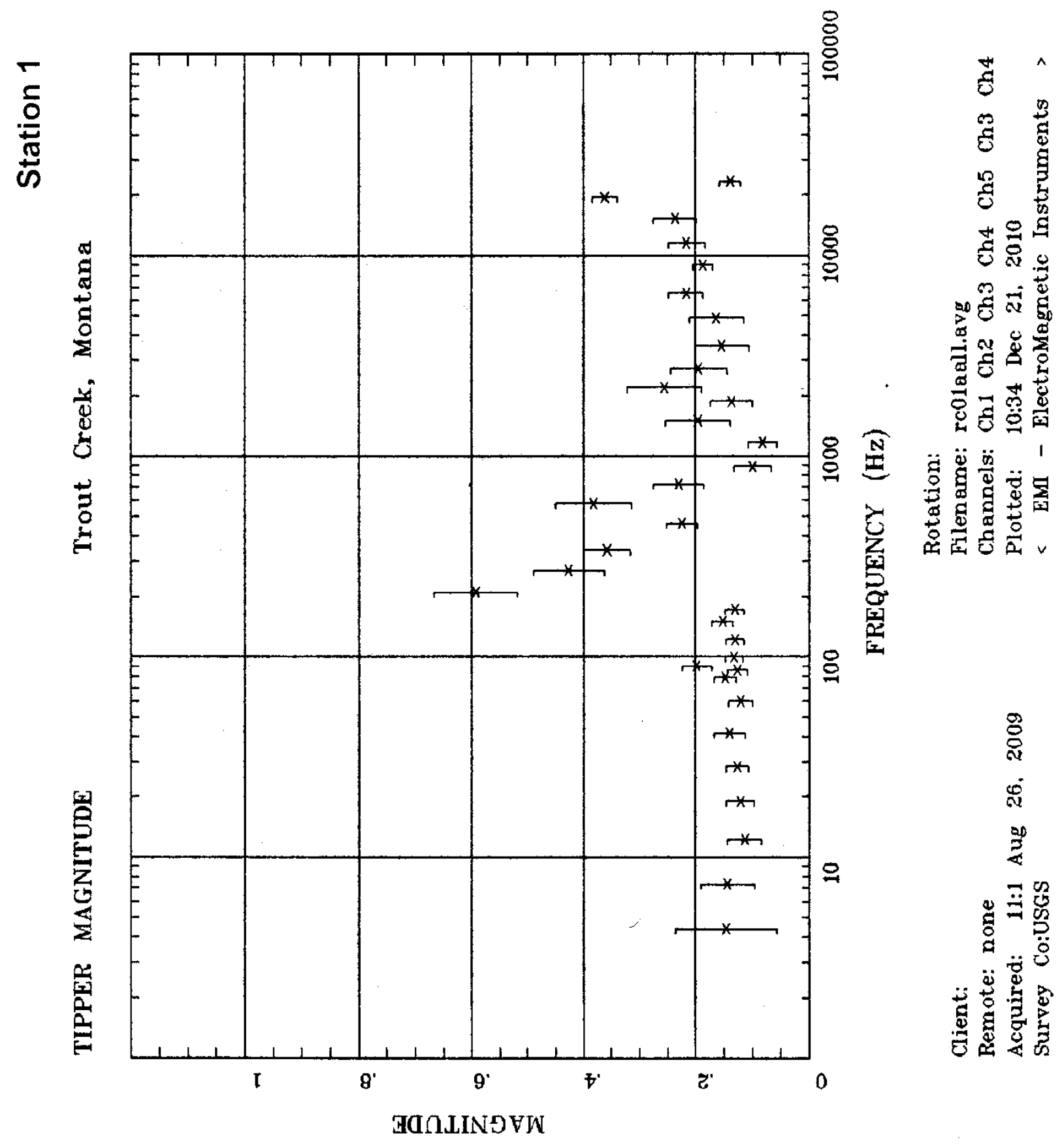




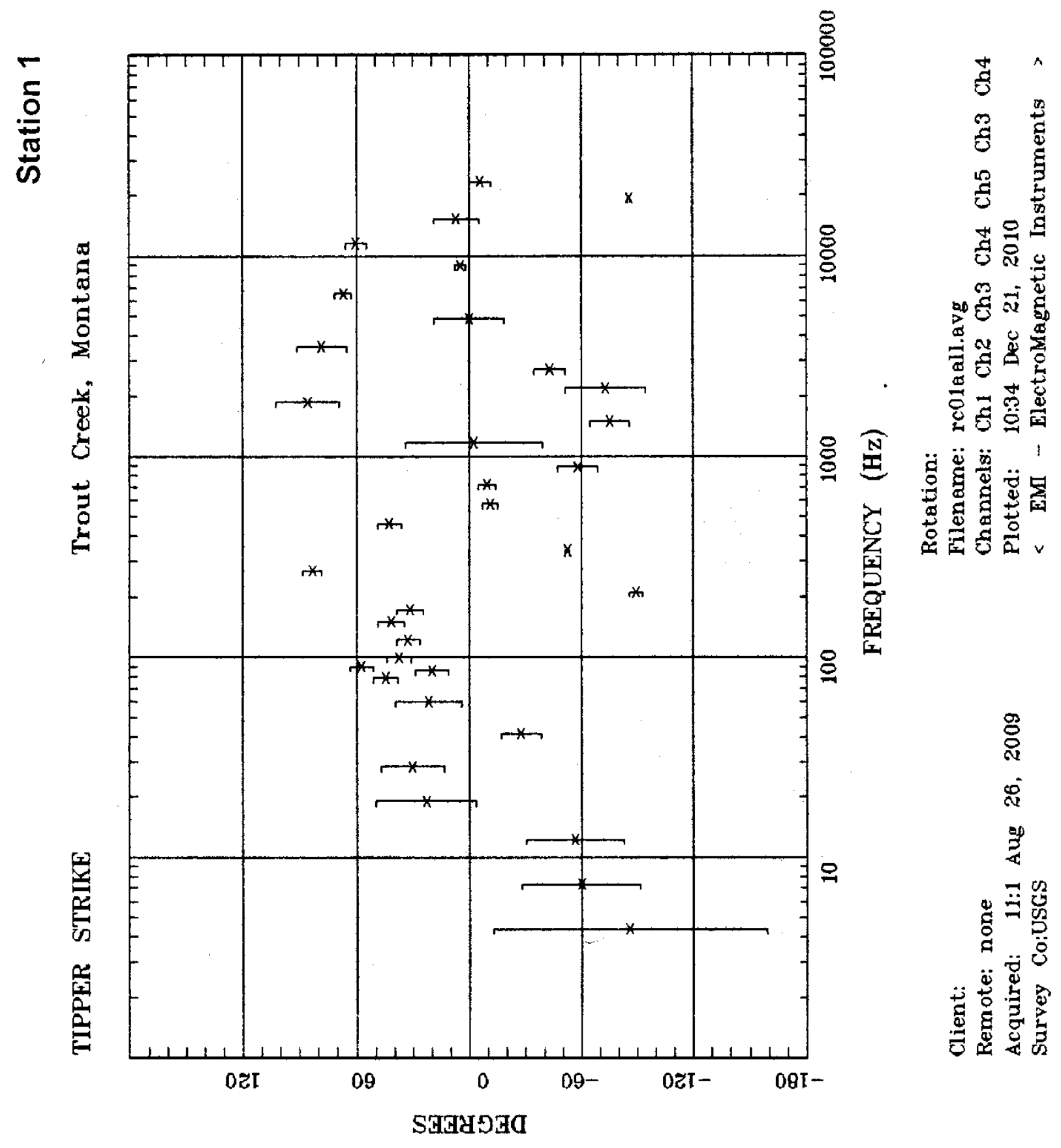




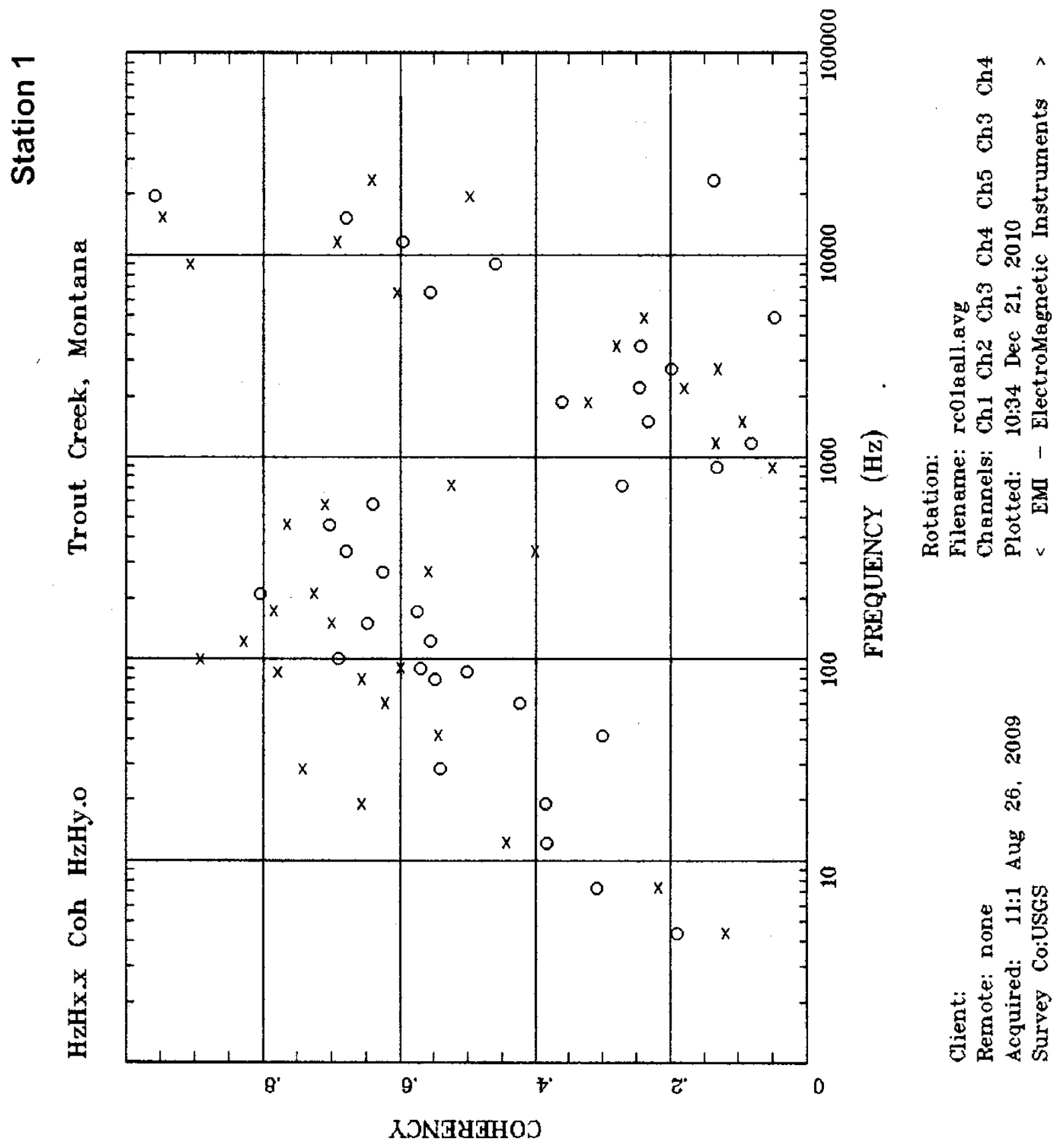




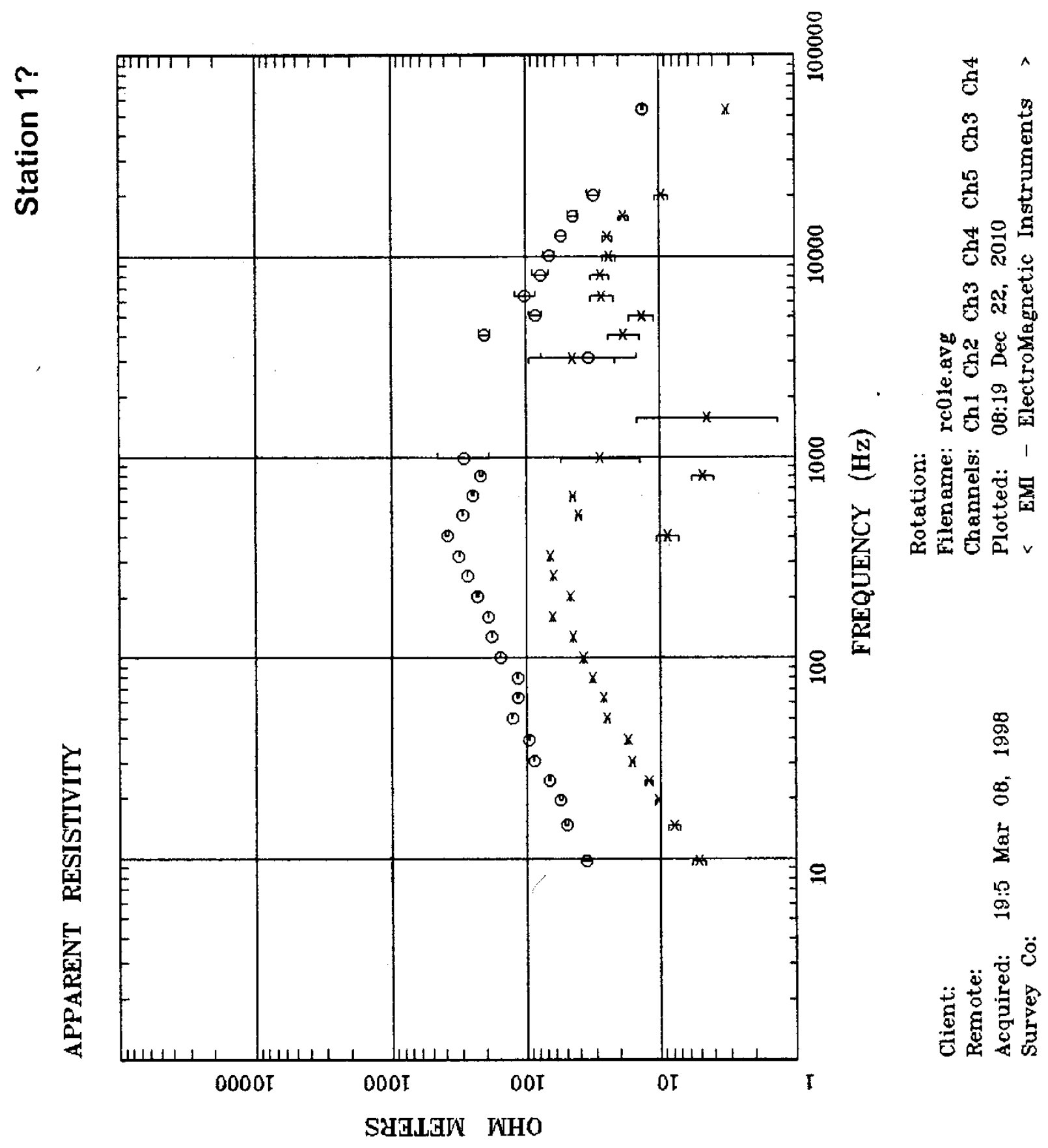




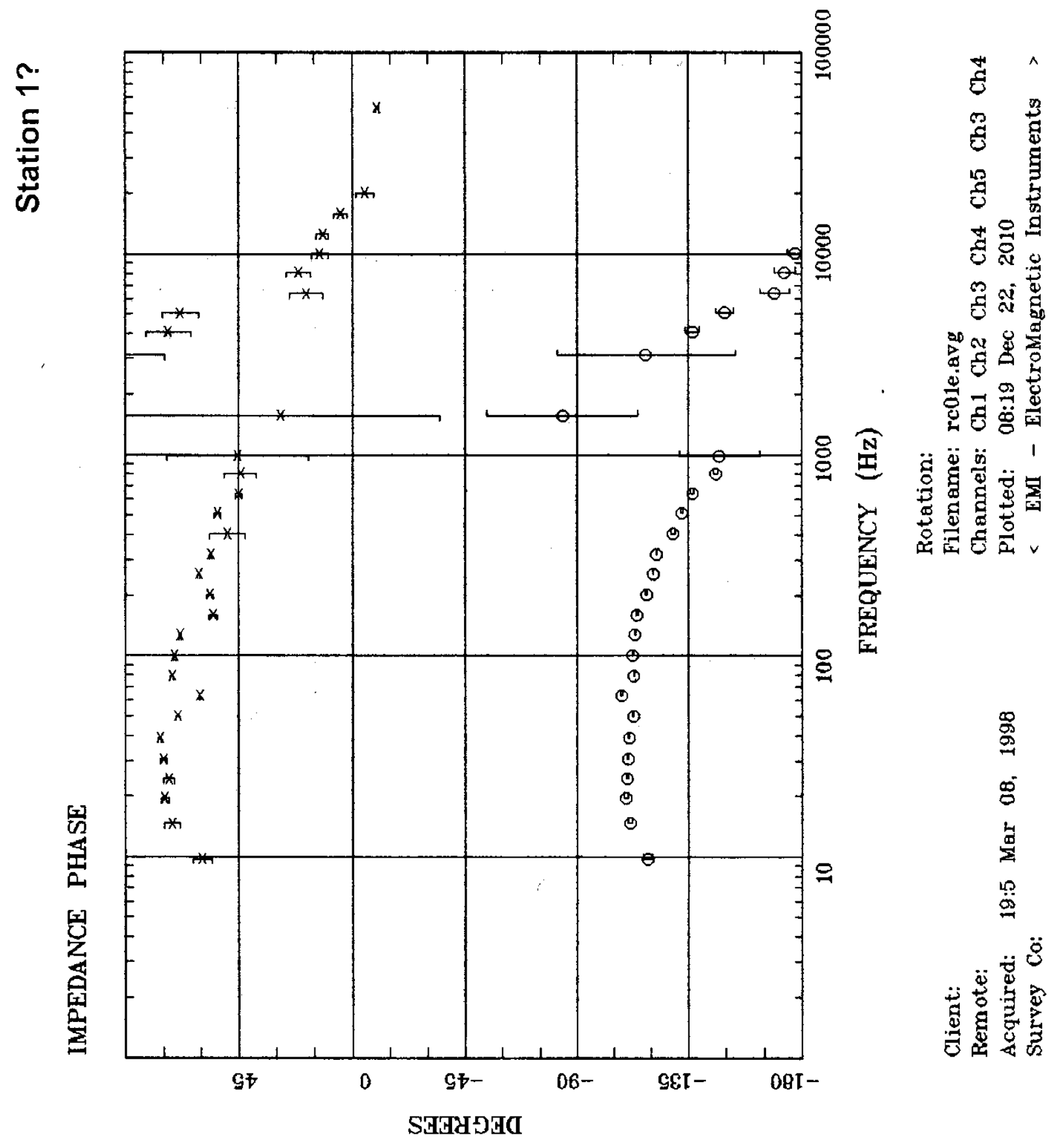




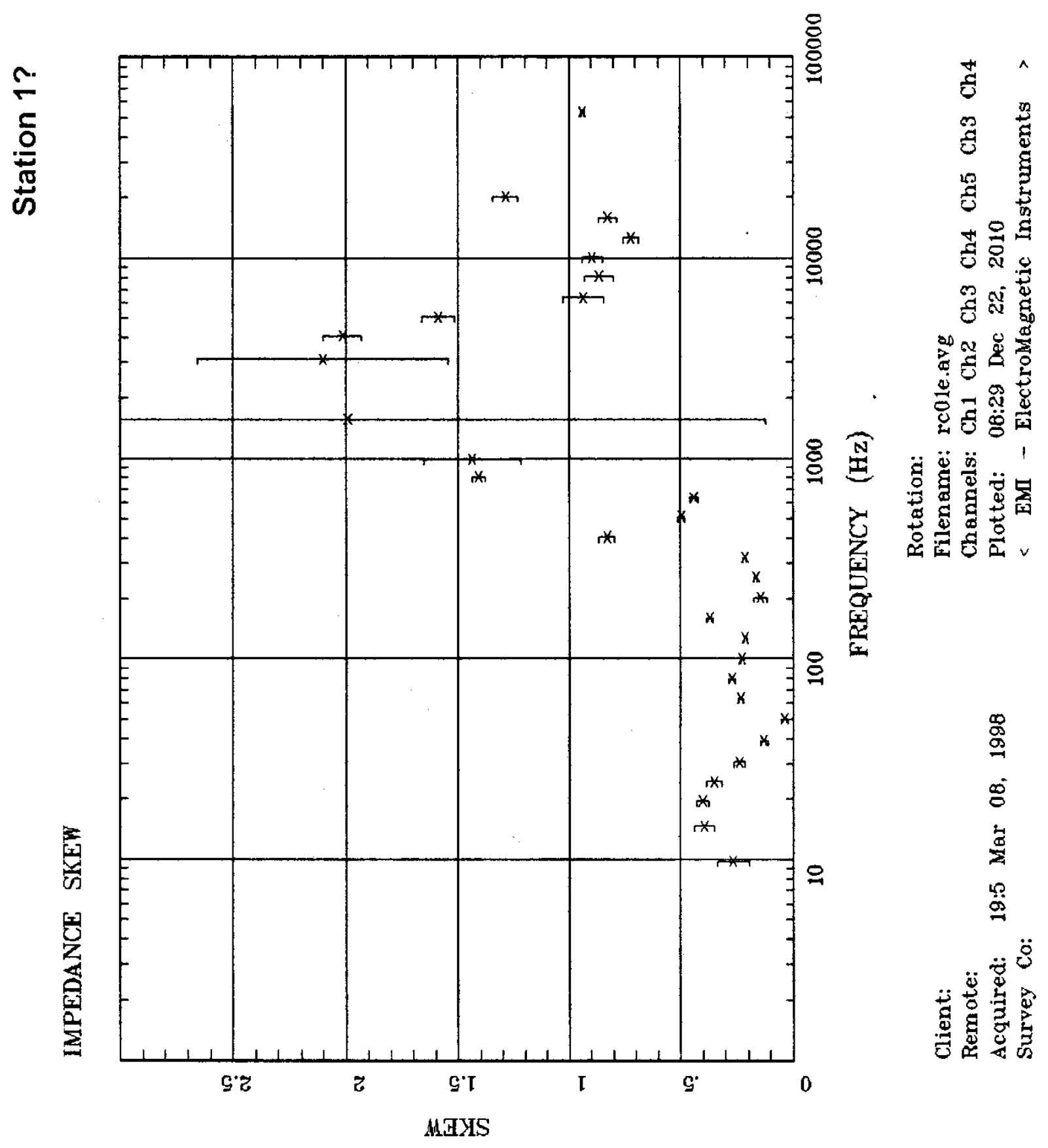




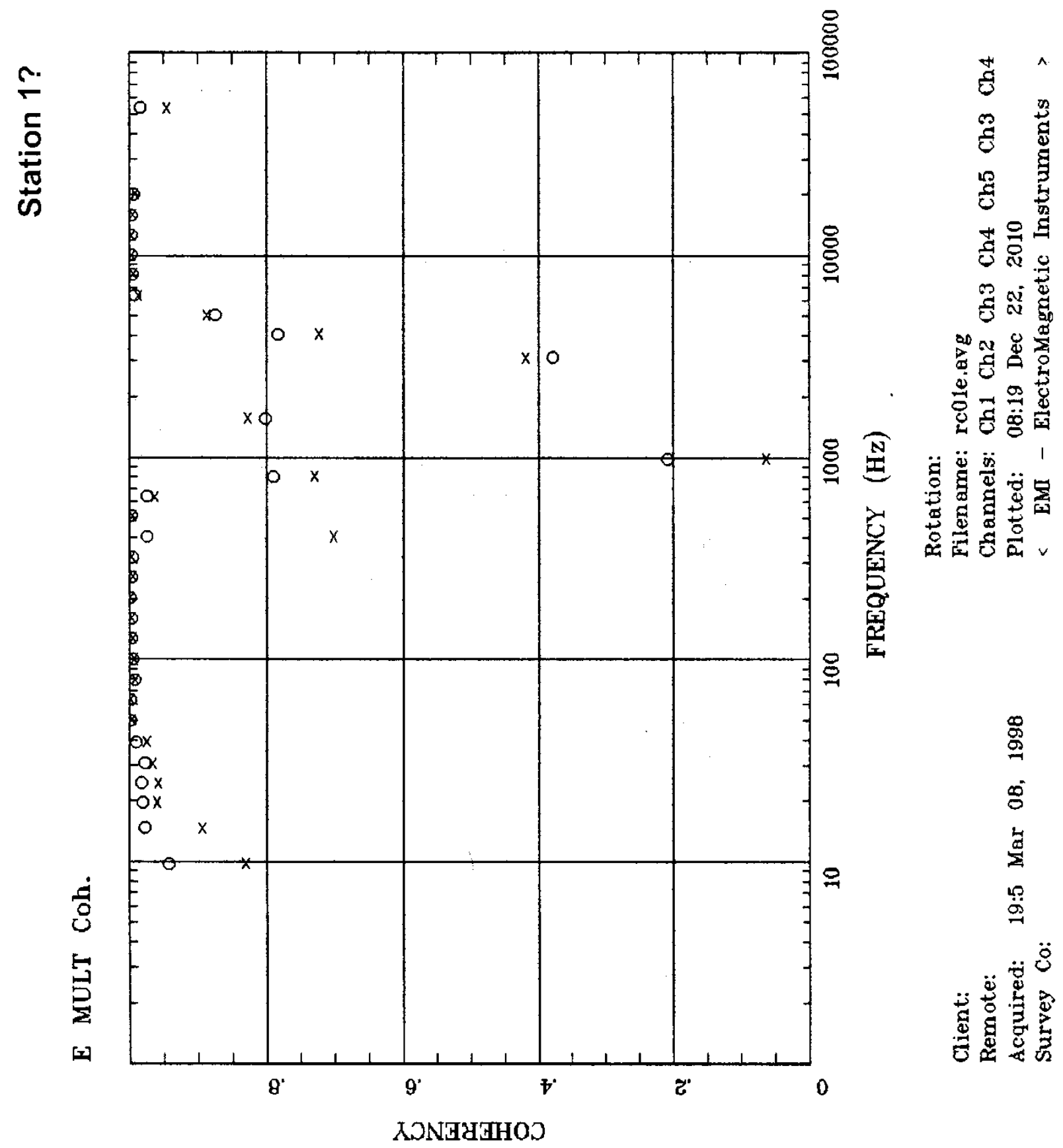




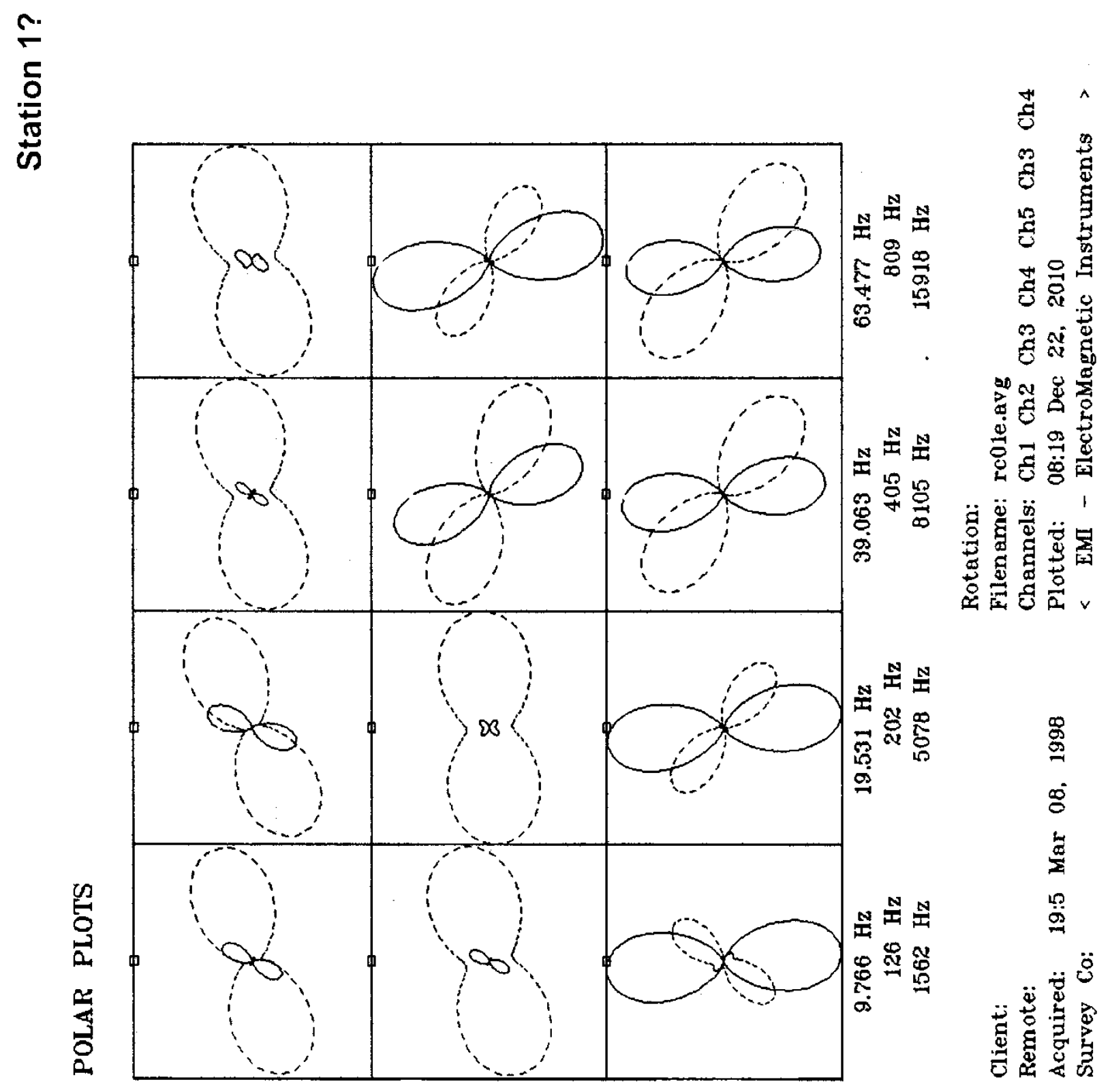




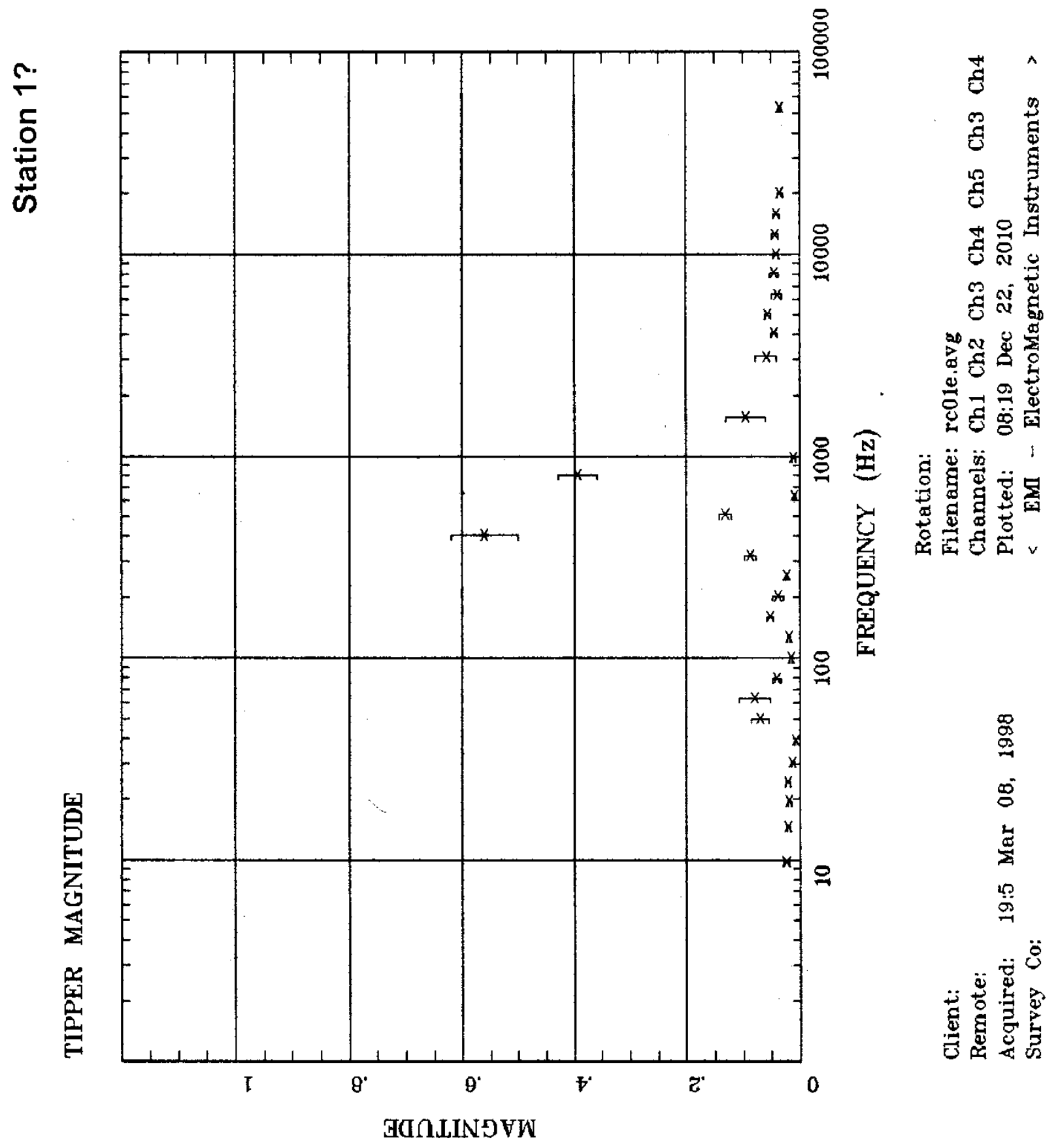




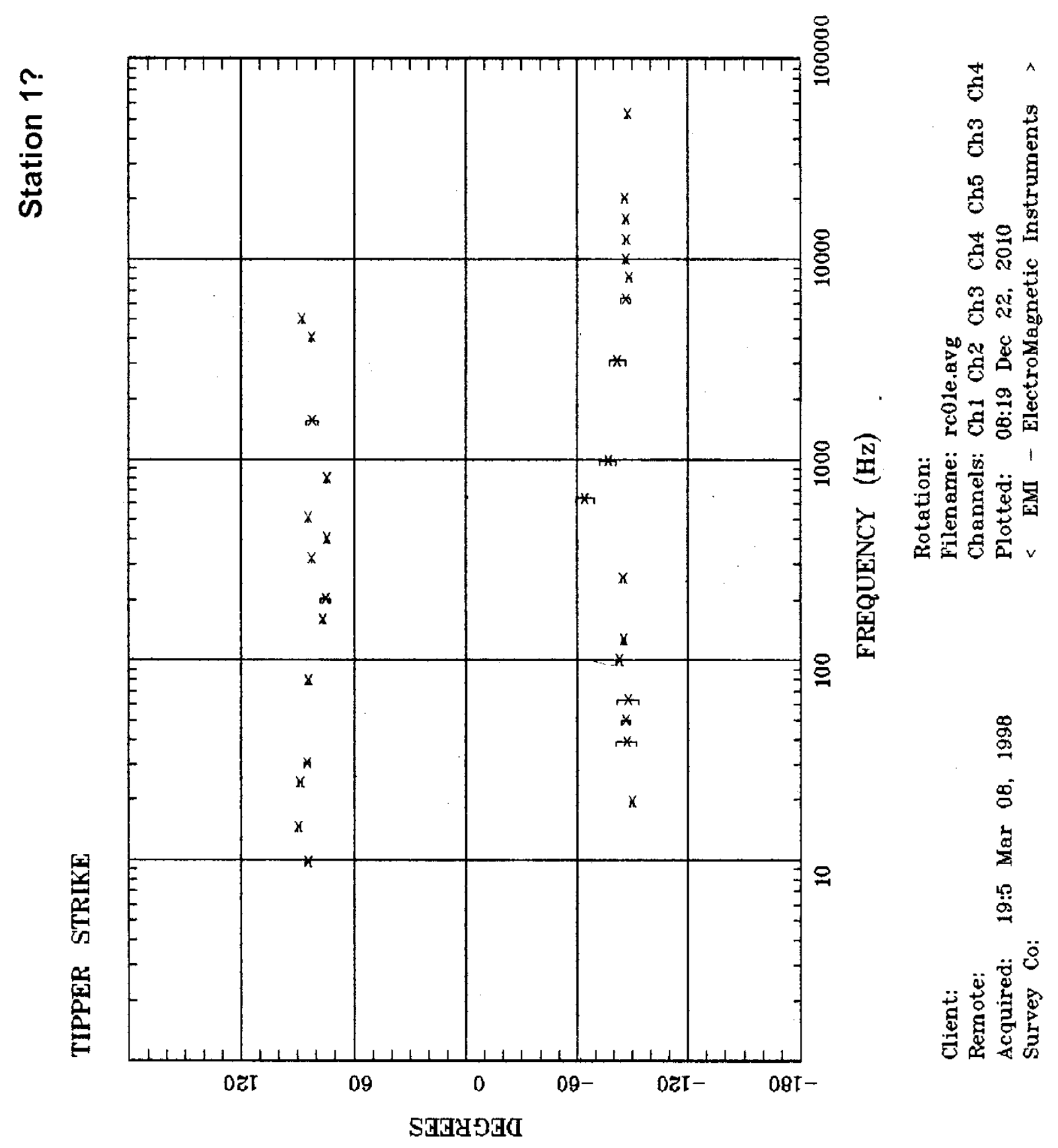




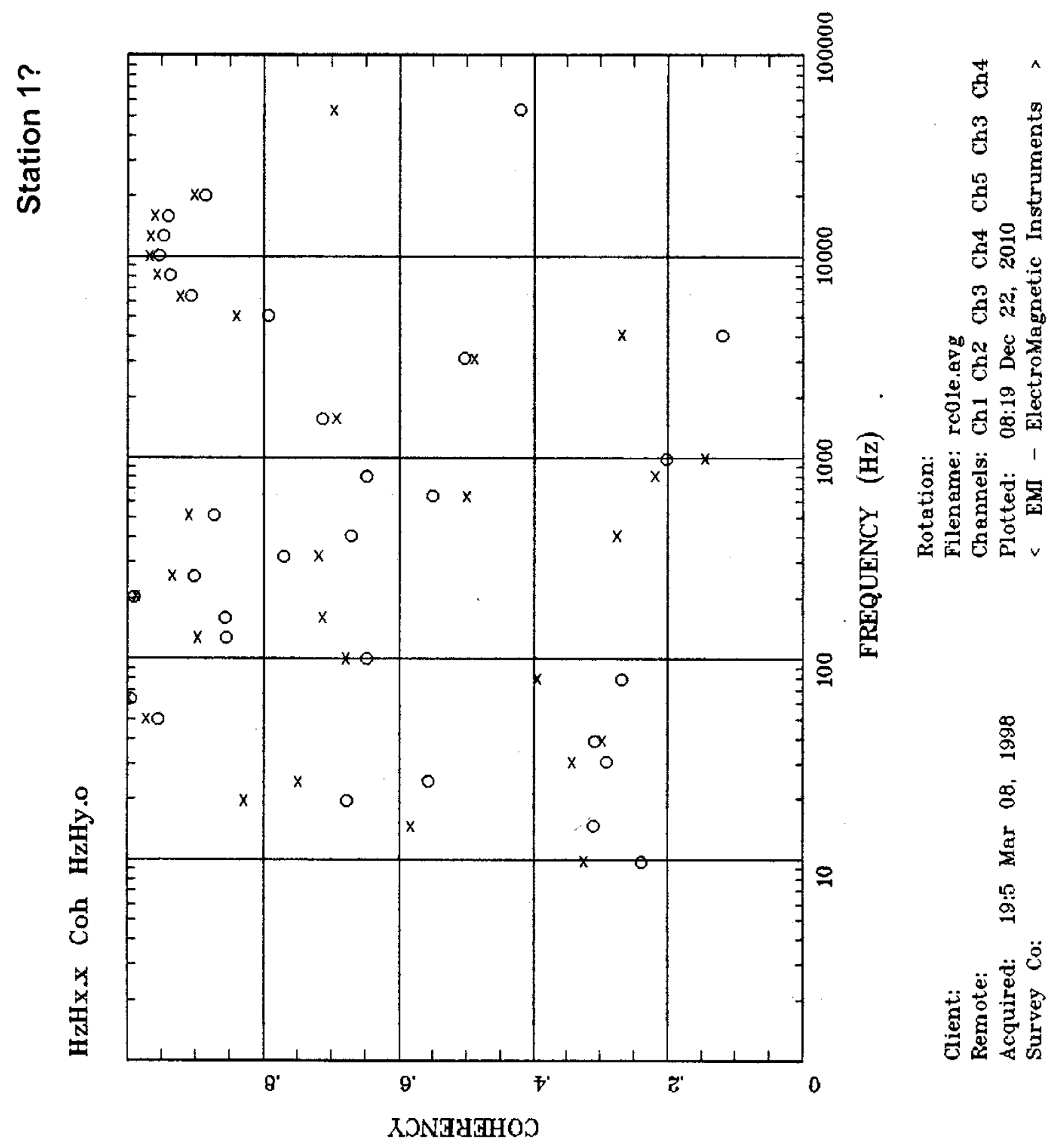




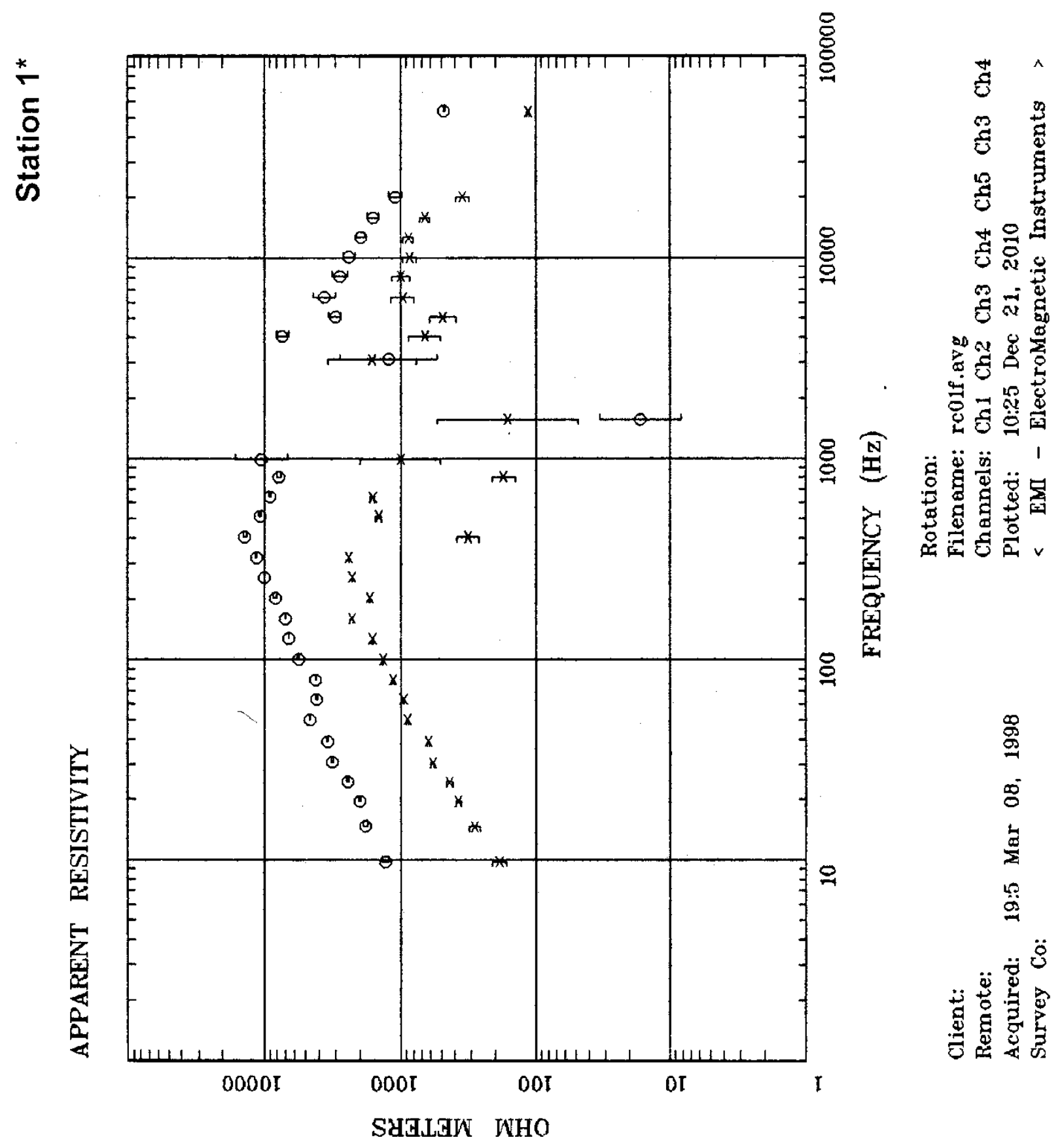




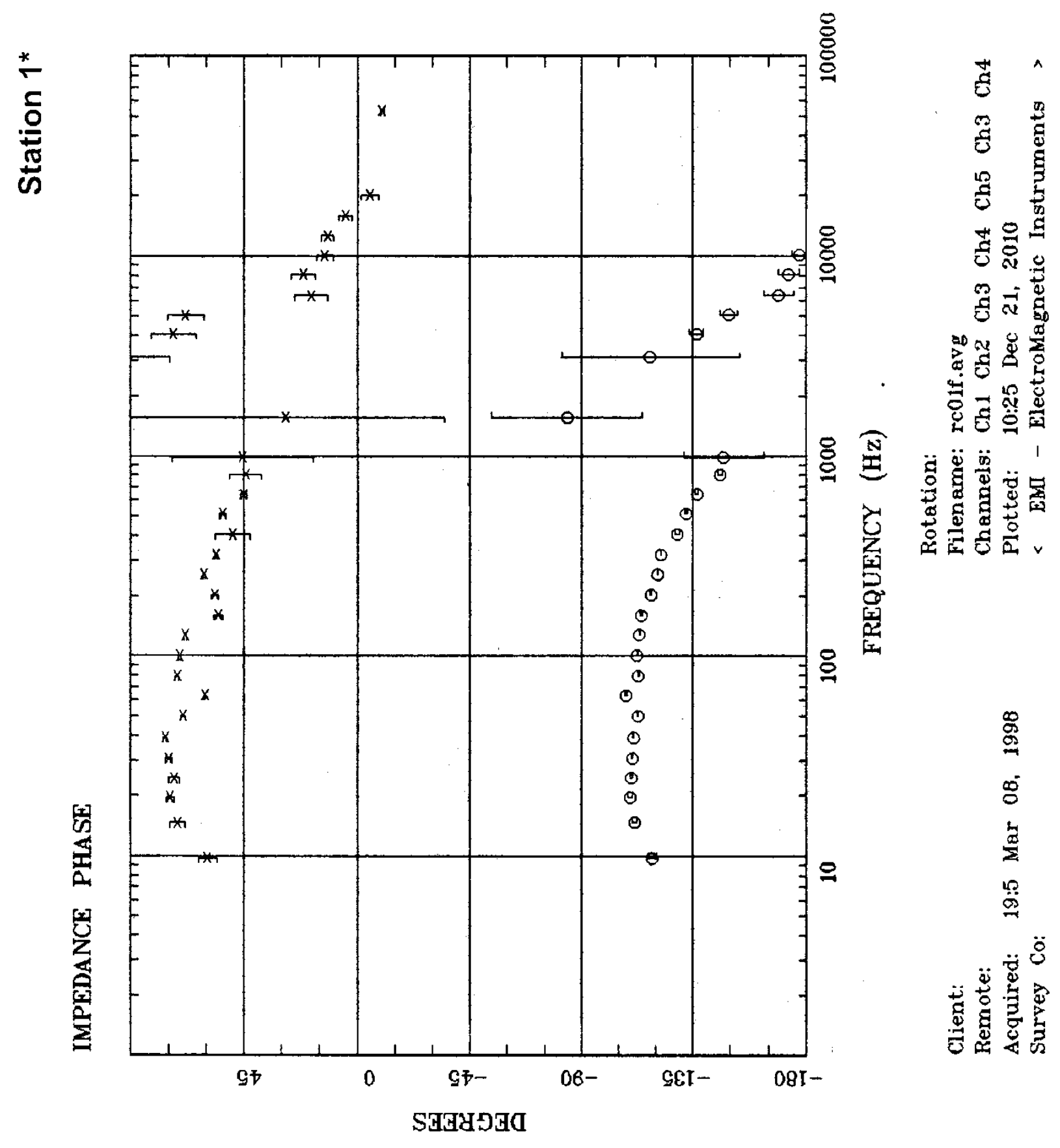




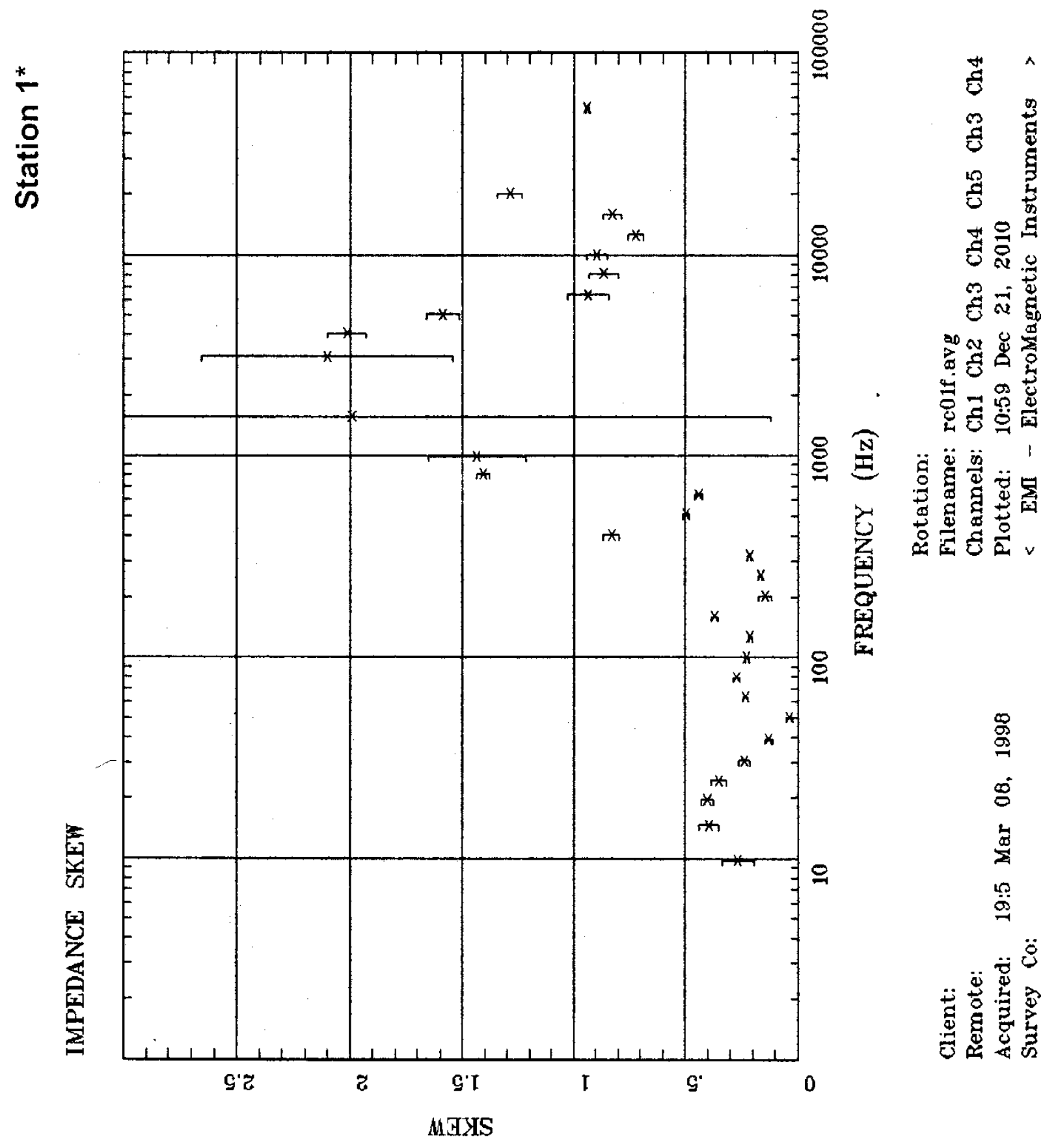




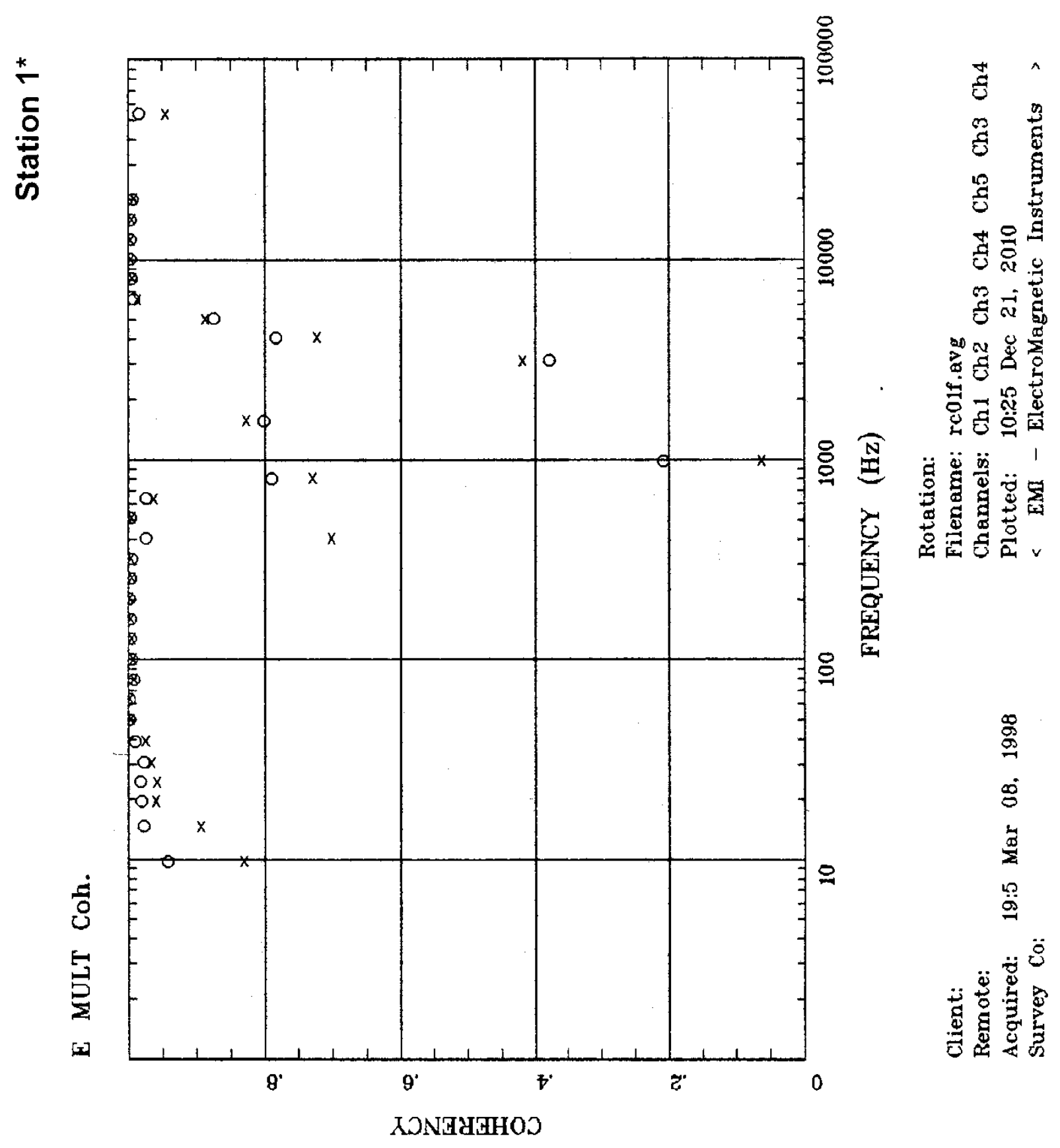




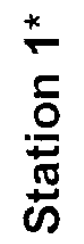

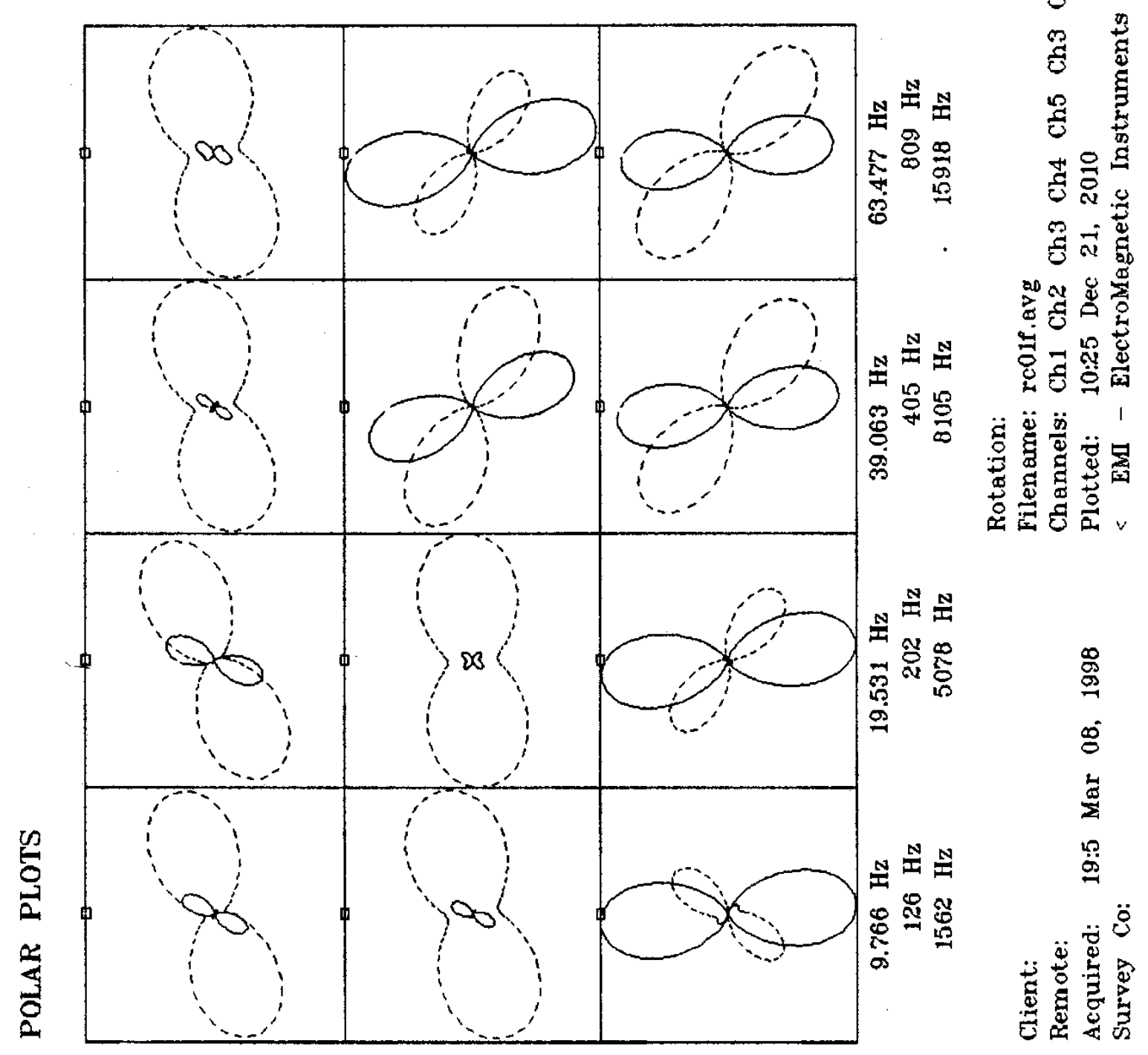




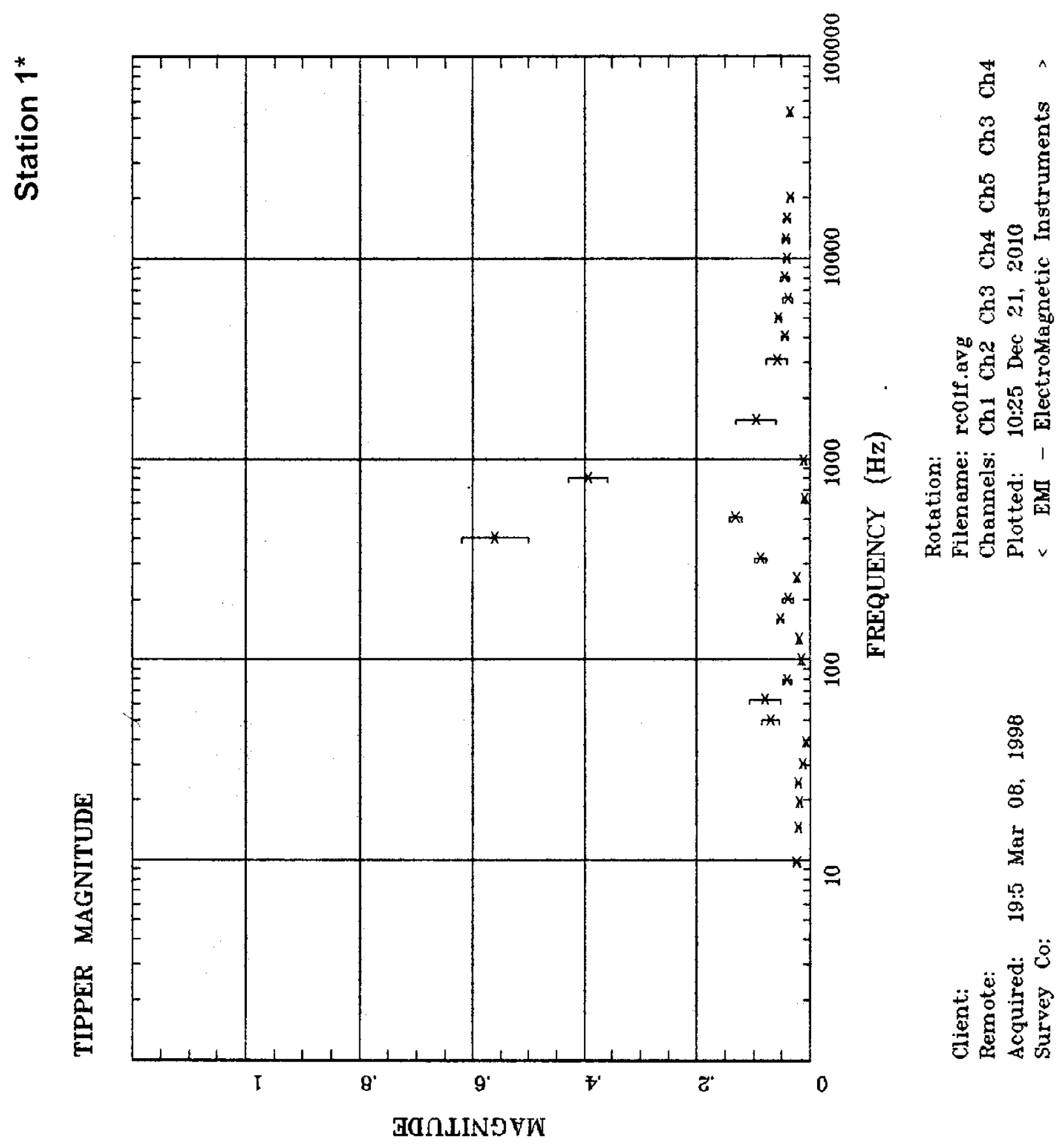




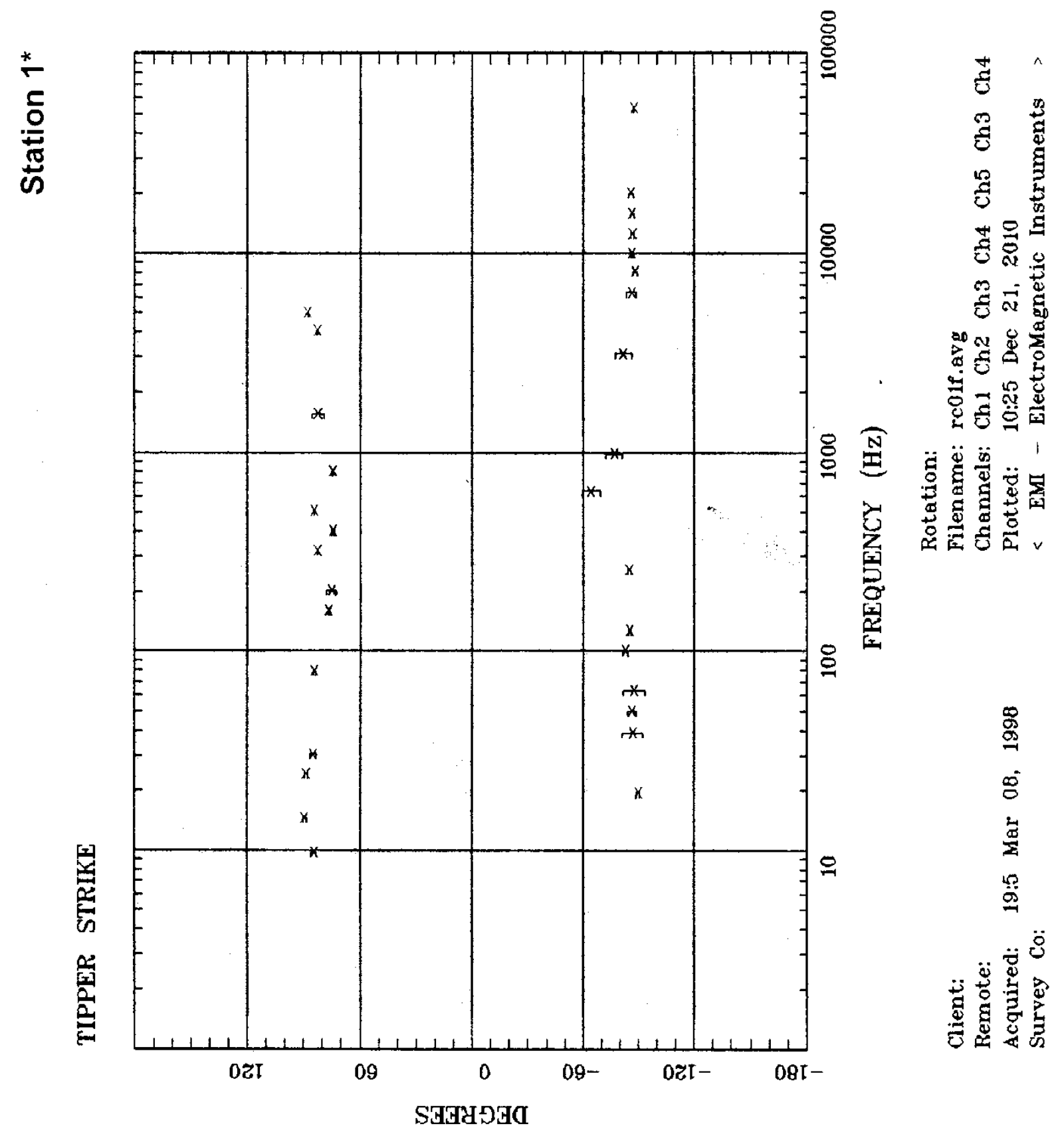




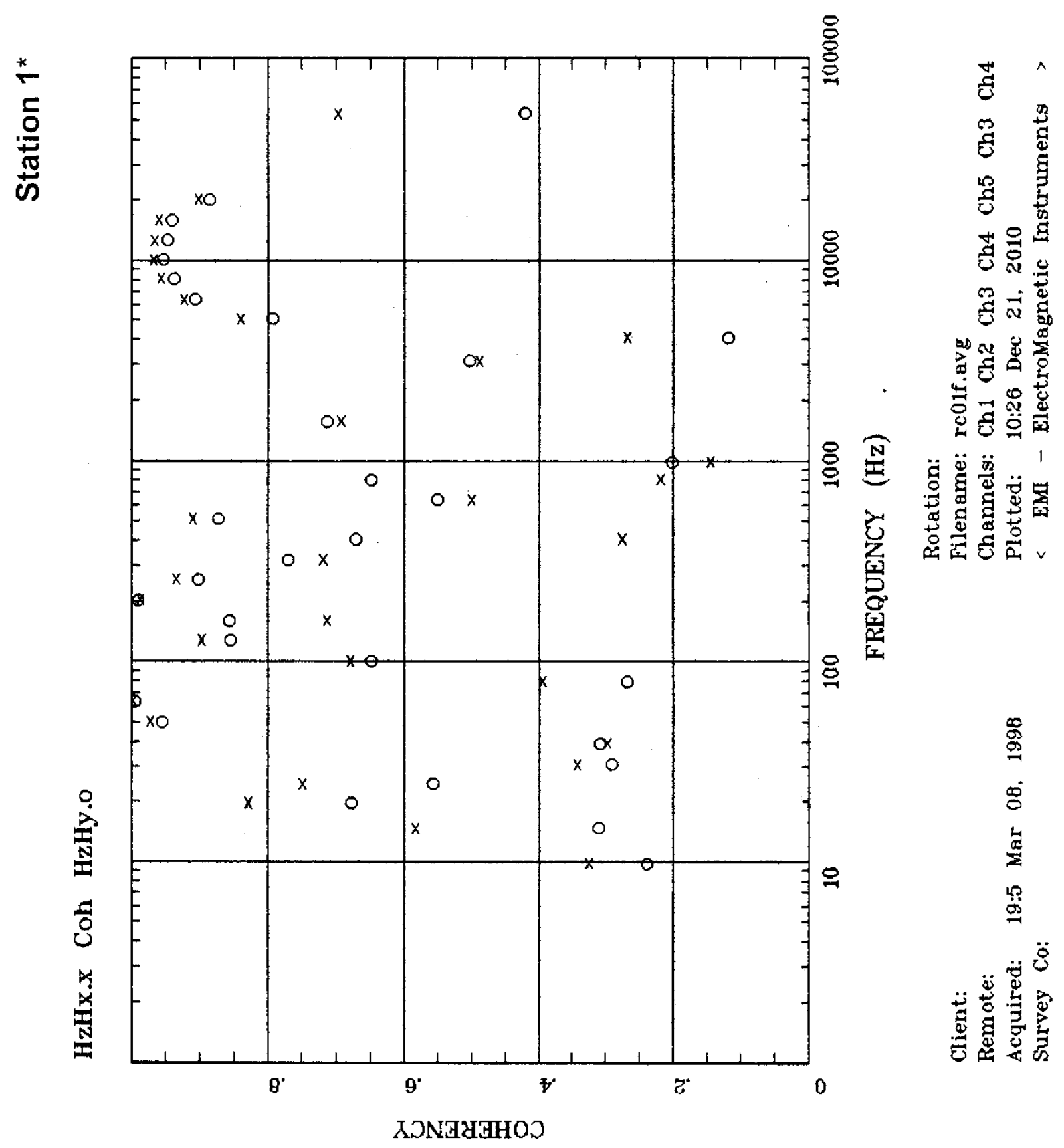




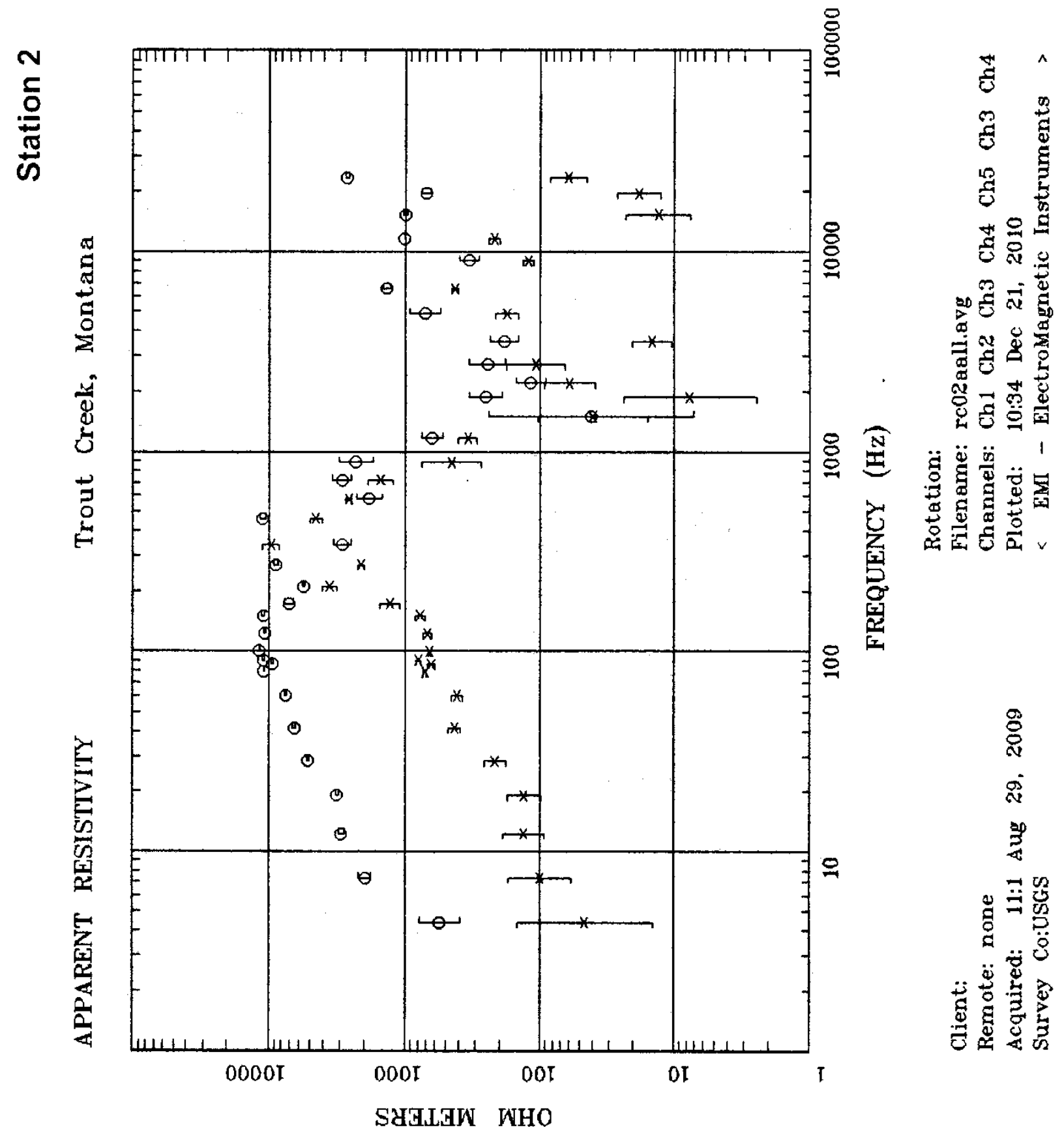




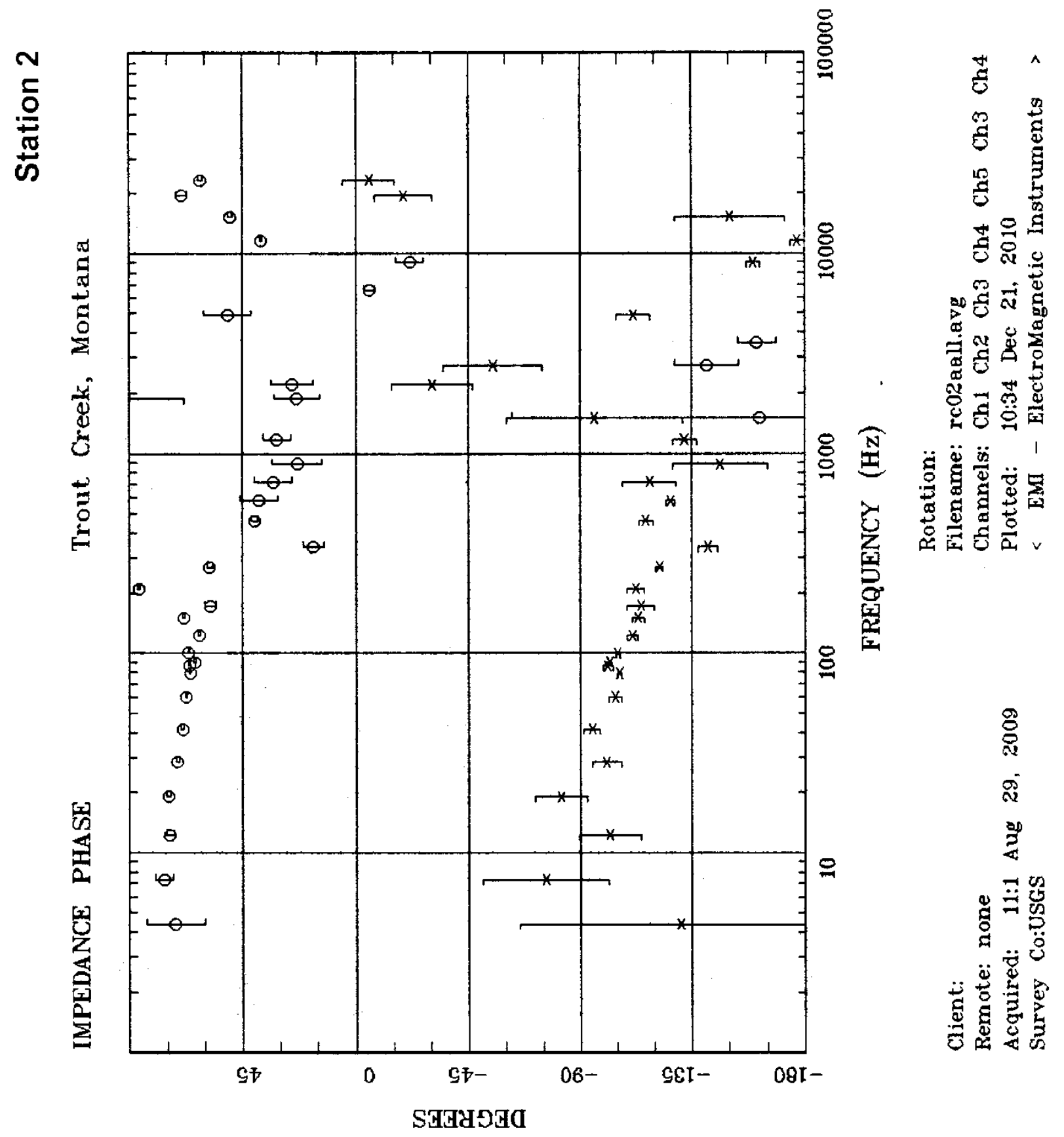




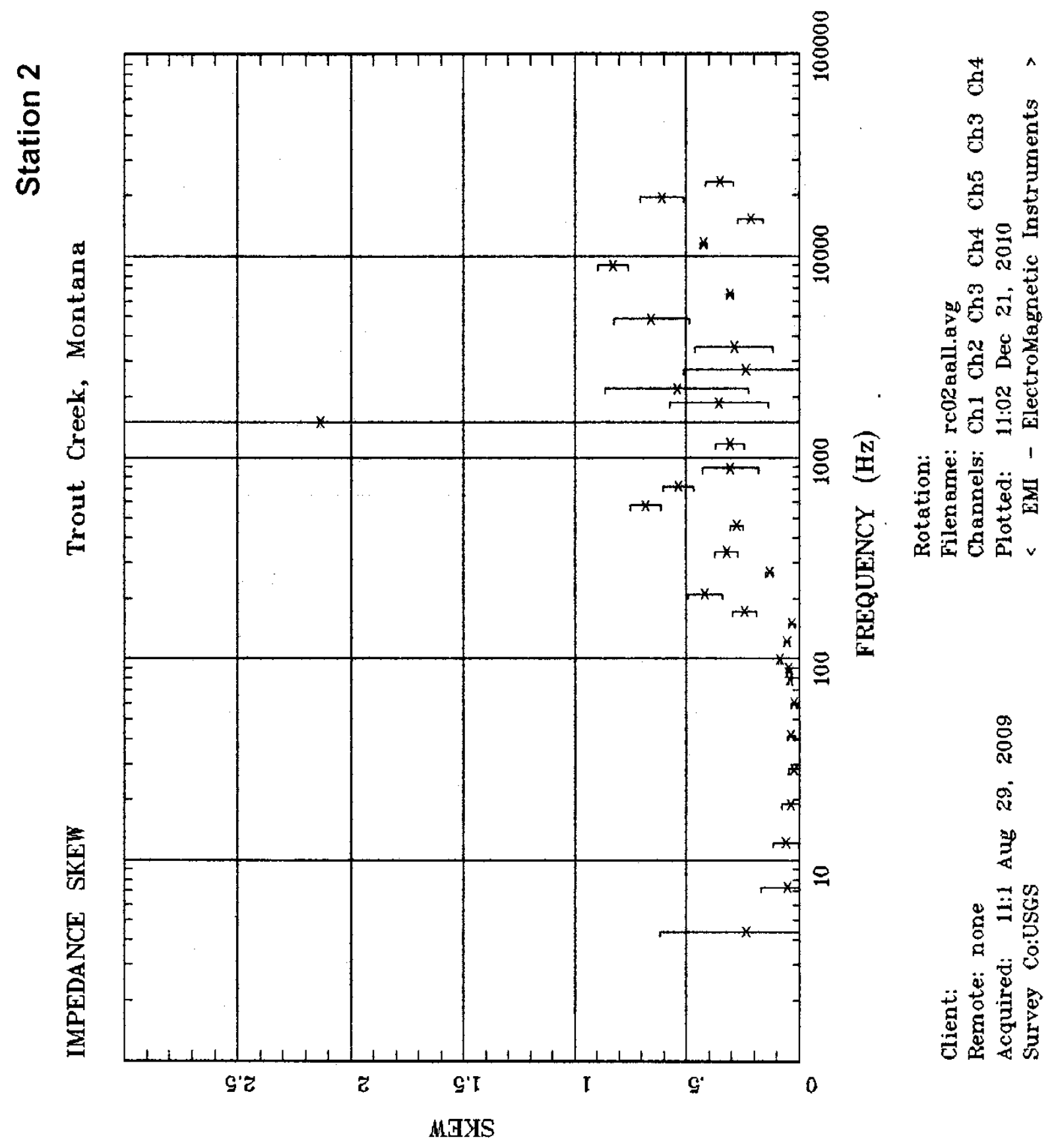




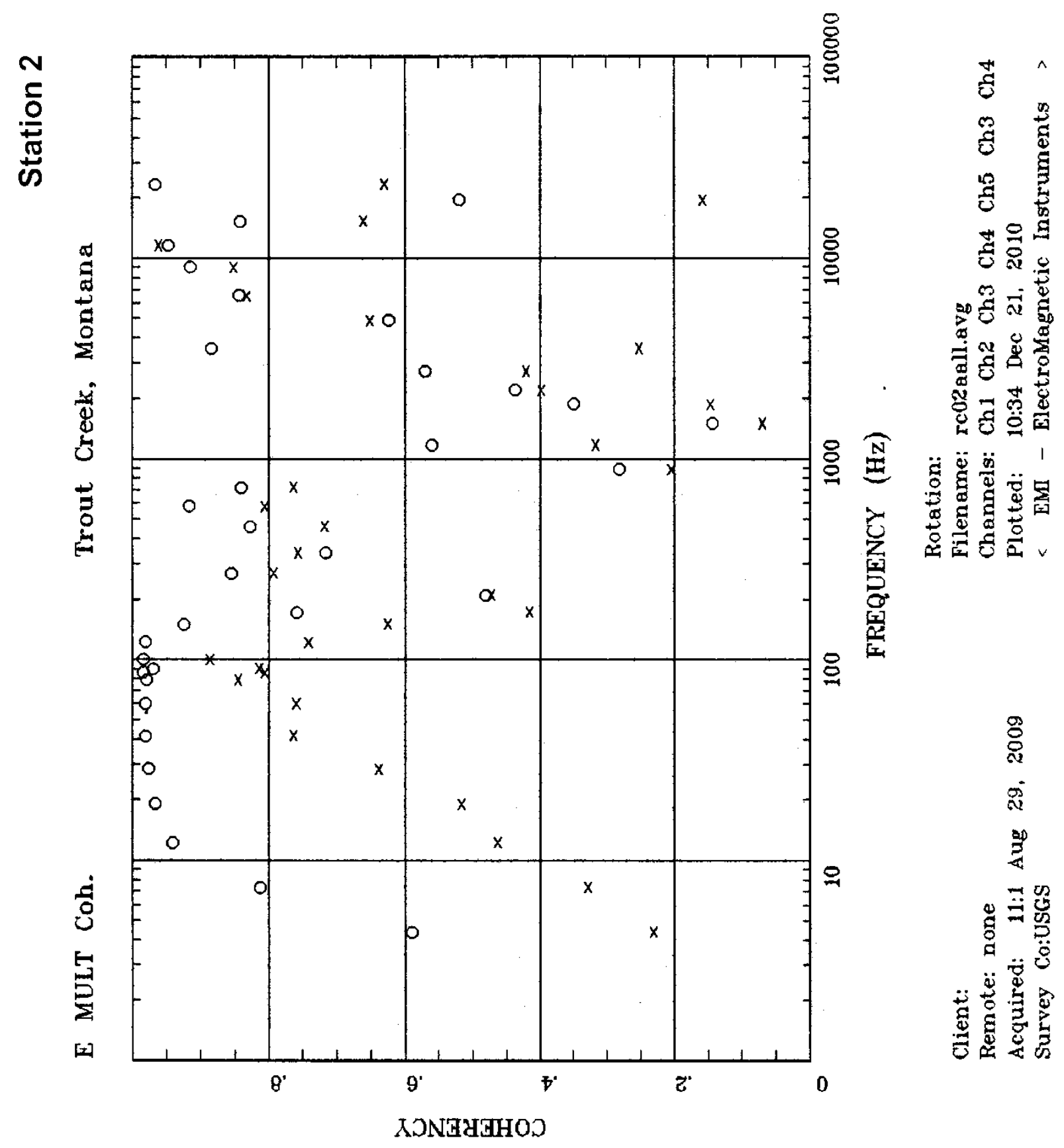




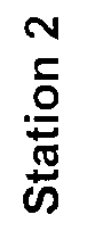

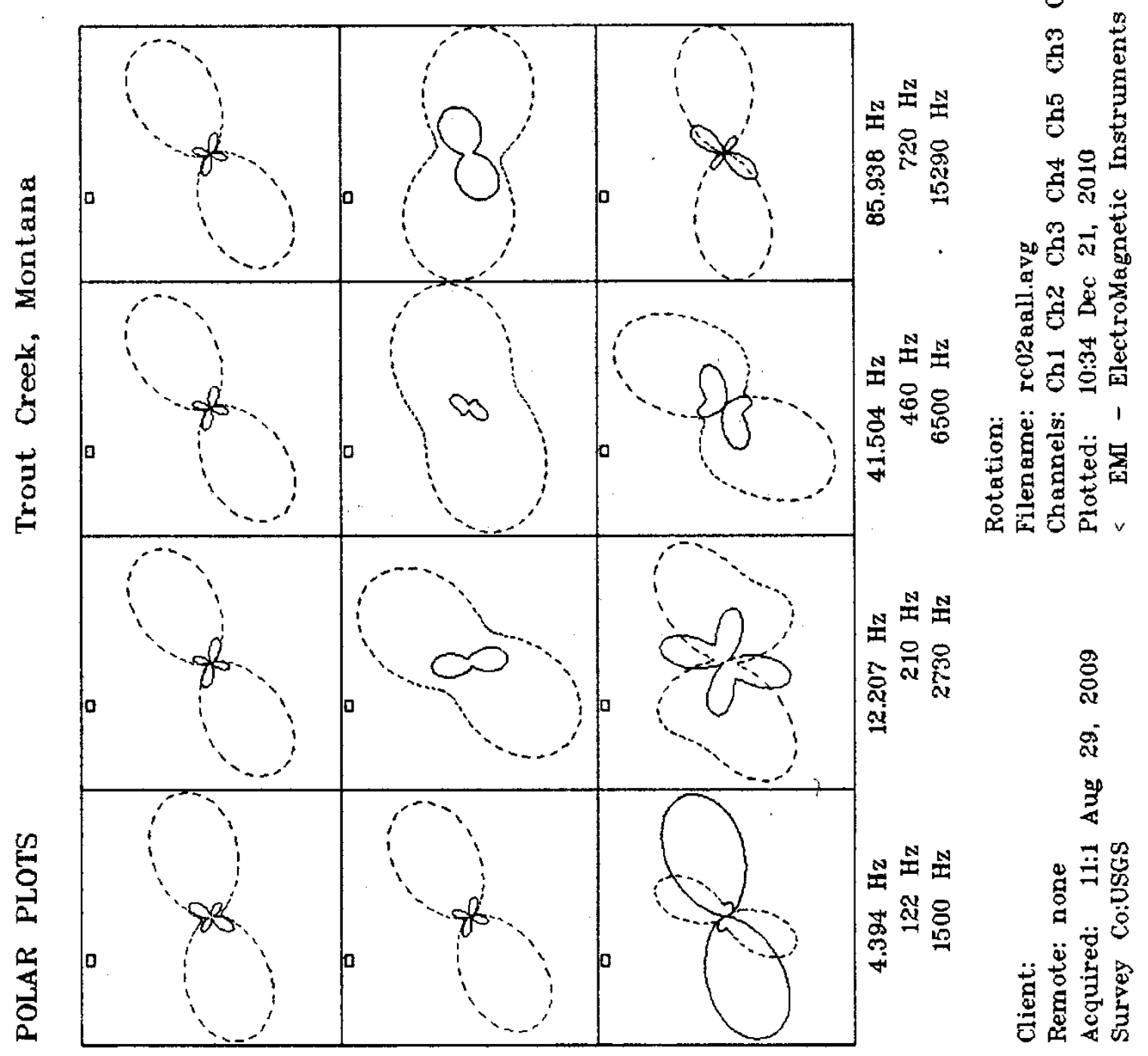




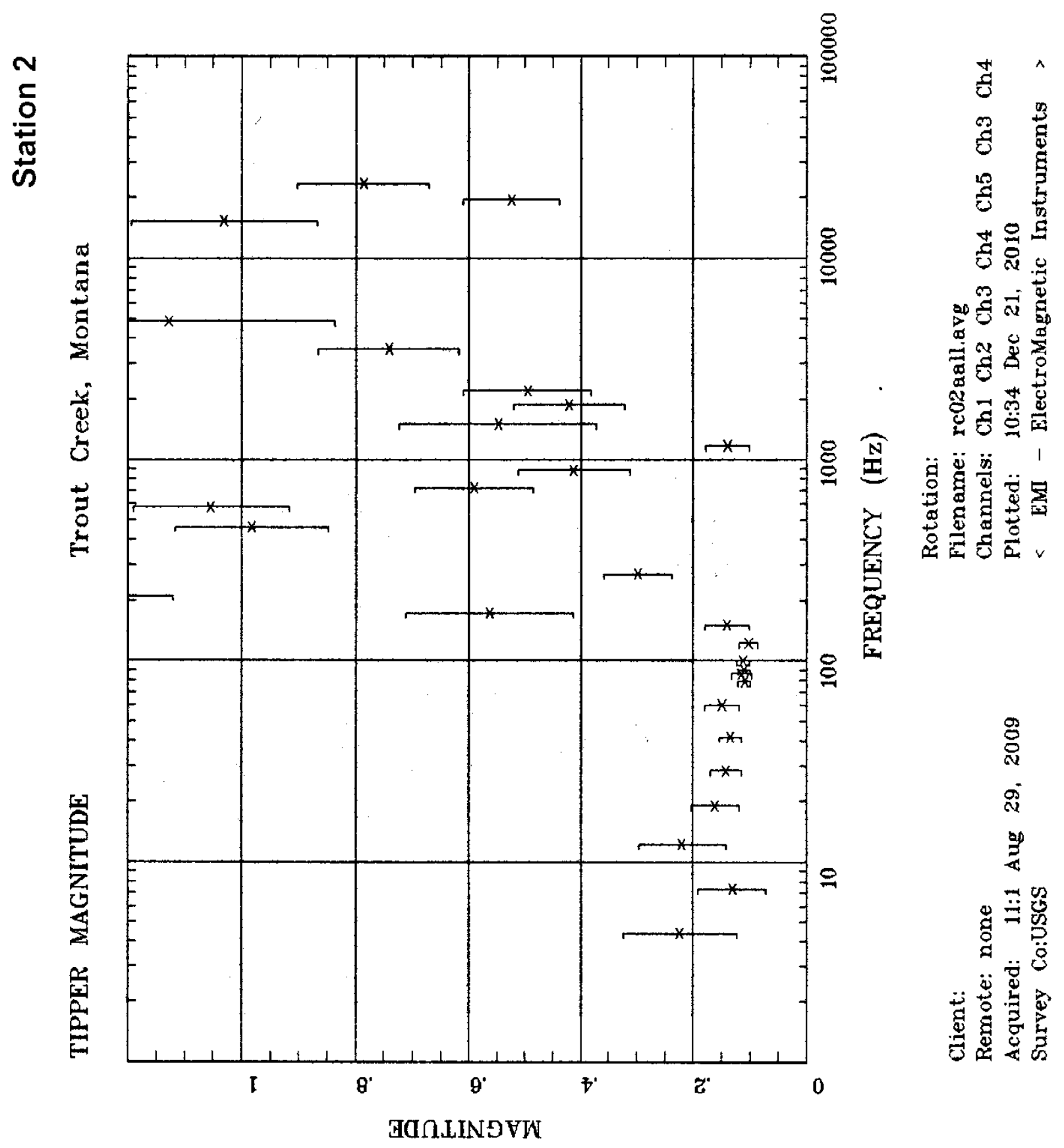




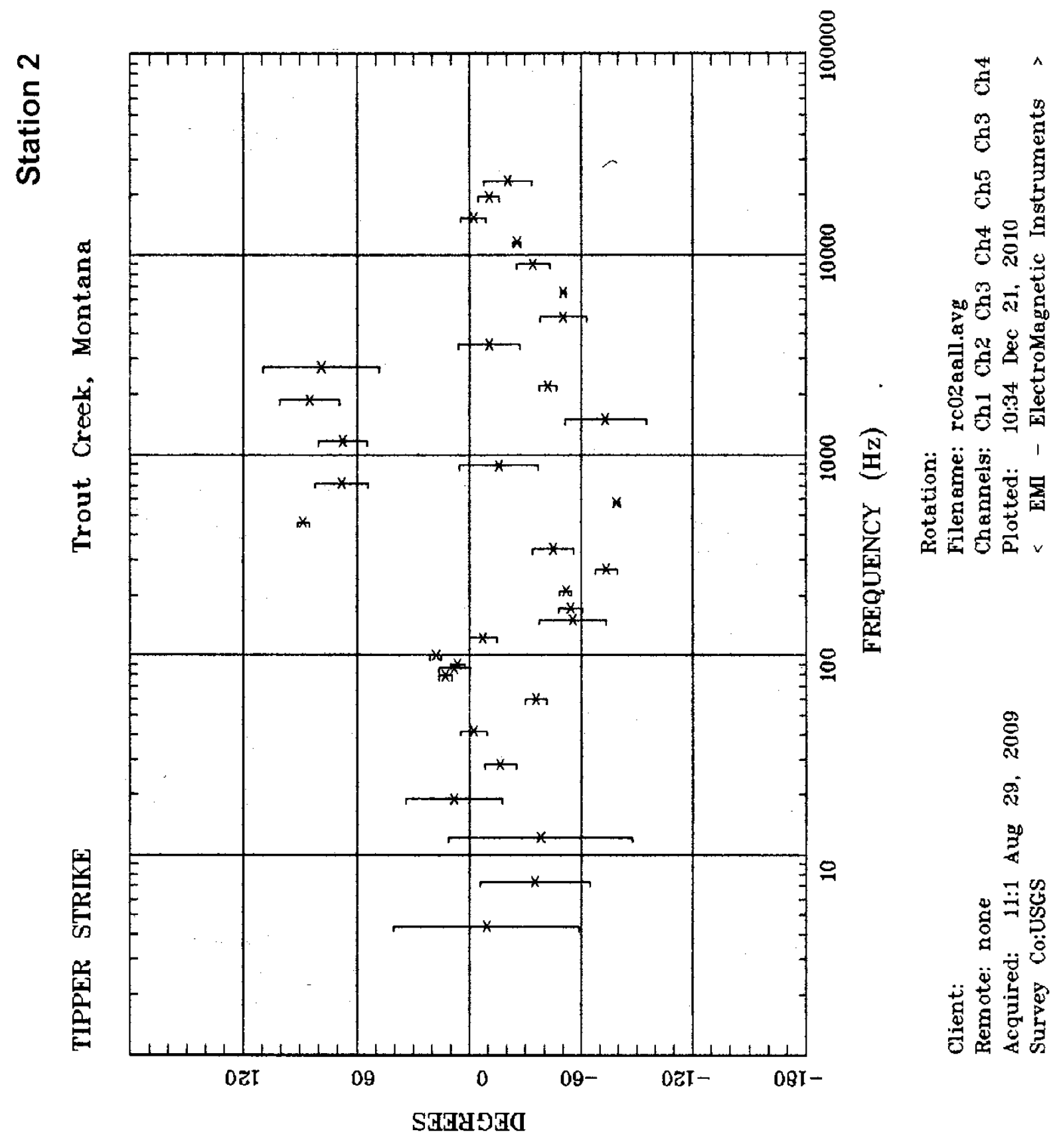




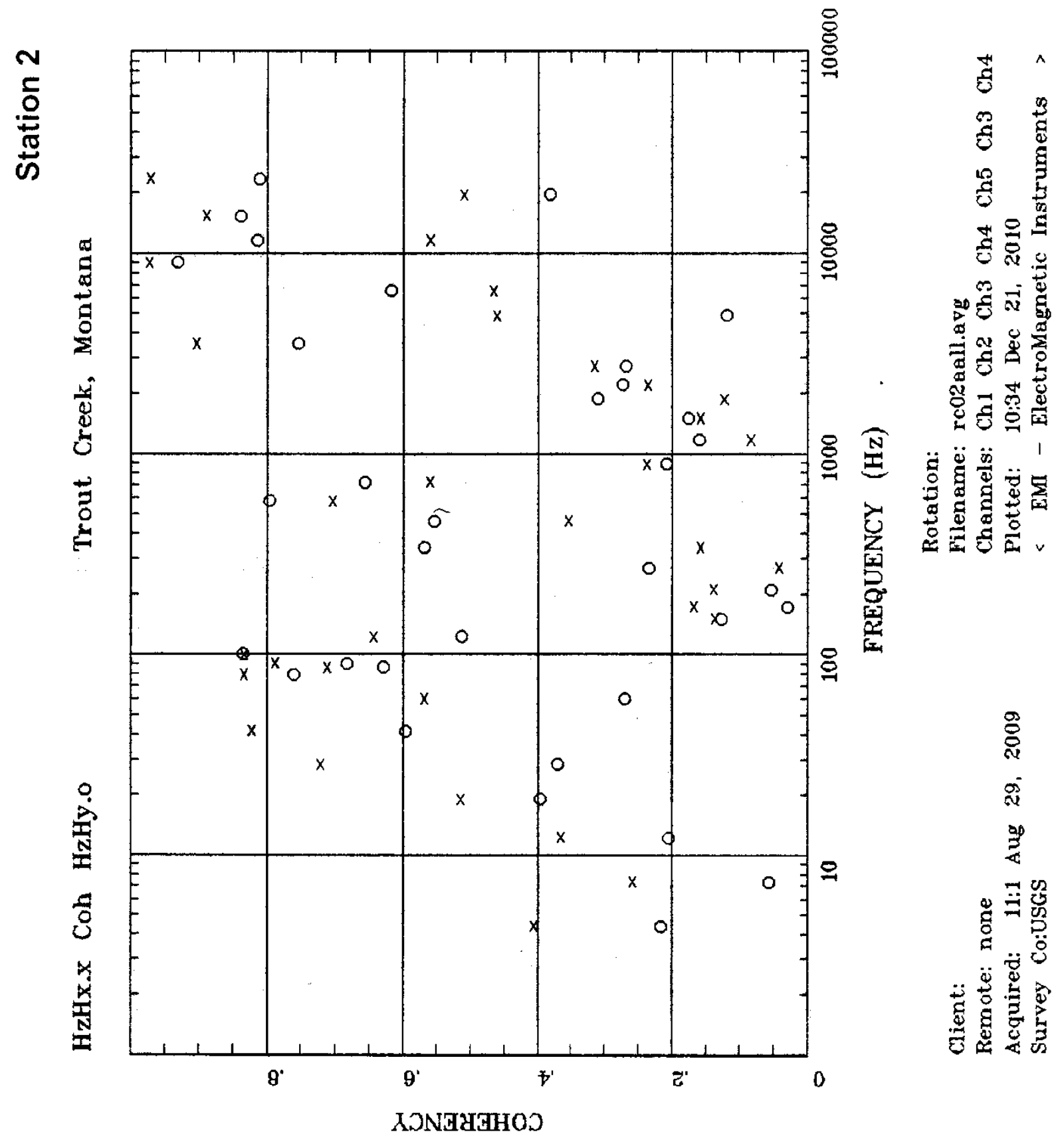




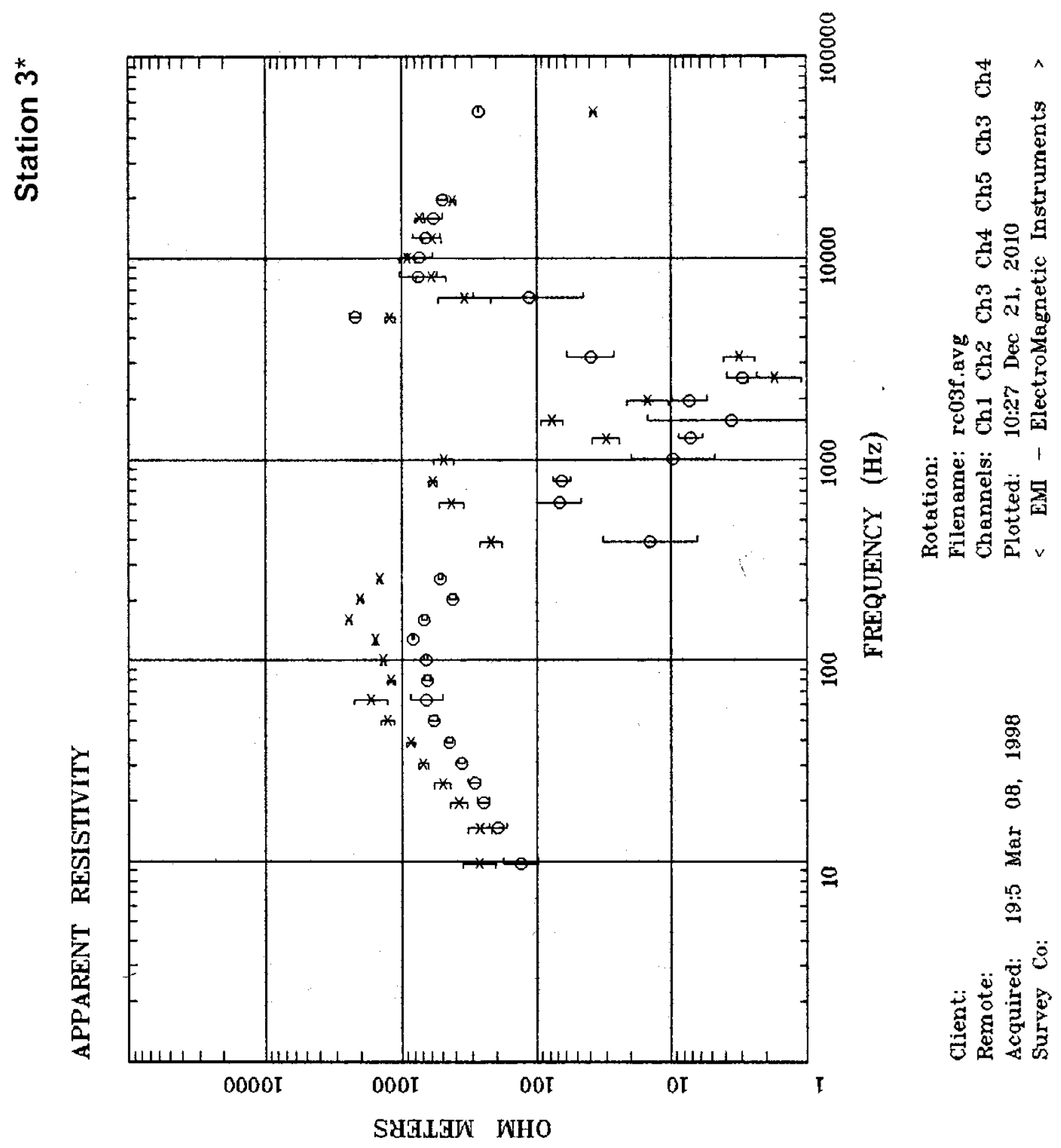




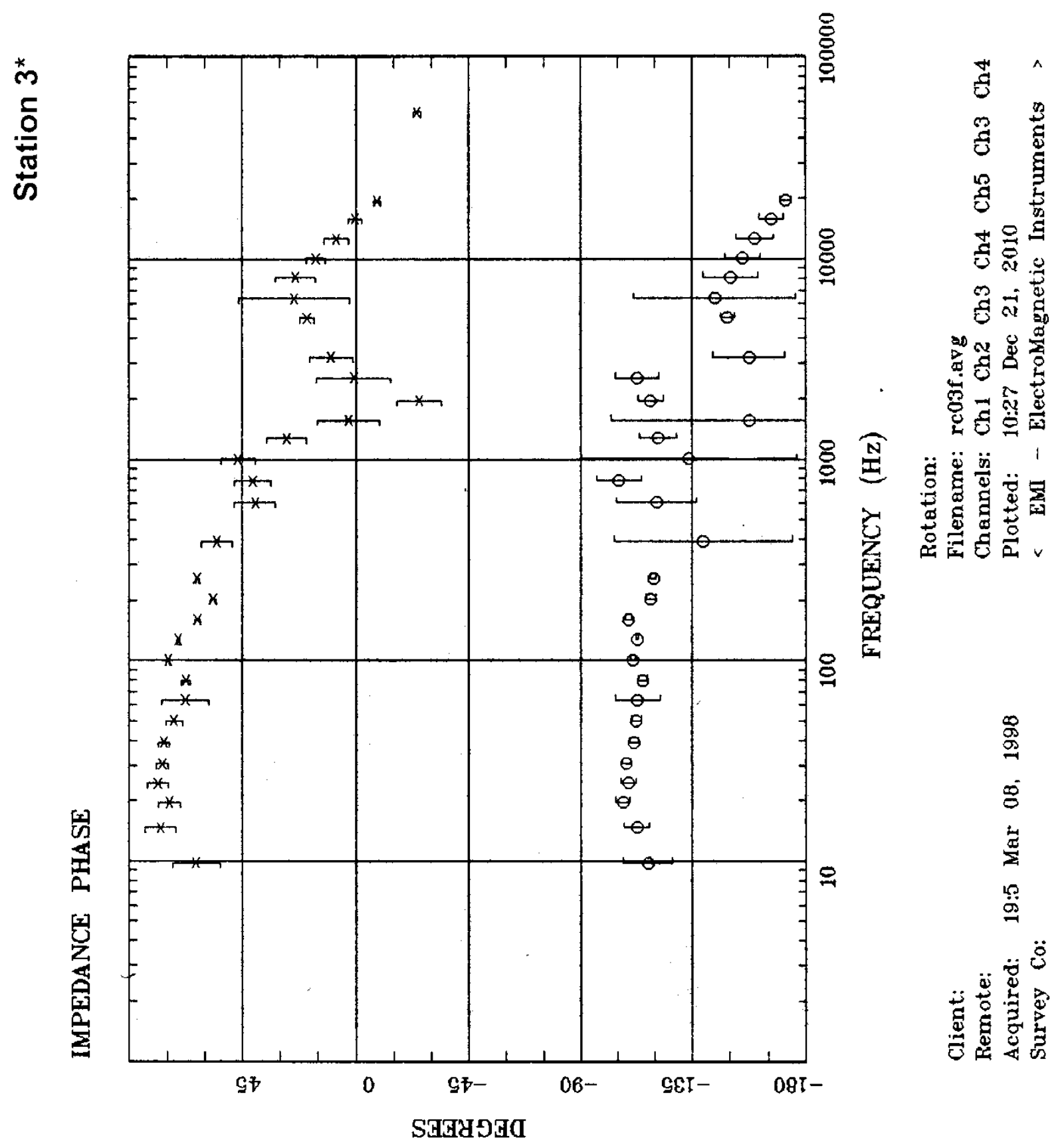




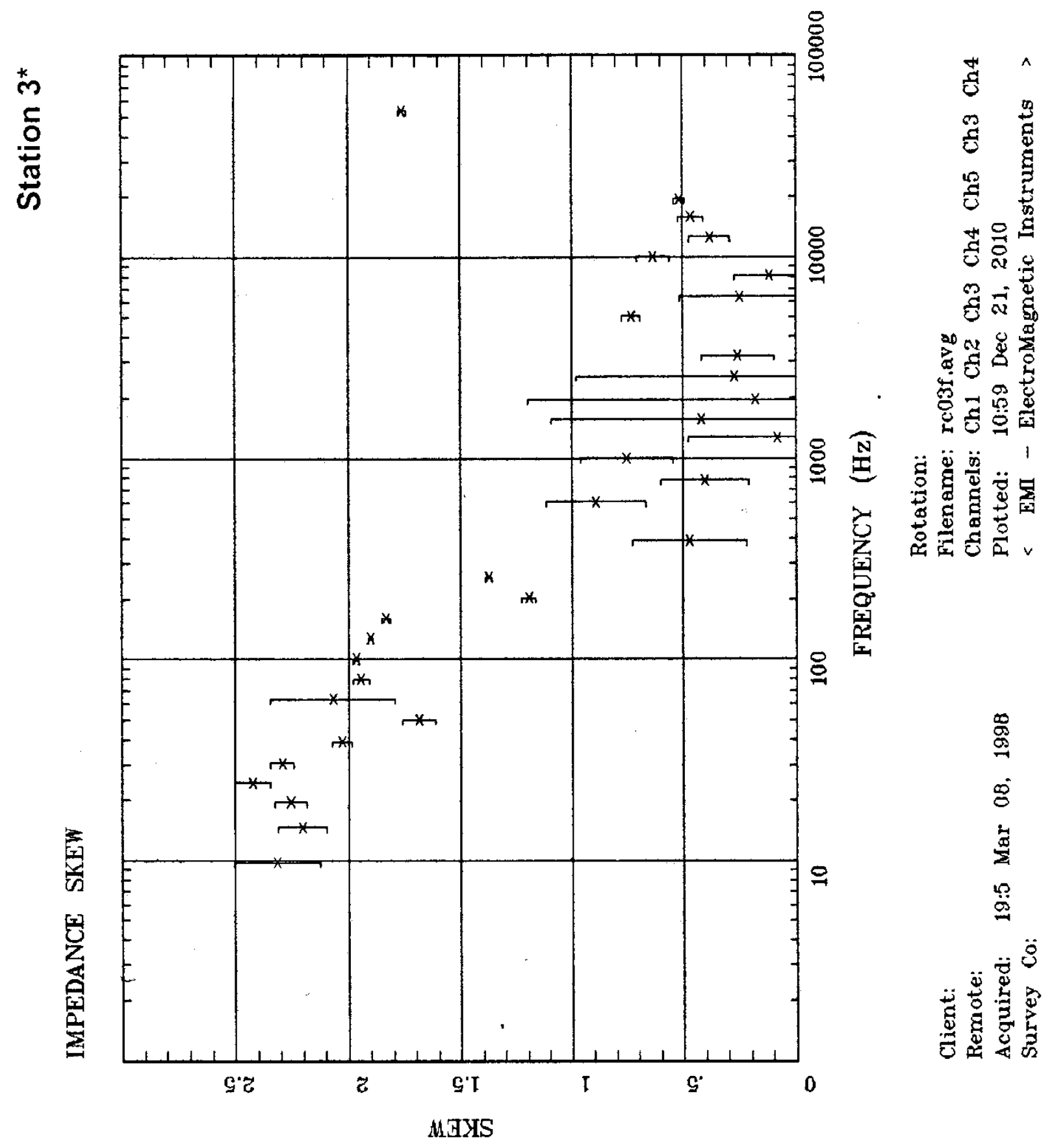




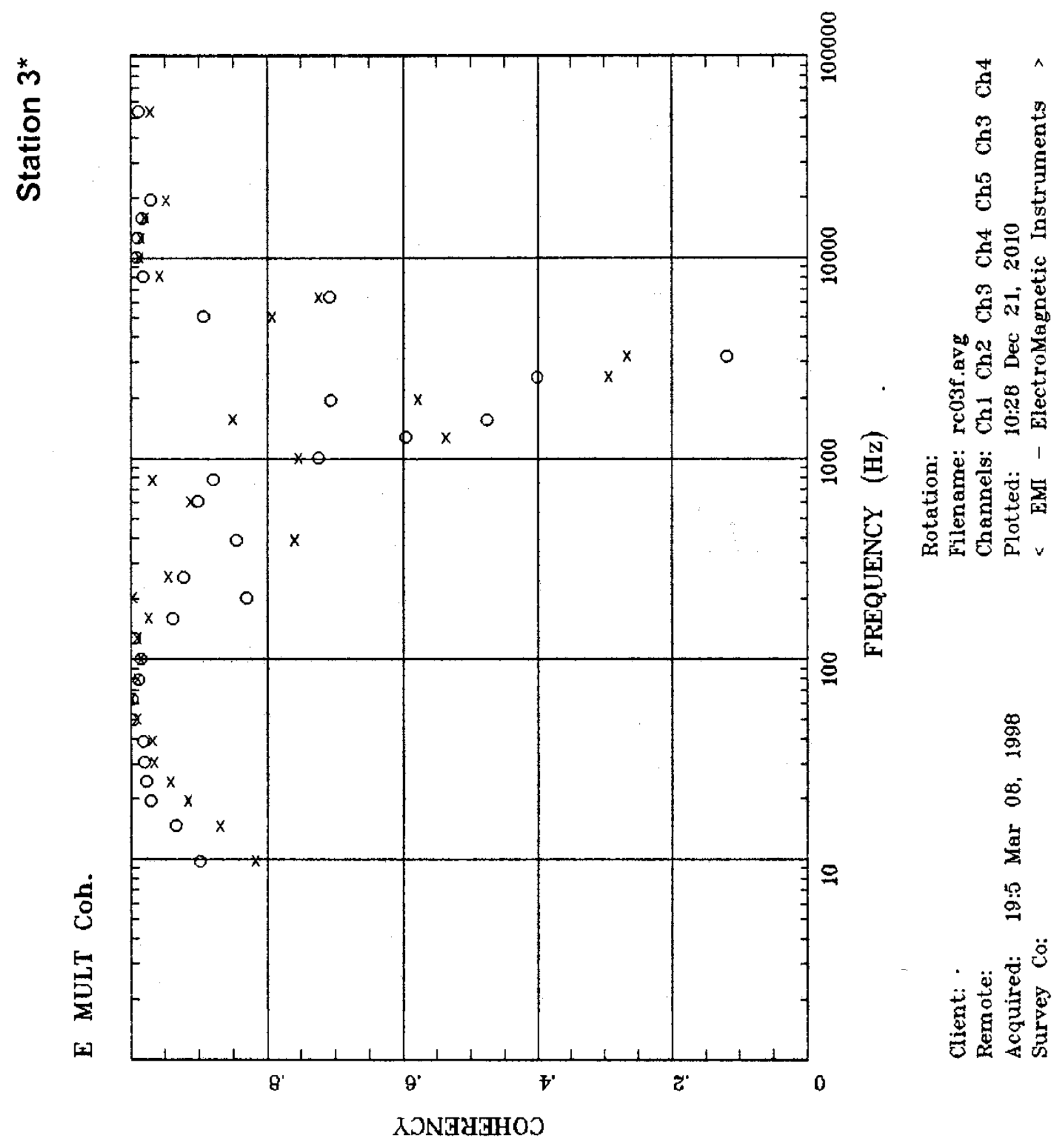




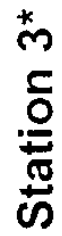

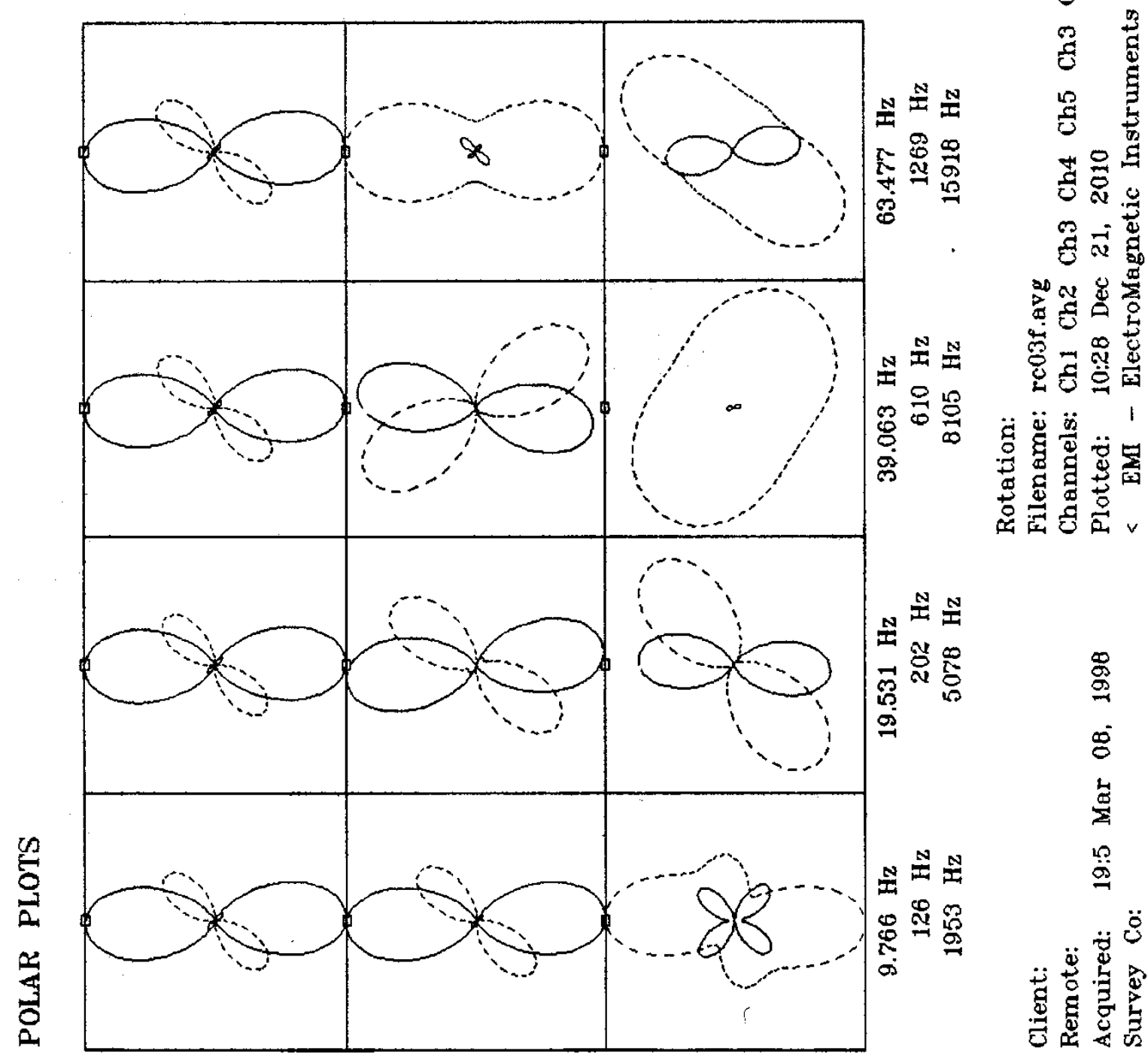




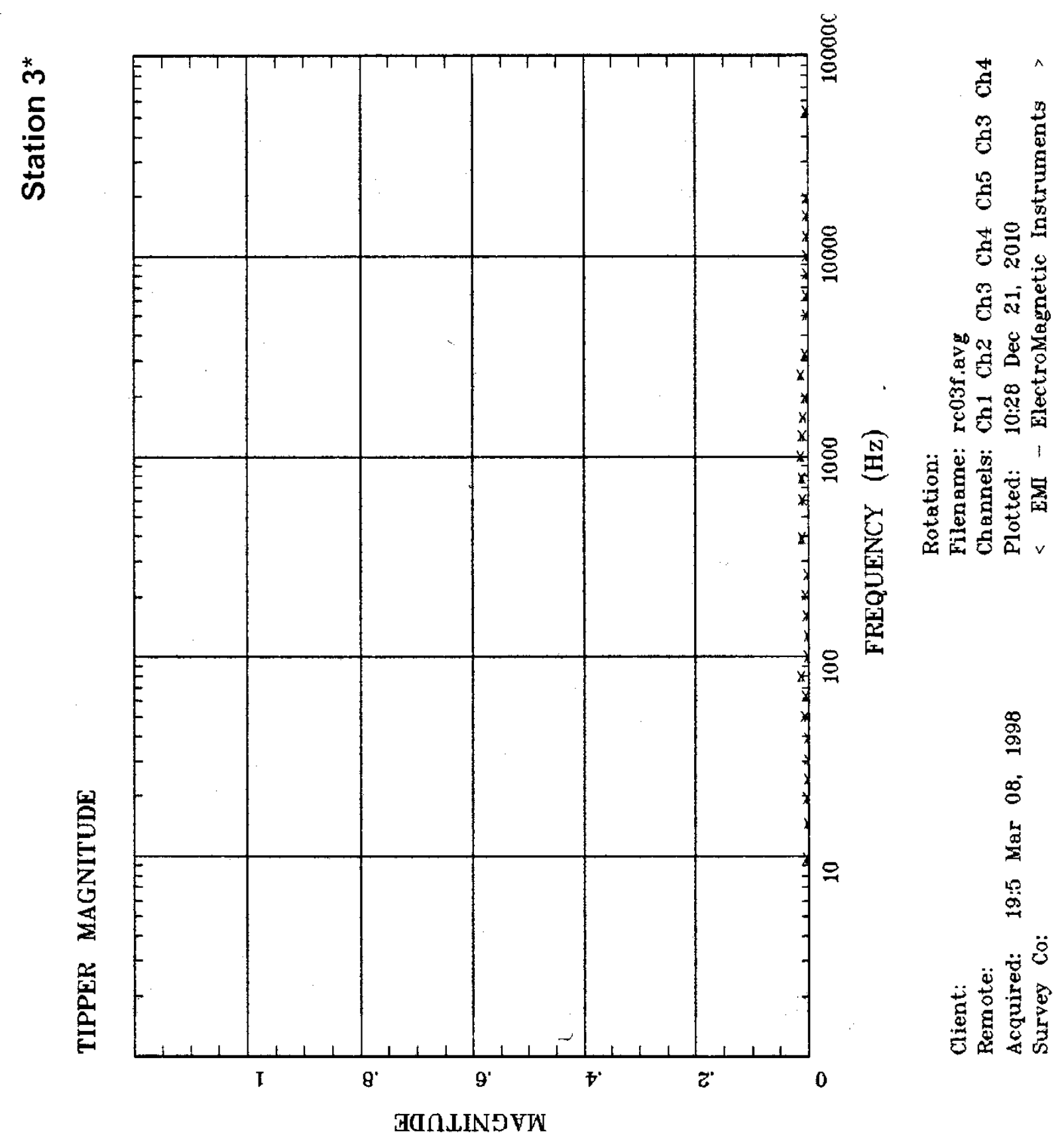




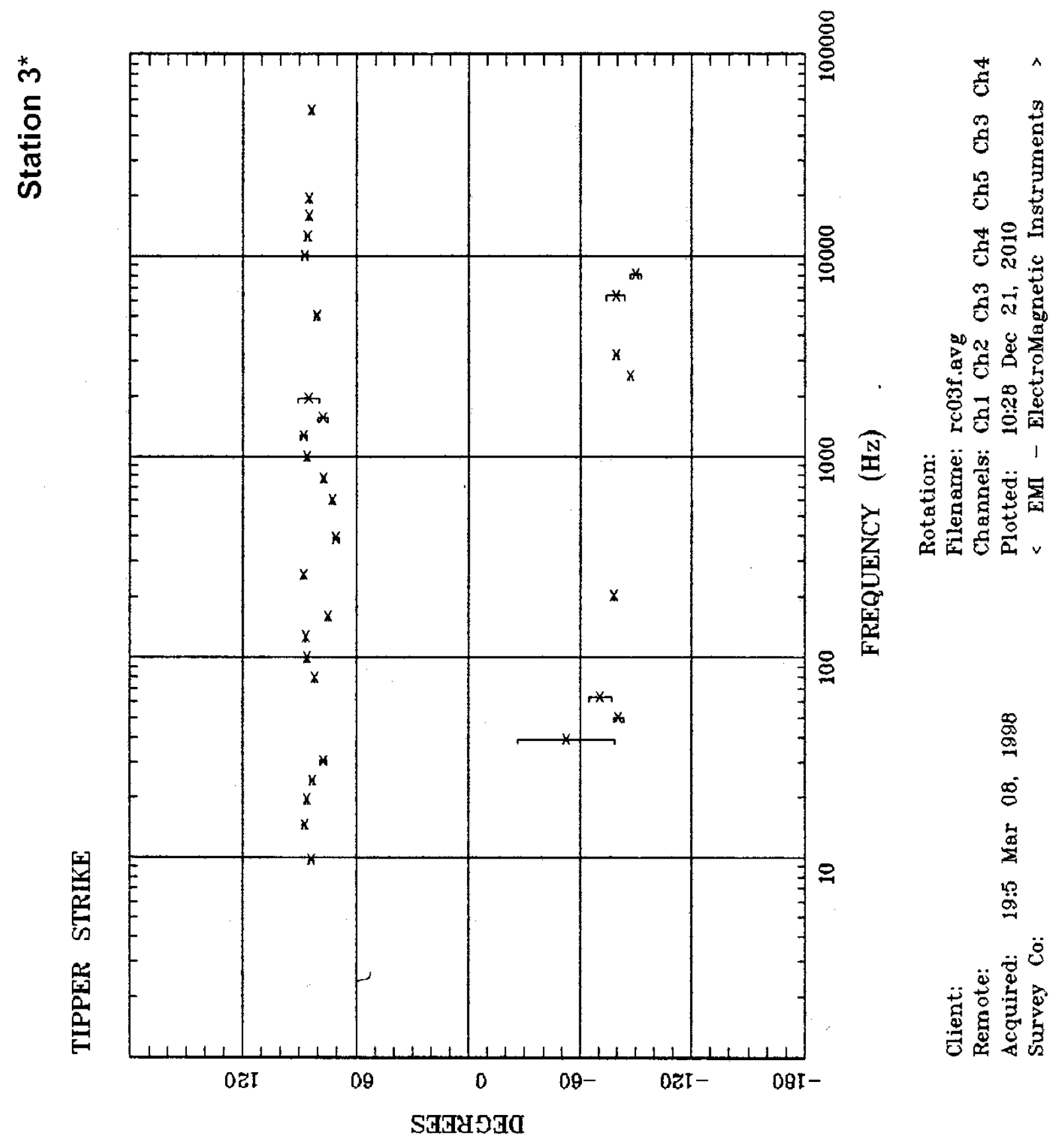




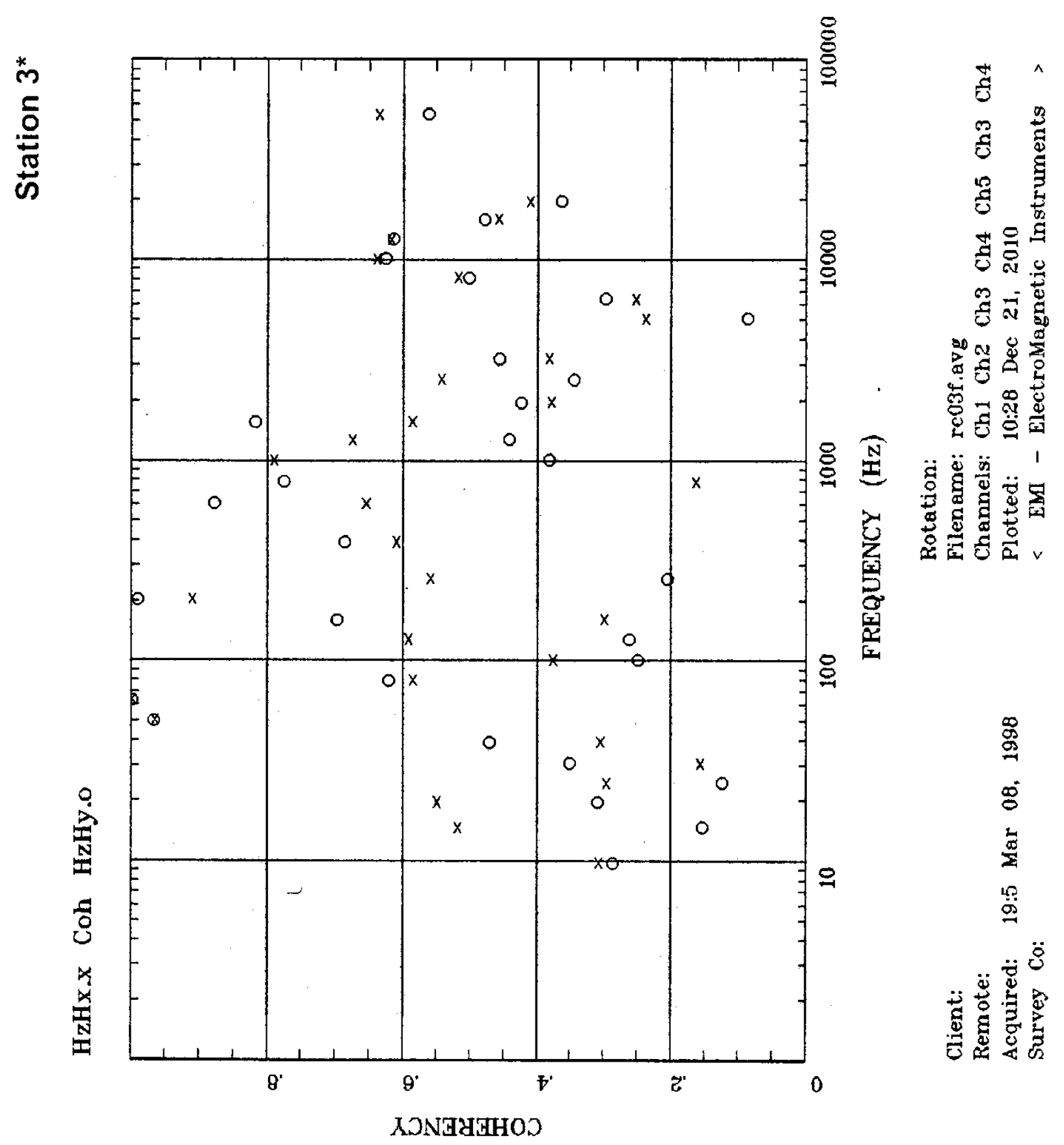




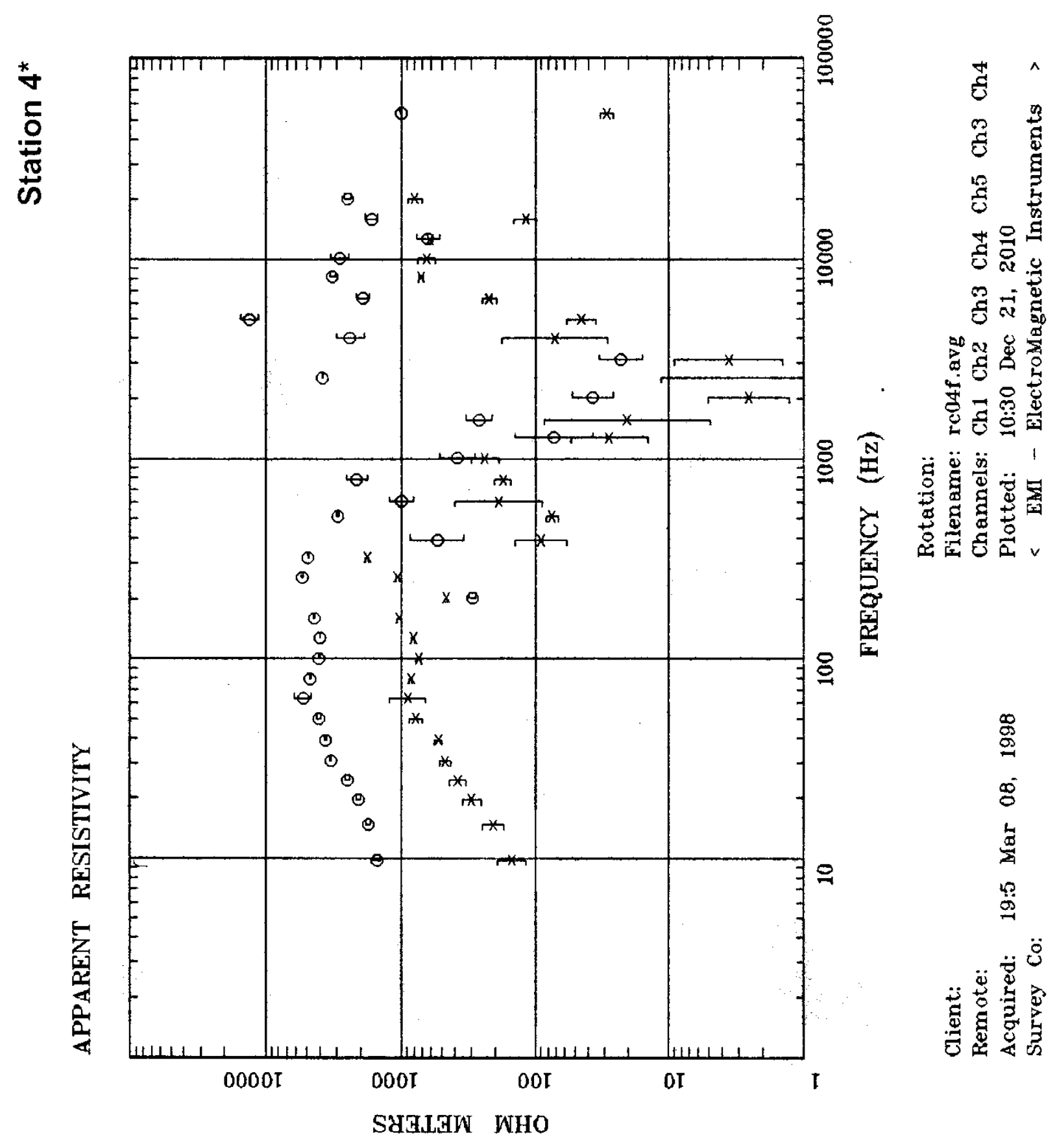




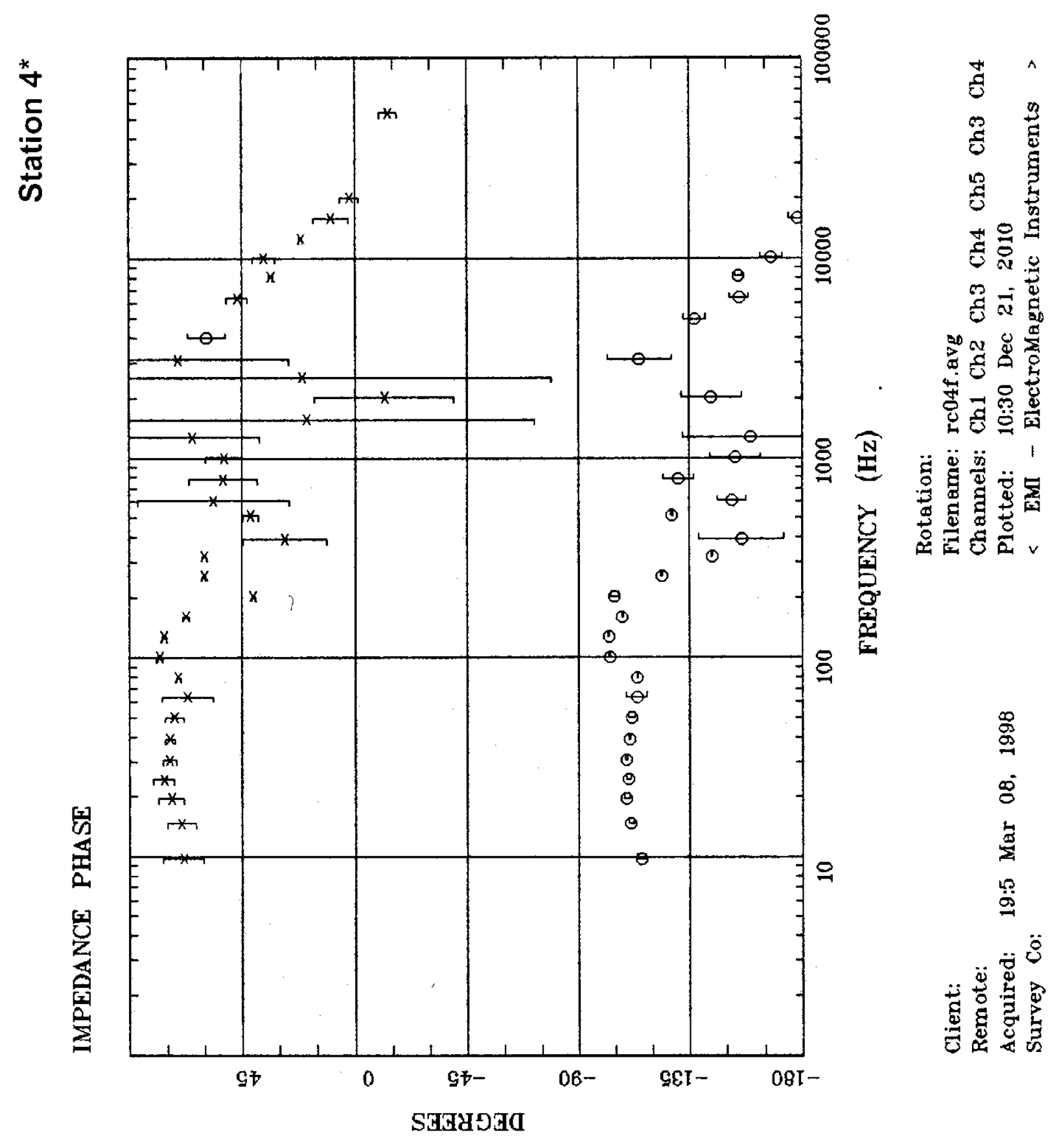




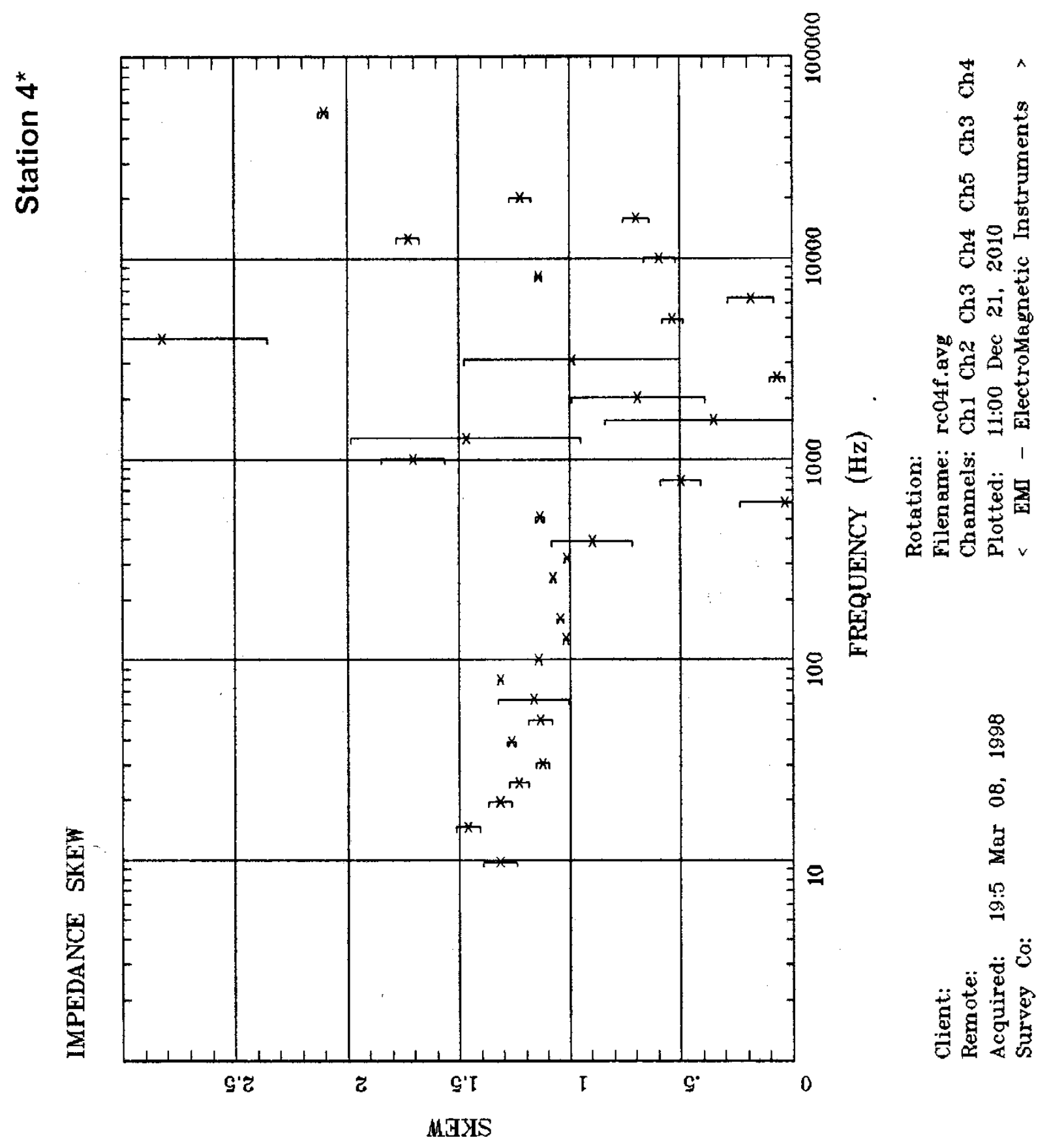




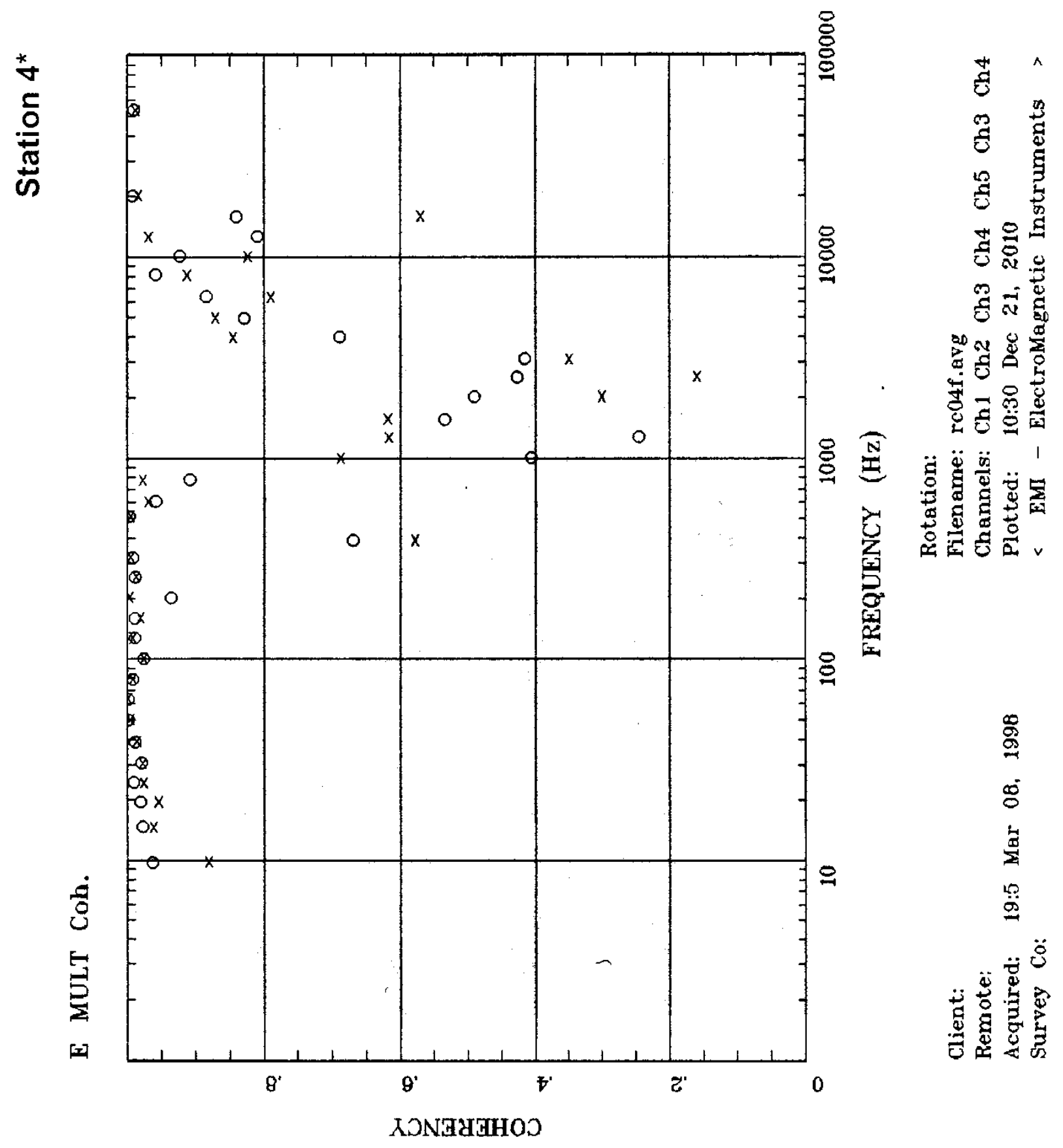




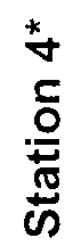

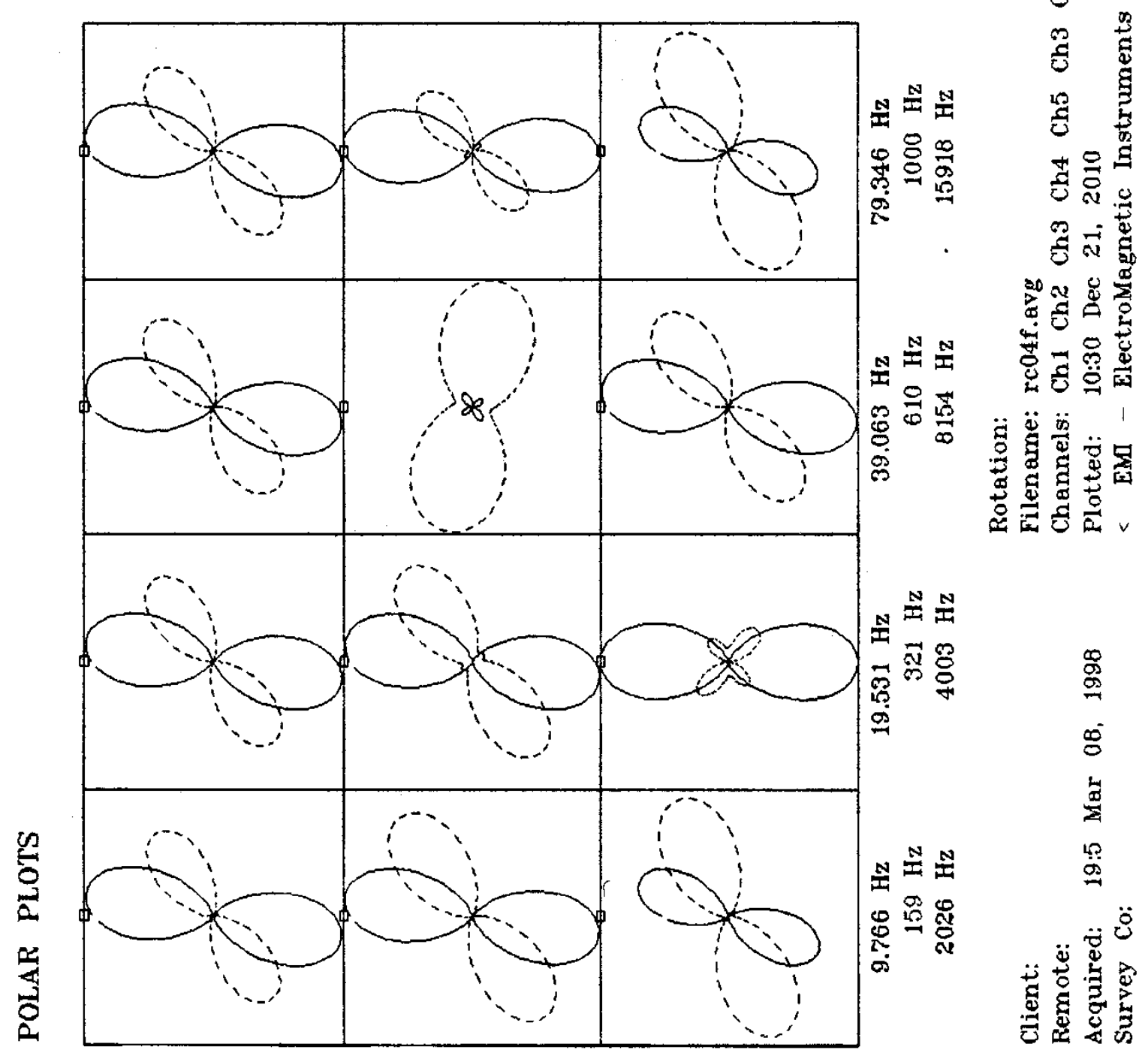




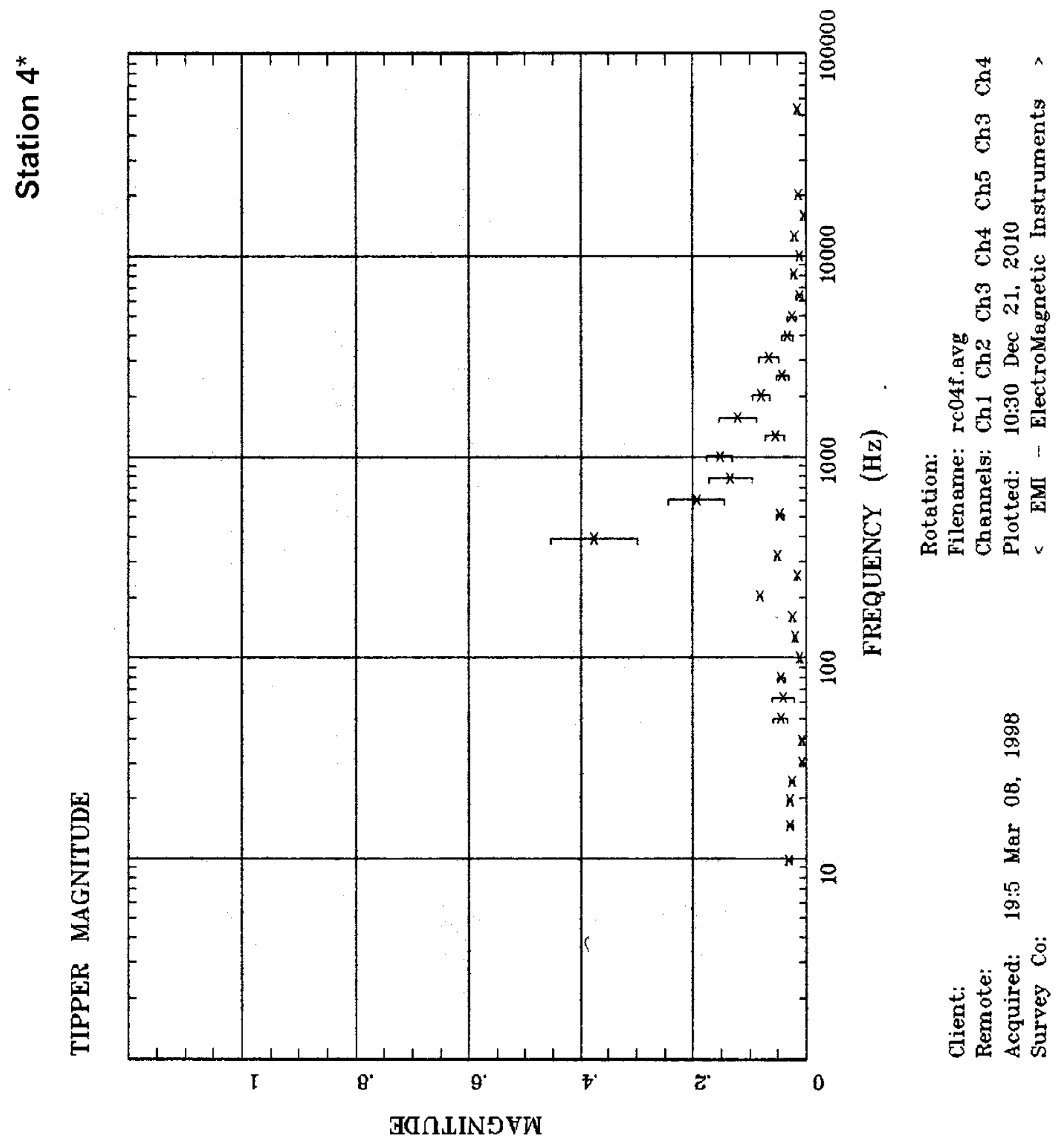




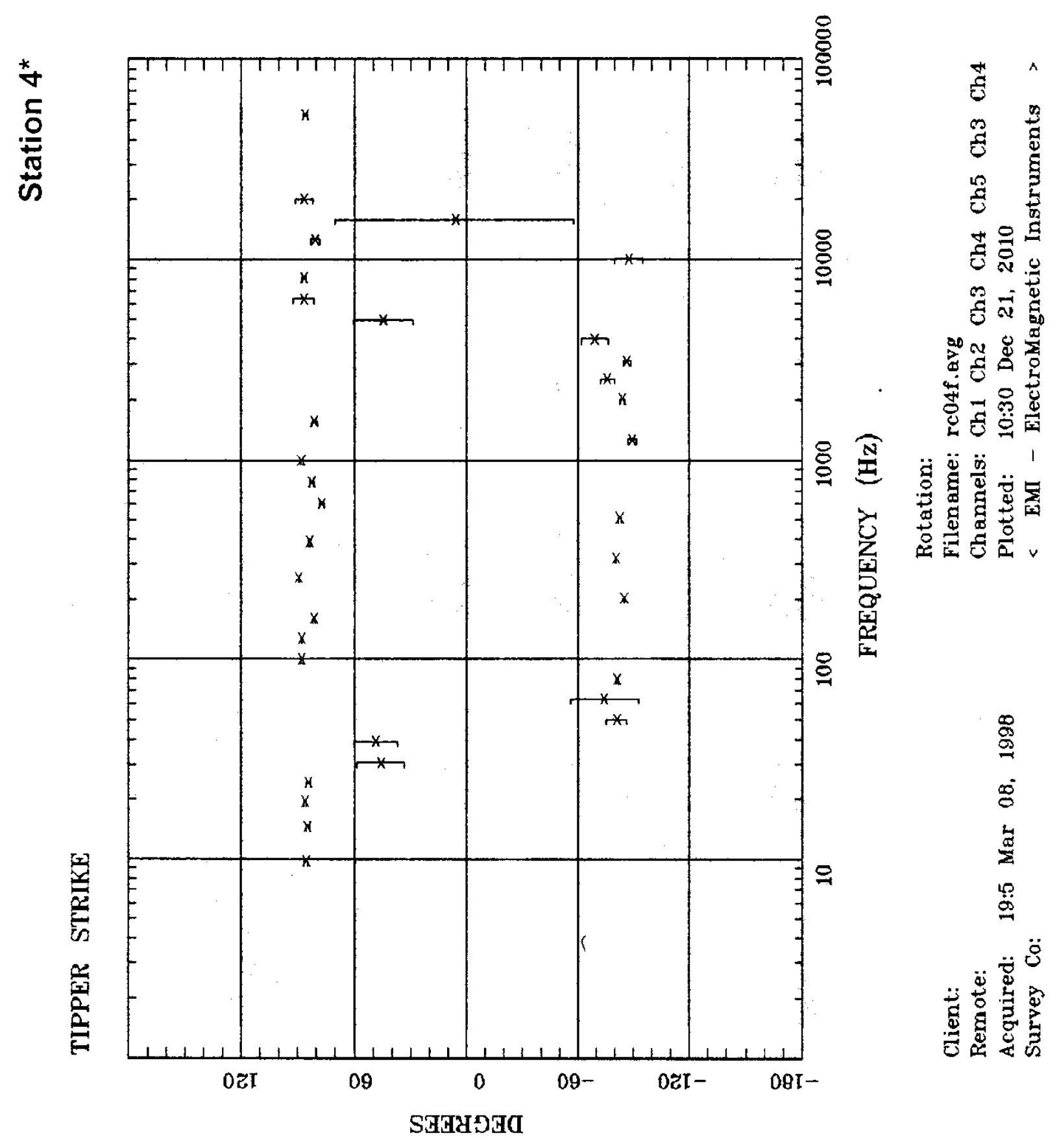




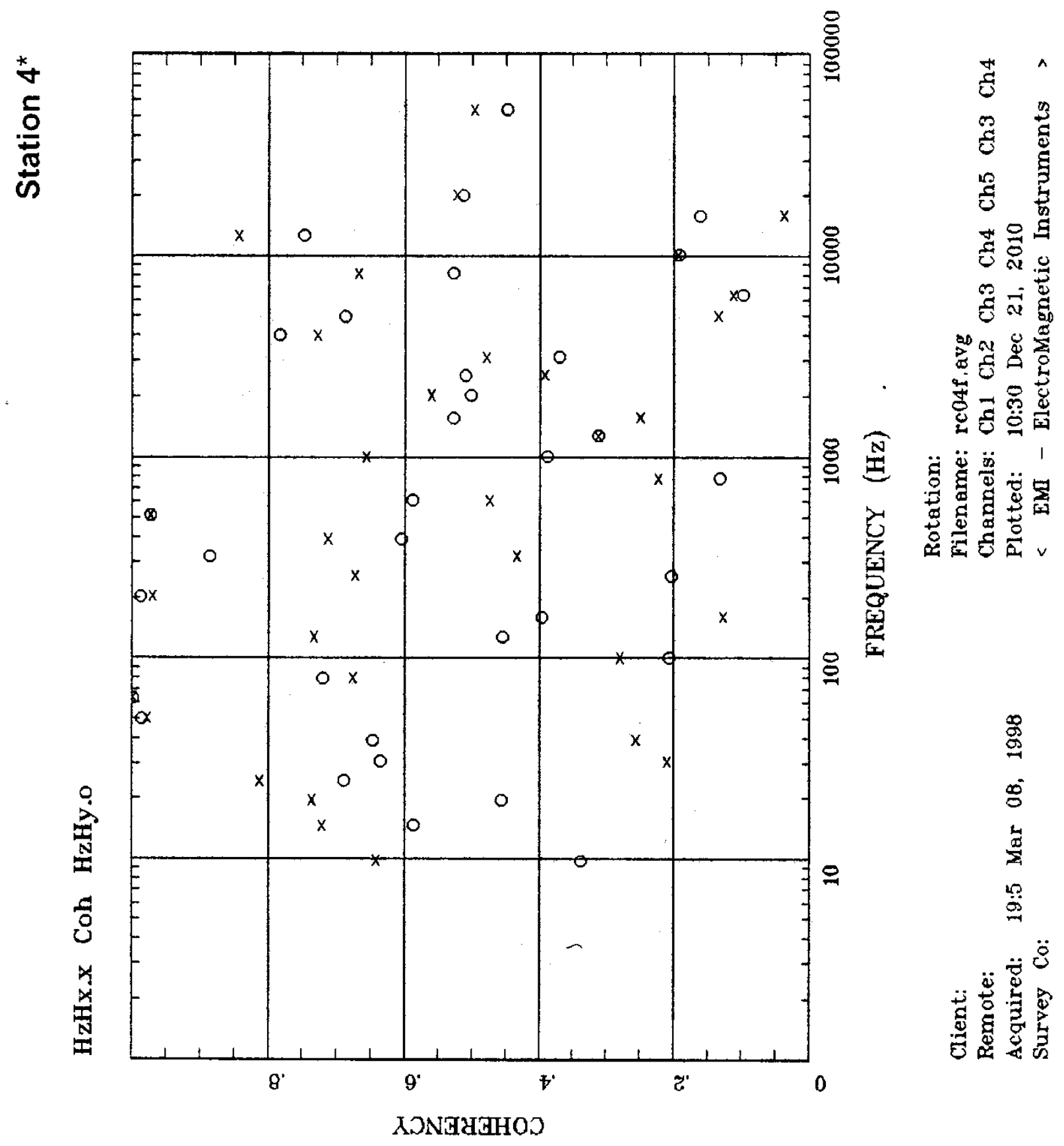




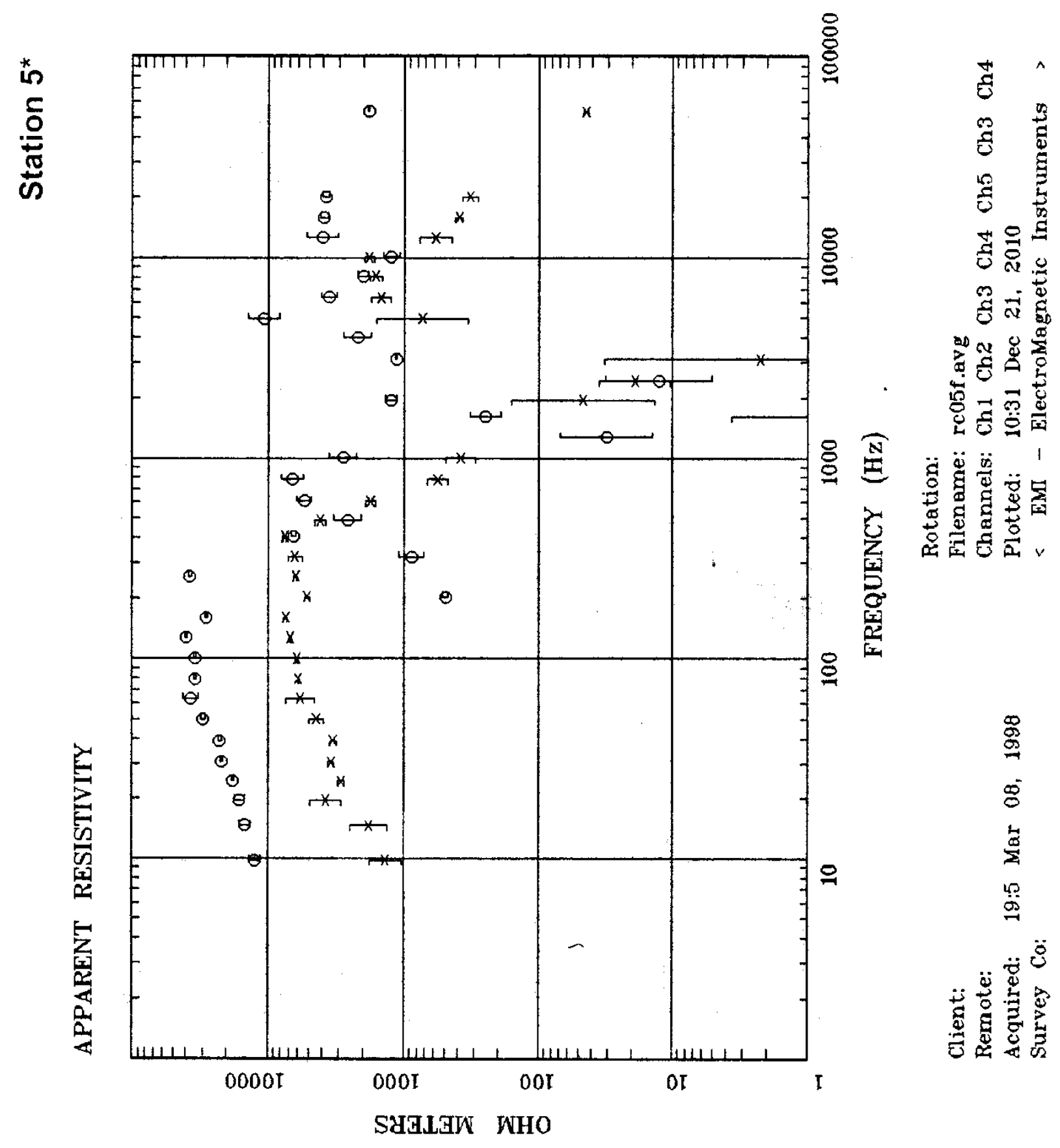




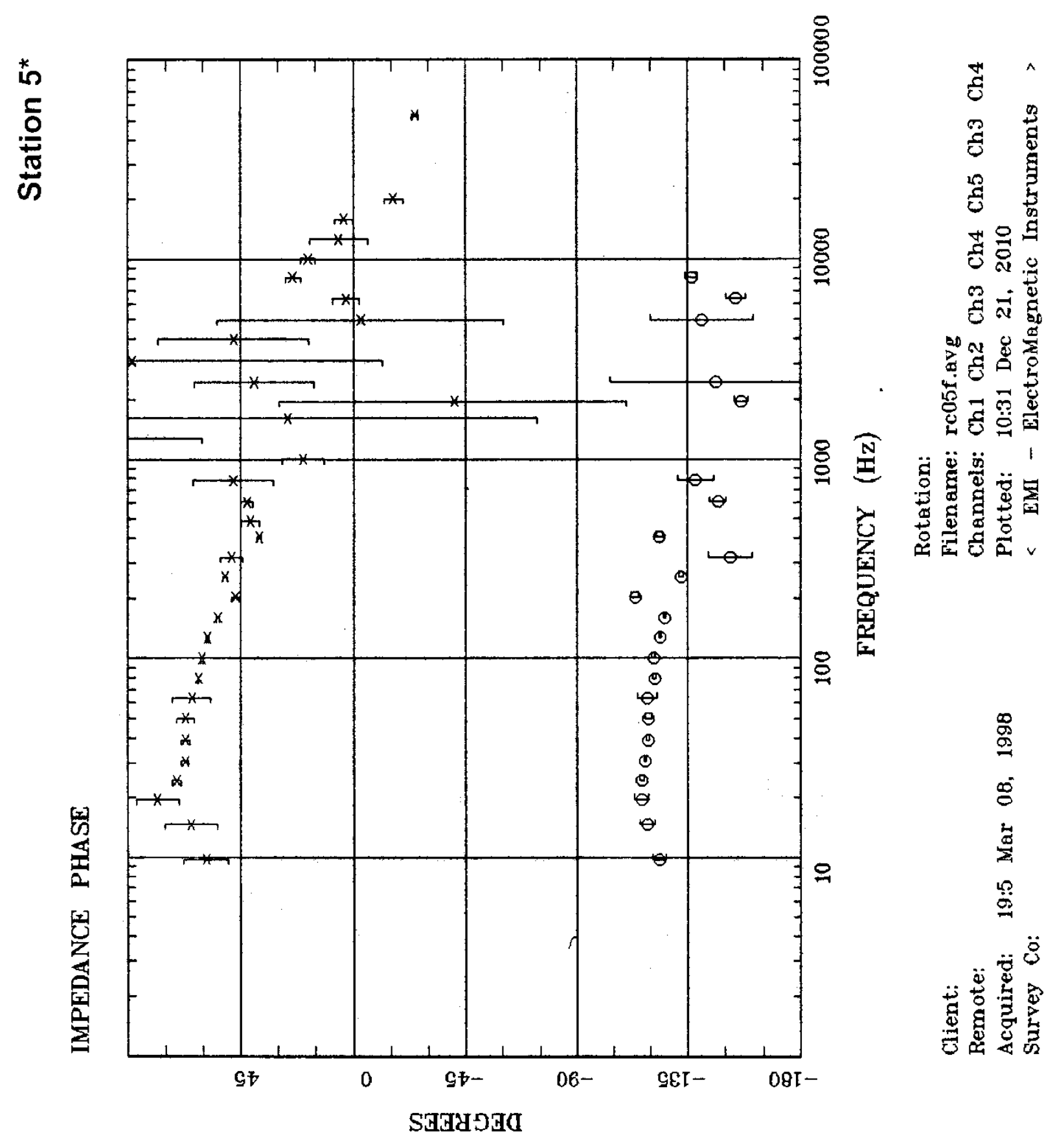




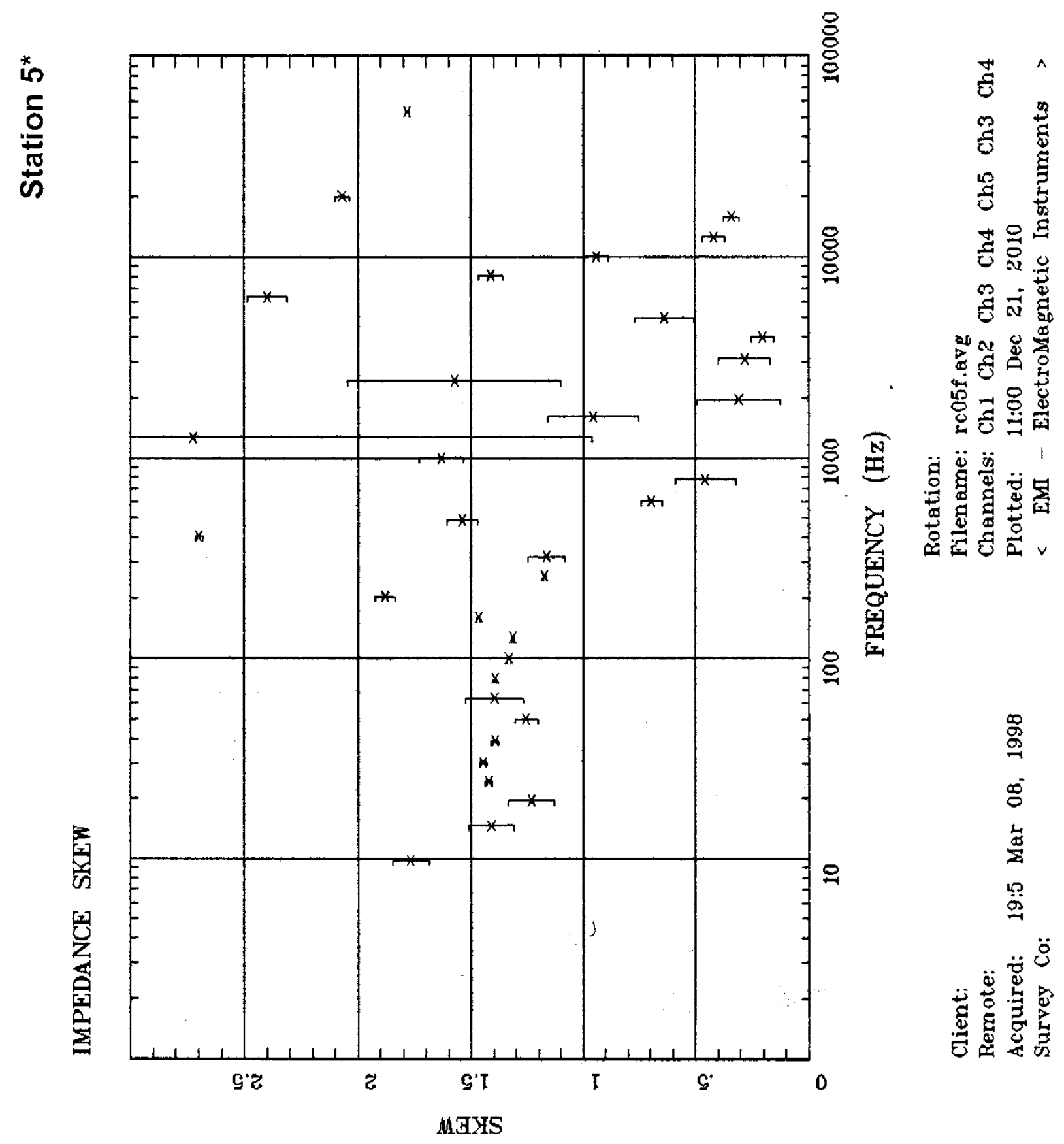




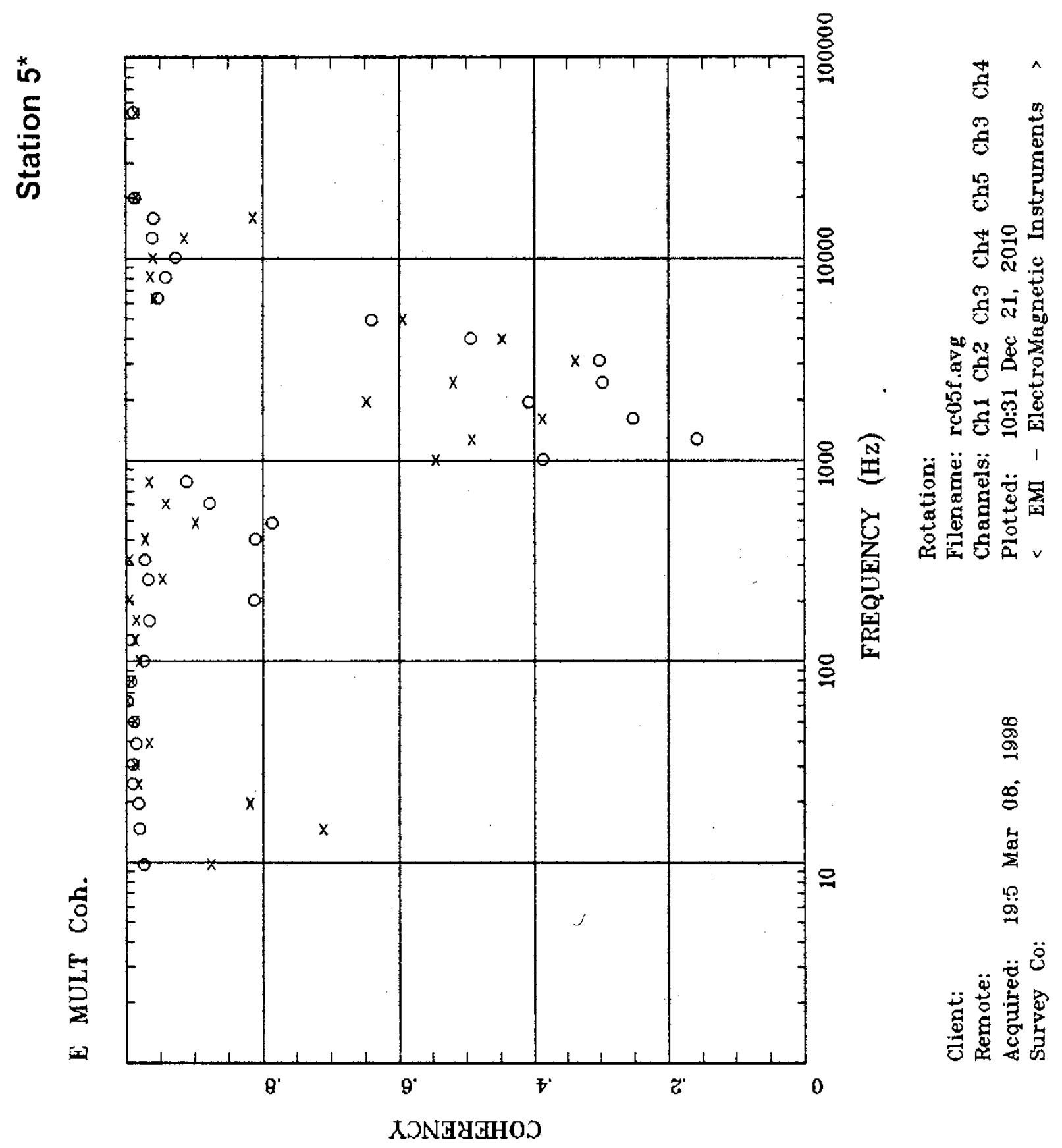




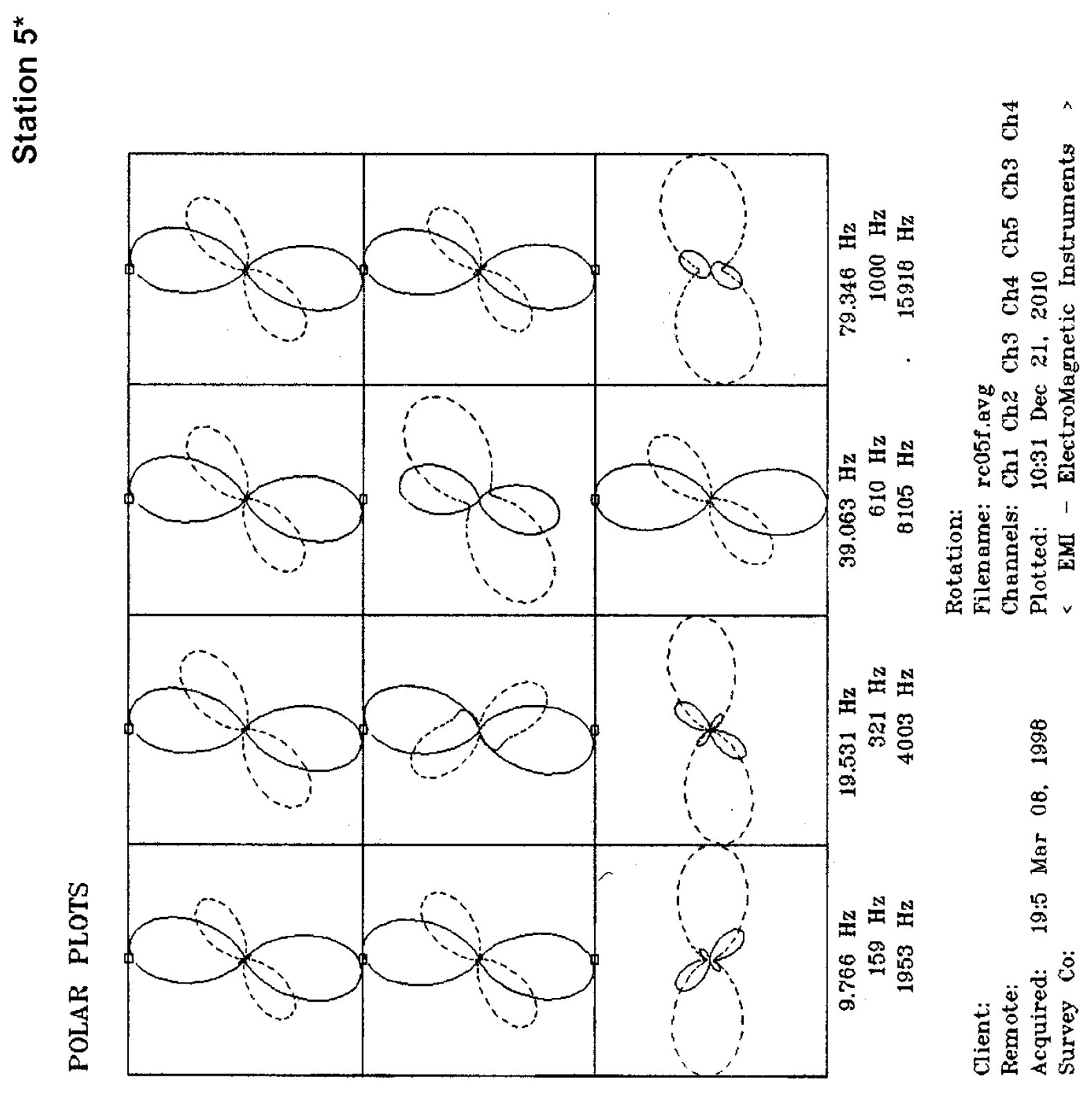




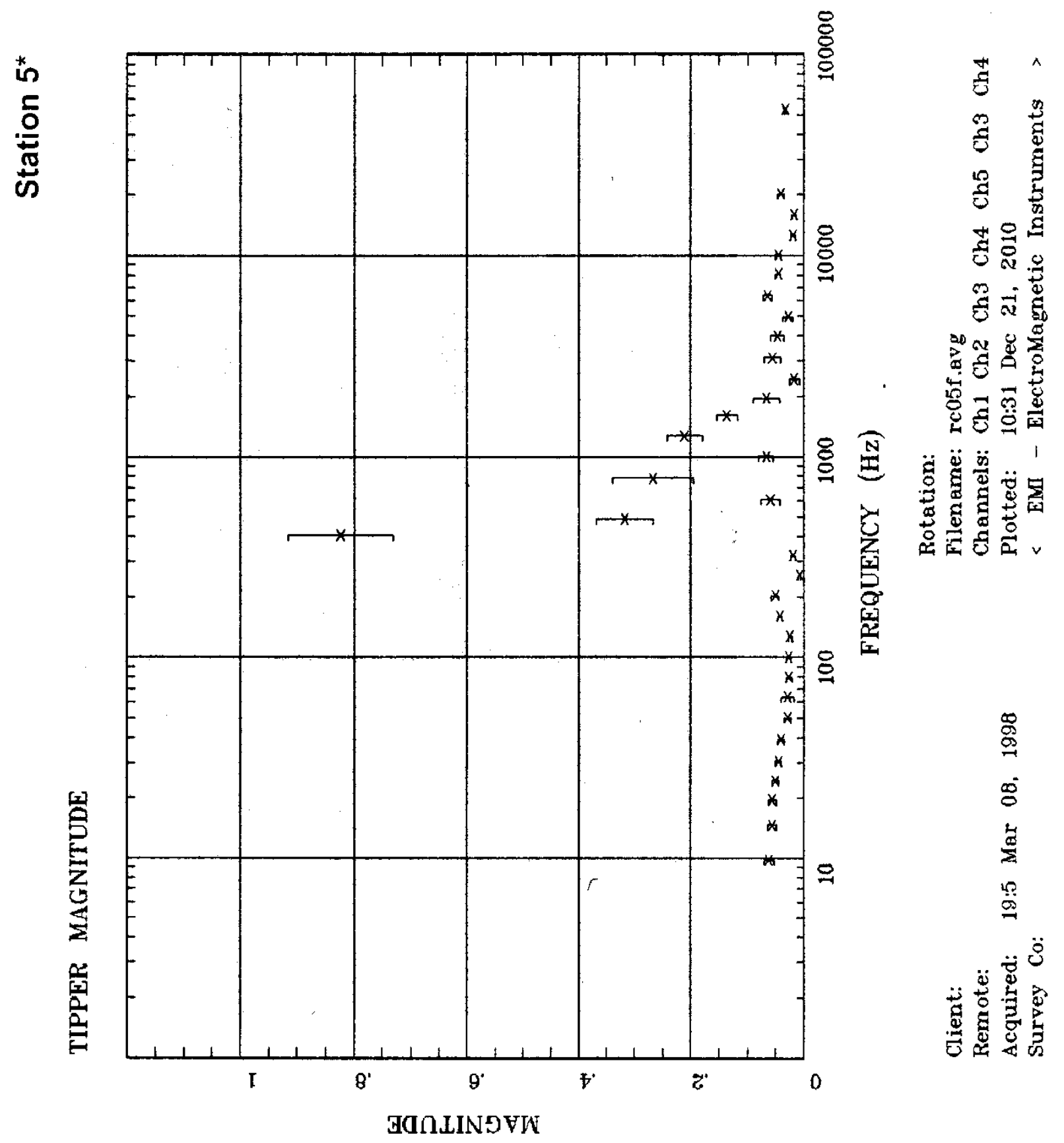




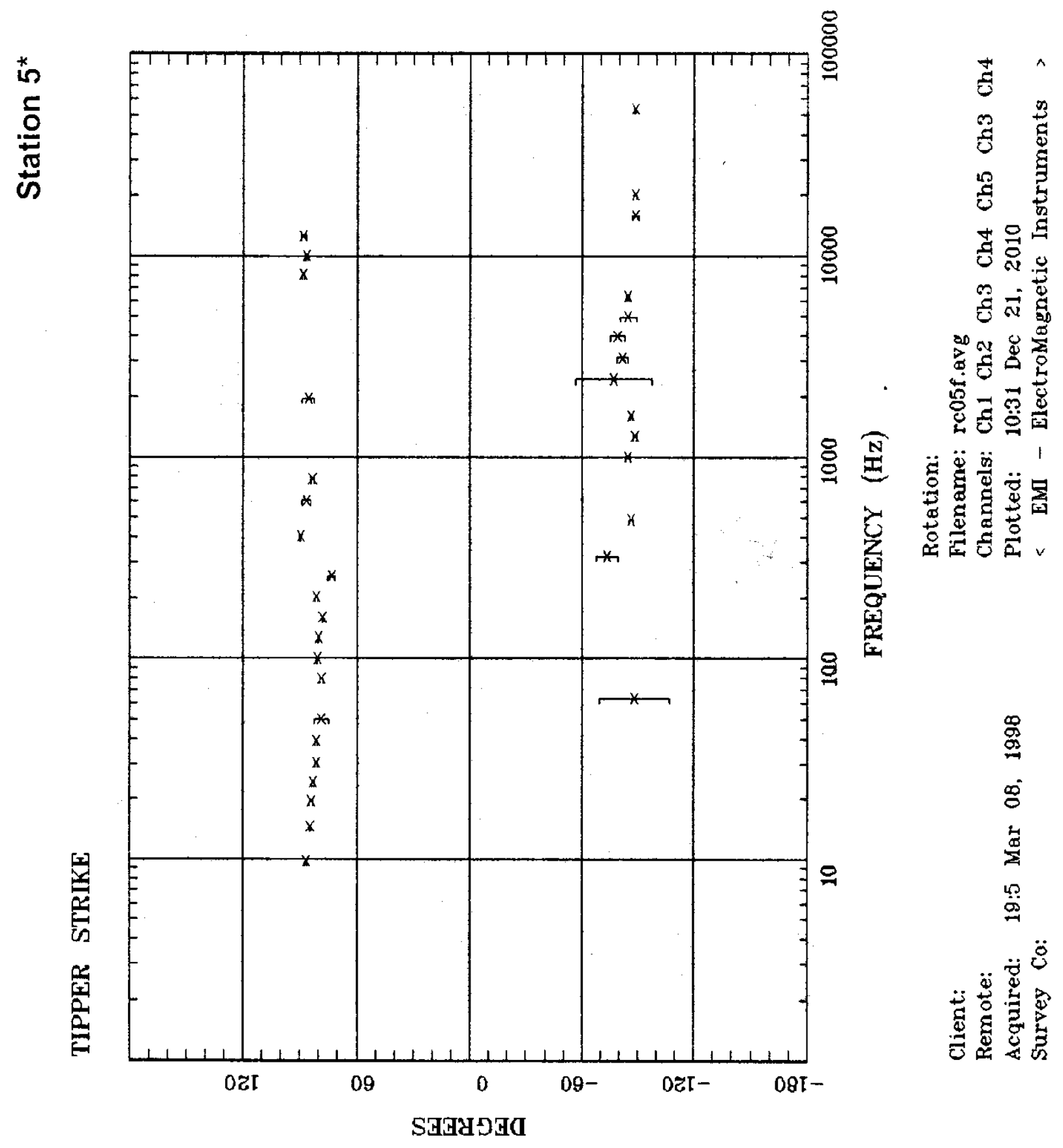




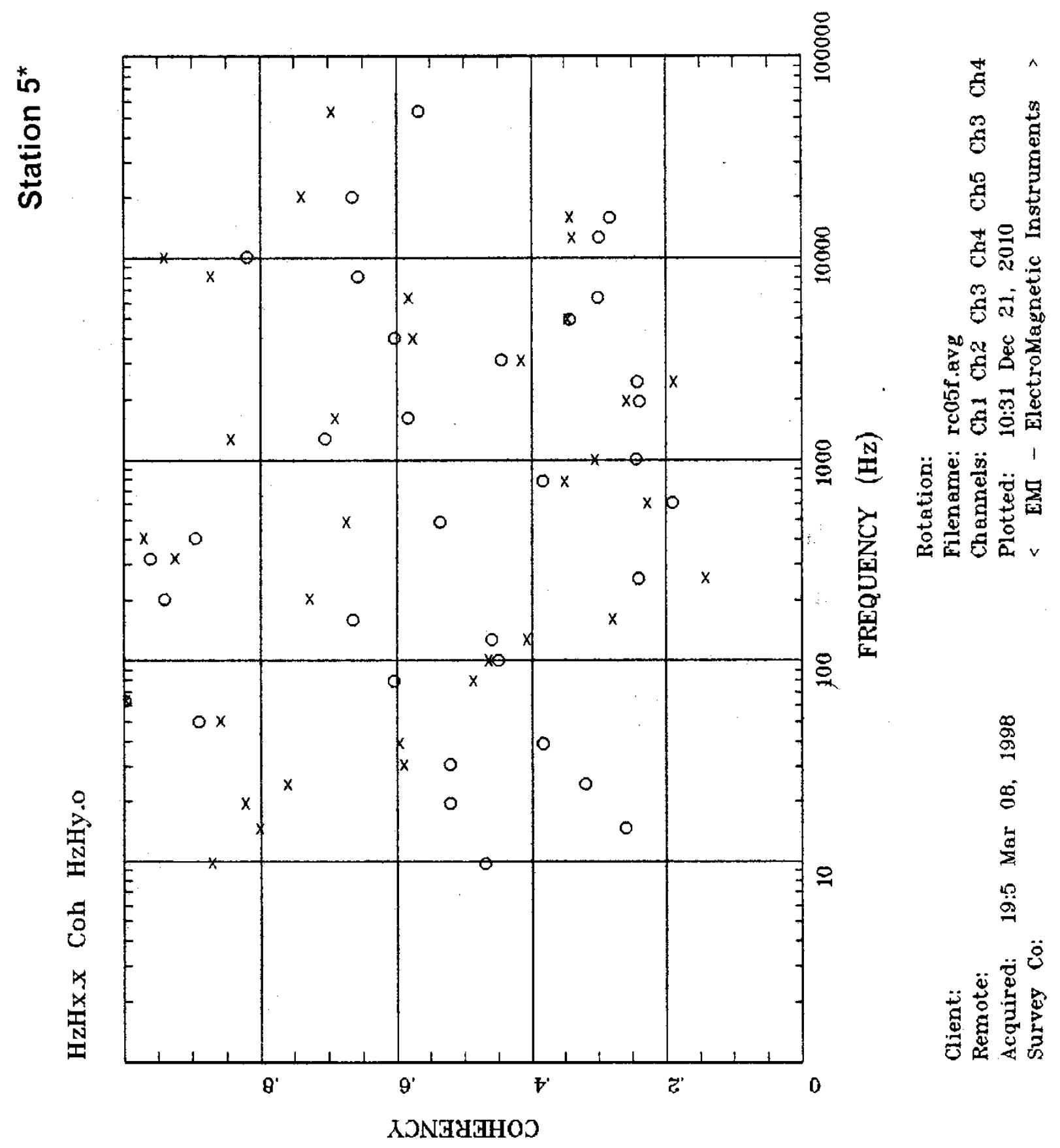

